\title{
Las prestaciones de los geriátricos en la Provincia de Buenos Aires: \\ El caso de los hogares de \\ La Plata y Chascomús \\ (período 2005-2006)
}

Autora: Lic. Paula Mara DANEL

Maestría en Trabajo Social

Facultad de Trabajo Social Universidad Nacional de La Plata 
Tesis "Las prestaciones de los geriátricos en la Provincia de Buenos Aires" El caso de los hogares de La Plata y Chascomús (período 2005 - 2006), presentada como requisito parcial para la obtención del título de Magister en Trabajo Social de la Facultad de Trabajo Social de la Universidad Nacional de La Plata. Dirigida por la Dra. Margarita Rozas Pagaza y co - dirigida por el Magister Mariano Barberena. 
Página de aprobación: 


\section{RESUMEN}

La presente tesis es producto de la investigación llevada a cabo por la maestranda Paula Danel durante los meses de marzo 2004 e igual mes del año 2007. El objetivo del trabajo estuvo orientado a dar cuenta de las características de las prestaciones brindadas en los establecimientos Hogar Geriátrico radicados en la Provincia de Buenos Aires. Se analizaron las prestaciones que se brindan en los establecimientos de gestión privada habilitadas, privadas que funcionan sin habilitación (clandestinas) y en los de gestión municipal. El objeto de la investigación introdujo una doble dimensión. Una que llamamos de definición y la encontramos en el plano normativo, en la función regulatoria del Estado y otra dimensión que llamamos de puesta en acto (práctica social). Esta doble expresión del objeto nos obligó a que en el proceso de investigación juguemos en estos dos planos. En el proceso analítico analizamos los factores económicos, políticos y culturales que se entrelazan en esta oferta prestacional.

Trabajamos caracterizando el escenario en el que se desarrollan estas prestaciones por lo que necesariamente hicimos un recorrido de la historia de la atención al grupo etario. La investigación fue de tipo cualitativa, desarrollando un trabajo etnográfico, centrando la mirada en el Trabajo Social. Advertimos que para el Trabajo Social este se configura en un campo de ejercicio profesional. En este campo aparecían definidas las dos dimensiones, de definición y de puesta en acto (regulación estatal y acciones institucionales al interior de los geriátricos). 


\section{Summary}

The current thesis is the result of a research carried out by magister Paula Danel during March 2004 and march 2007. The aim of the work was directed to give into account the characteristics of the benefits given in geriatrics home establishments in Bs As, Province. The benefits that were analyzed were those which are given by qualified institutions of private management, private establishments which work without rating ( clandestine), and in those of municipal management.

The object of the research introduced a double dimension: one, that we call of definition and that we find it in a normative aspect, in the regulatory function of the state, and the other dimension that we call of setting up in act (social practice). This double expression of the object conducted us to play with these double aspects in the research process. In the analytical process, we analyze the economical, political and cultural factors which are interlaced in this offering of benefits.

We work characterizing the scene in which these benefits develop.

That is why we necessarily made a historical background of the attention to the group of age. The research was of qualitative type, developing an ethnographic work, focussing the look in the Social Work. For the case of Social work, we notice that this field of the third age group gets into a field of professional training area. In this field, both dimensions would appear defined: one of definition, and the other of setting up in act ( state regulation, and institutional actions inside the geriatrics institutions) 


\section{Dedicatorias:}

A mi compañero de la vida, Sergio, por amarme, respetar mis elecciones y transitar conmigo el camino.

A mi hijo Valentín por su dulzura, inteligencia y fortaleza.

A mi madre, Chichita, por enseñarme a ser feliz en la adversidad.

A mi viejo, a pesar del poco tiempo compartido. A mi abuela, Dorita Chavero por haberme iniciado en el respeto y admiración a los adultos mayores. Siempre están aquí...

A las personas mayores que transitan su vida en un geriátrico. 


\section{Agradecimientos}

En primer lugar quiero expresar mi agradecimiento a mi Directora de Tesis, Dra. Margarita Rozas Pagaza quien me orientó en el proceso de investigación. Y al mismo tiempo me entusiasmó con lo que estaba haciendo. También quiero agradecer enormemente a mi Co - Director, el Mag. Mariano Barberena quien me acompañó tanto en el proceso de investigación como en la elaboración de interrogantes sobre la disciplina y el tema específico. Ambos Directores me posibilitaron la construcción de competencias para avanzar y terminar la tesis.

Deseo expresar mi reconocimiento a la Directora de la Maestría, Mag. Susana Malacalza y al equipo docente por su clara decisión de jerarquizar nuestra profesión apostando a la configuración de intelectuales críticos. Asimismo agradezco a los compañeros de la Cohorte 20022004 con quienes experimenté el placer de la reflexión conjunta.

No puedo menos que mencionar a los estudiantes de la carrera de Trabajo Social quienes con sus interrogantes y miradas renovadoras nos permiten seguir problematizando. También a los compañeros de las cátedras de Trabajo Social II y Antropología Social II y a los docentes de otras disciplinas con quienes nos enriquecemos en cada espacio compartido. A los graduados de "caminanTeS" por continuar creyendo que otro país y otro Trabajo Social son posibles. A todos los colegas del campo del Trabajo Social, la Gerontología, y la Discapacidad por sus aportes e interrogantes.

También creo necesario agradecer a los "interlocutores" del trabajo de campo por permitirme "ingresar" en su vida cotidiana.

A mis compañeros de la Dirección de Fiscalización Sanitaria por haberme permitido interpelarlos en más de una oportunidad y por compartir interrogantes y algunas certezas sobre la tarea realizada. A los alumnos del Curso de Capacitación en Inspección Sanitaria de Establecimientos Asistenciales por su genuino interés por generar un cambio relevante en el nivel prestacional de los establecimientos de la Provincia. Al equipo docente de ese curso por la oportunidad de aprendizaje que obtuve.

A cada uno de los agentes sociales con los que me fui cruzando en este arduo camino transitado, que con acuerdos, desacuerdos, aciertos y errores logramos llegar a la socialización del conocimiento producido.

Paula Danel 


\section{ÍNDICE}

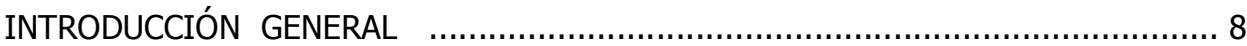

\section{CAPITULO I}

ALGUNAS REFERENCIAS EN TORNO A LA POLÍTICA DE VEJEZ EN ARGENTINA

I -

Primer eje: Asistencia social hacia la vejez …...................................................... 19

Segundo Eje: Seguridad Económica ……...................................................... 21

Tercer Eje: "Atención Sanitaria" ...................................................................... 24

Cuarto Eje: "Seguridad Alimentaria" ............................................................. 27

II -

Regulación del funcionamiento de los hogares geriátricos

CAPITULO II

HOGARES GERIÁTRICOS: ¿ESCENARIOS DE VIOLENCIA?

Viejos ciudadanos

35

De viejos, geriátricos, tragedias y ¿violencias? ................................................ 37

Acerca de la clandestinidad $\quad$................................................................... 42

¿Qué evaluamos cuándo fiscalizamos? ..................................................... 45

Configuración de instrumentos metodológicos .............................................. 47

CAPITULO III

CARACTERIZANDO LA PRESTACIÓN BRINDADA EN LAS INSTITUCIONES

DE LARGA ESTADÍA: SUS DIMENSIONES MATERIAL Y SIMBÓLICA. ...................... 52

I - $\quad$ Historia institucional - trayectoria institucional - mito de origen ................. 53

II - $\quad$ Residentes - personas mayores - población objetivo de la prestación ......... 56

Dimensión Admisión: ..................................................................... 56

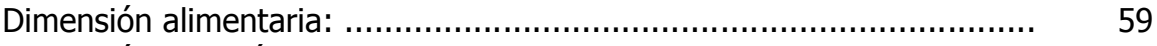

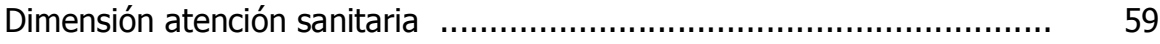

Dimensión autonomía: ............................................................... 61

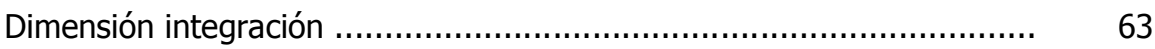

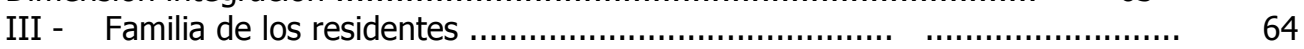

IV - Trayectoria de las personas mayores en el nuevo espacio $\quad$.......................... 67

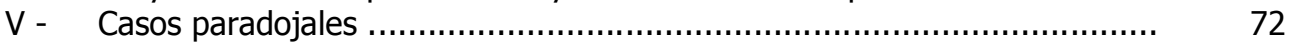

Vi - Caracterización de los propietarios y las instituciones .............................. 75

CAPITULO IV

A MODO DE COROLARIO

I Construcción social de la prestación. Cultura institucional:

"estrategias de vida y de muerte en las prácticas institucionales" ....................... 82

II Mirada de los agentes sociales sobre la regulación estatal $\quad$........................... 89

III A modo de síntesis .......................................................................... 91

IV Algunas propuestas de intervención ........................................................ 93

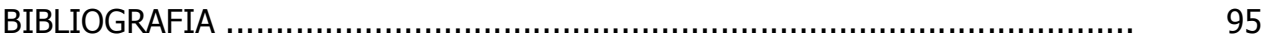




\section{INTRODUCCION GENERAL}

El trabajo que presentamos es el producto de la investigación desarrollada en el período comprendido entre los meses de marzo del año 2004 e igual mes del año 2007 en el marco de la Maestría en Trabajo Social de la Facultad de Trabajo Social de la Universidad Nacional de la Plata. El objetivo del trabajo estuvo orientado a dar cuenta de las características de las prestaciones brindadas en los establecimientos de larga estadía ${ }^{1}$ para personas mayores radicadas en la Provincia de Buenos Aires. Se analizaron las prestaciones que se brindan en los establecimientos de gestión privada habilitadas, privadas que funcionan sin habilitación (clandestinas) y en los de gestión municipal.

Definimos que el objeto de nuestra investigación eran las prestaciones (plural) y no la prestación ya que advertimos que no existe una única prestación posible. La puesta en acto de las mismas presentaba especificaciones territoriales, materiales y simbólicas particulares. Nuestro objeto introduce una doble dimensión. Una que llamamos de definición y la encontramos en el plano normativo, en la función regulatoria del Estado y otra dimensión que llamamos de puesta en acto (práctica social). Esta doble expresión del objeto nos obligó a que en el proceso de investigación juguemos en estos dos planos. En el proceso analítico analizamos los factores económicos, políticos y culturales que se entrelazan en esta oferta prestacional.

Estimamos que el aporte que pueda brindar el trabajo permitirá comprender en forma enriquecida lo que acontece actualmente en la provincia, y a partir de esto pensar y configurar estrategias de intervención estatal diferentes. Por lo tanto bucearemos en busca de las pistas que nos permitan comprender la problemática del funcionamiento de los geriátricos en nuestro país y en la provincia de Buenos Aires en particular. Partimos de concebir a la vejez como proceso que "da cuenta del entrecruzamiento particular y subjetivo de cada ser humano y su propia historia." ${ }^{\prime 2}$ La abordamos analíticamente en sus múltiples dimensiones (Psicológica, biológica y socio - cultural del proceso de envejecimiento). Retomando el aporte de Graciela Petriz ${ }^{3}$ decimos que la vejez es el proceso de elaboración y resignificación de la historia de investiduras, que conmocionan las estructuras constitutivas (narcisística, edípica y proyecto identificatorio), generando transformaciones en la subjetividad que, cuando se resuelven, alcanzan la nueva posición." Es decir que el proceso de envejecimiento es singular. "El cuerpo del viejo comenzó a ser caracterizado entonces a partir del desgaste y su disminución energética, con lo cual se creó una sinonimia cada vez

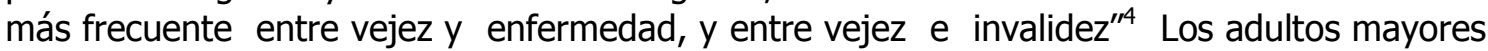
son portadores de la memoria colectiva, como ya dijimos son singulares y por sobre todos los atributos son ciudadanos. Mas allá de la condición física en que se encuentren tienen derechos. Agregamos una frase que hemos escuchado, y aunque se carece de datos de su autoría creemos necesario compartirla "Los pueblos que no cuidan a sus niños no tienen derecho al futuro, los que no cuidan a sus viejos no tienen derecho a la historia".

\footnotetext{
${ }^{1}$ Se considera como institución de larga estadía para personas mayores a aquellos establecimientos destinados al albergue, alimentación, salud, higiene y recreación asistida. Artículo $69^{\circ}$ Decreto 3280/90.

${ }^{2}$ ALVAREZ, María del Pilar "El concepto de Vejez". En: ENVEJECIMIENTO Y VEJEZ. NUEVOS APORTES. Editorial Atuel, Buenos Aires, 1998 (pp.16)

${ }^{3}$ PETRIZ, Graciela "Transformaciones psíquicas en el proceso de envejecer" (Ficha de cátedra Piscología Evolutiva. Facultad de Psicología - UNLP)

${ }^{4}$ IACUB, Ricado (pp. 83)
} 
A lo largo de los capítulos pondremos en juego el concepto de vejez en sus múltiples dimensiones.

Creemos oportuno señalar que la elección del tema estuvo vinculado a la inserción profesional y a los antecedentes de indagación en el tema de la autora. El tránsito por la Maestría permitió situarse diferente en el Trabajo Social y construir una mirada disciplinar. Esta tesis pretende ser la cristalización de un proceso de reflexión que se transita desde la graduación como Trabajadora Social y se sostuvo durante el proceso de formación de Posgrado.

Esta doble inscripción institucional, como trabajadora estatal y como docente investigadora de la UNLP posibilitó enriquecer la mirada sobre este tema que más de una vez le quitó el sueño. El grado de vulnerabilidad en el que se encuentran los adultos mayores institucionalizados nos interpelaba una y otra vez. Al mismo tiempo instaba a buscar formas diferentes de intervención tendientes a instalar en la agenda pública provincial el tema del control del funcionamiento de los geriátricos como algo ineludible, como una de las funciones esenciales de la salud pública. Esperamos que desde este lugar, la producción de conocimiento, podamos aportar a la reflexión y análisis colectivo.

\section{Relevancia del tema}

A continuación daremos cuenta de las razones por las que el tema de la institucionalización de los adultos mayores en la provincia de Buenos Aires es relevante. Argentina es considerado un país envejecido ya que del total de la población, el 13,2\% son personas 60 años o más. El 9,4\% son personas de 65 años y más y el 3,4\% de 75 y más años. De acuerdo a lo estipulado por Naciones Unidas un país es considerado envejecido cuando el $7 \%$ de su población tiene 60 y más años.

En el caso de la Provincia de Buenos nos encontramos con un porcentaje de 10,6 de personas de 65 y más años ${ }^{5}$ (1.461.118 habitantes). Este distrito está conformado por 134 Municipios, siendo una de las características principales su heterogeneidad. En cuanto a la concentración de población nos encontramos con la concentración que se refleja en el cuadro y gráfico $1^{6}$.

\footnotetext{
${ }^{5}$ De acuerdo a las proyecciones efectuadas por la Dirección Provincial de Estadísticas la Provincia presentaría para el 2007 un $14,83 \%$ de personas de 60 y más años. (2.213.316 personas)

${ }^{6}$ Elaboración propia de acuerdo a los datos del censo 2001.
} 
Distribución de Partidos según cantidad de habitantes.

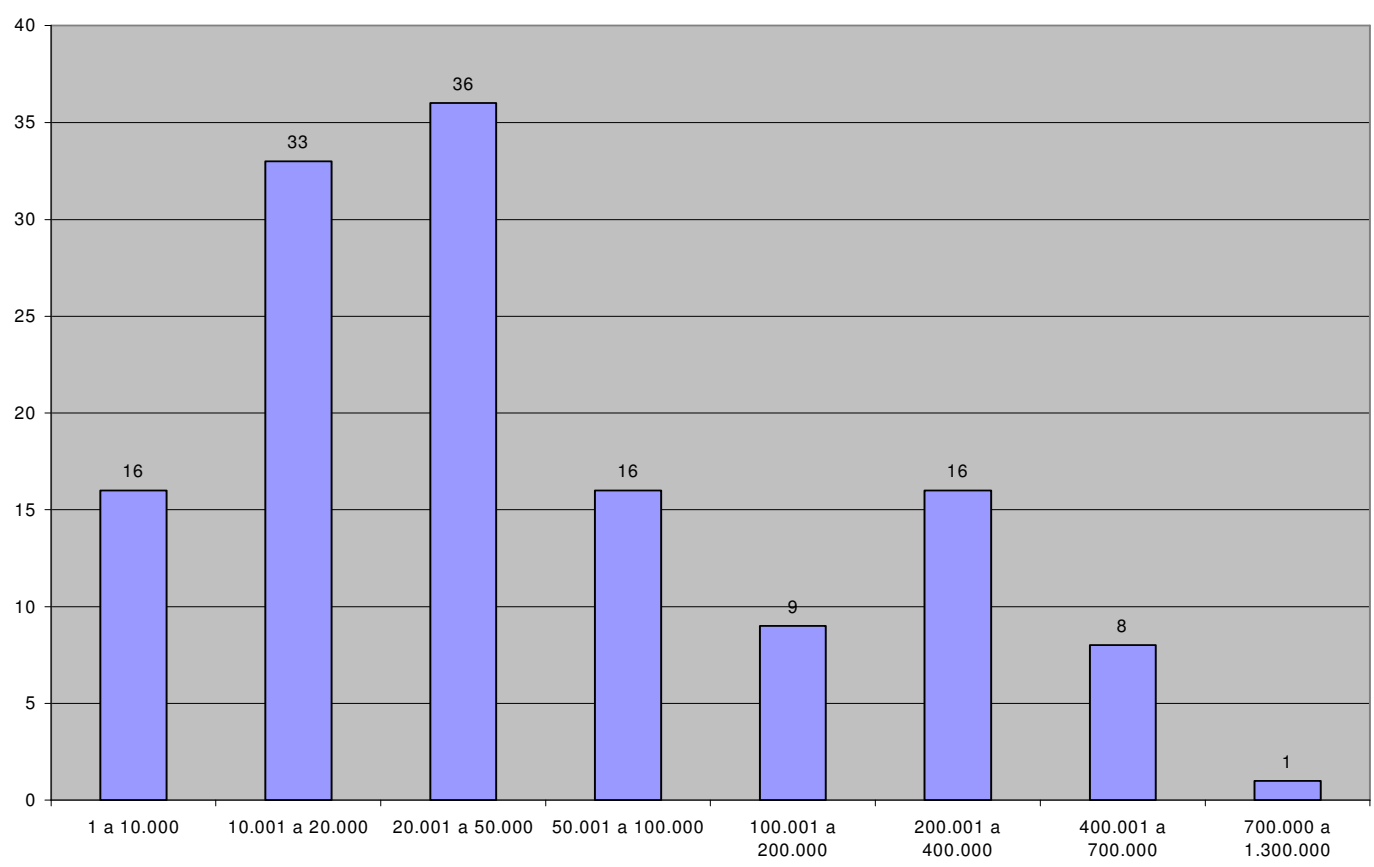

\begin{tabular}{|l|r|}
\hline Habitantes & Cantidad Partidos \\
\hline 1 a 10.000 & 16 \\
\hline 10.001 a 20.000 & 33 \\
\hline 20.001 a 50.000 & 36 \\
\hline 50.001 a 100.000 & 16 \\
\hline 100.001 a 200.000 & 9 \\
\hline 200.001 a 400.000 & 16 \\
\hline 400.001 a 700.000 & 8 \\
\hline 700.000 a 1.300 .000 & 1 \\
\hline
\end{tabular}

En la Provincia no sólo es dispar la concentración de población sino también los porcentajes de población adulta mayor. Aquí presentamos los datos obtenidos en el censo 2001, y sistematizados por la Dirección Provincial de Estadísticas.

\begin{tabular}{|l|c|c|c|c|}
\hline $\begin{array}{l}\text { División Político - } \\
\text { Administrativa }\end{array}$ & Total & $\mathbf{0 - 1 4}$ & $\mathbf{1 5}-\mathbf{6 4}$ & $\mathbf{6 5}$ y más \\
\hline TOTAL PROVINCIA & $\mathbf{1 3 . 8 2 7 . 2 0 3}$ & $\mathbf{2 6 , 6}$ & $\mathbf{6 2 , 8}$ & $\mathbf{1 0 , 6}$ \\
\hline ADOLFO ALSINA & 16.245 & 25,0 & 60,9 & 14,1 \\
\hline ADOLFO G. CHAVES & 12.037 & 25,8 & 59,2 & 15,0 \\
\hline ALBERTI & 10.373 & 21,6 & 61,3 & 8,1 \\
\hline ALMIRANTE BROWN & 515.556 & 29,6 & 62,4 & 13,2 \\
\hline ARRECIFES & 27.279 & 26,2 & 60,7 & 13,9 \\
\hline AVELLANEDA & 328.980 & 22,0 & 64,1 & 13,5 \\
\hline AYACUCHO & 19.669 & 26,5 & 60,0 & 13,3 \\
\hline AZUL & 62.996 & 25,1 & 61,6 & 12,5 \\
\hline BAHIA BLANCA & 284.776 & 23,8 & 63,6 & \\
\hline
\end{tabular}




\begin{tabular}{|c|c|c|c|c|}
\hline BALCARCE & 42.039 & 24,9 & 62,2 & 12,9 \\
\hline BARADERO & 29.562 & 26,0 & 61,3 & 12,7 \\
\hline BENITO JUAREZ & 19.443 & 26,1 & 60,9 & 13,0 \\
\hline BERAZATEGUI & 287.913 & 28,8 & 63,4 & 7,8 \\
\hline BERISSO & 80.092 & 26,4 & 63,1 & 10,5 \\
\hline BOLIVAR & 32.442 & 23,0 & 60,0 & 17,0 \\
\hline BRAGADO & 40.259 & 24,4 & 60,3 & 15,4 \\
\hline BRANDSEN & 22.515 & 28,3 & 61,6 & 10,1 \\
\hline CAMPANA & 83.698 & 28,8 & 62,8 & 8,3 \\
\hline CAÑUELAS (2) & 42.575 & 30,1 & 61,7 & 8,2 \\
\hline CAPITAN SARMIENTO & 12.854 & 26,7 & 61,0 & 12,3 \\
\hline CARLOS CASARES & 21.125 & 25,4 & 60,0 & 14,5 \\
\hline CARLOS TEJEDOR & 11.539 & 25,4 & 60,6 & 14,0 \\
\hline CARMEN DE ARECO & 13.992 & 26,0 & 62,3 & 11,7 \\
\hline CASTELLI & 7.852 & 26,0 & 60,6 & 13,4 \\
\hline CHACABUCO & 45.445 & 23,4 & 61,8 & 14,8 \\
\hline CHASCOMUS & 38.647 & 26,2 & 62,2 & 11,6 \\
\hline CHIVILCOY & 60.762 & 22,8 & 61,6 & 15,6 \\
\hline COLON & 23.179 & 26,1 & 61,0 & 12,9 \\
\hline CORONEL DORREGO & 16.522 & 23,4 & 60,3 & 16,3 \\
\hline CORONEL PRINGLES & 23.794 & 26,3 & 59,9 & 13,8 \\
\hline CORONEL ROSALES & 60.892 & 26,6 & 63,0 & 10,4 \\
\hline CORONEL SUAREZ & 36.828 & 24,5 & 61,9 & 13,5 \\
\hline DAIREAUX & 15.857 & 28,8 & 60,0 & 11,2 \\
\hline DOLORES & 25.216 & 25,9 & 61,5 & 12,6 \\
\hline ENSENADA & 51.448 & 27,2 & 62,3 & 10,5 \\
\hline ESCOBAR & 178.155 & 32,3 & 62,0 & 5,8 \\
\hline ESTEBAN ECHEVERRIA & 243.974 & 30,9 & 62,5 & 6,6 \\
\hline EXALT. DE LA CRUZ & 24.167 & 29,7 & 61,6 & 8,7 \\
\hline EZEIZA & 118.807 & 33,0 & 61,4 & 5,6 \\
\hline FLORENCIO VARELA & 348.970 & 34,1 & 60,9 & 5,0 \\
\hline FLORENTINO AMEGHINO & 8.171 & 29,0 & 59,1 & 11,9 \\
\hline GENERAL ALVARADO & 34.391 & 26,7 & 60,8 & 12,6 \\
\hline GENERAL ALVEAR & 10.897 & 22,9 & 66,9 & 10,2 \\
\hline GENERAL ARENALES & 14.876 & 22,6 & 60,6 & 16,7 \\
\hline GENERAL BELGRANO & 15.381 & 23,8 & 60,8 & 15,4 \\
\hline GENERAL GUIDO & 2.771 & 23,9 & 60,9 & 15,3 \\
\hline GENERAL LA MADRID & 10.984 & 27,1 & 61,5 & 11,4 \\
\hline GENERAL LAS HERAS & 12.799 & 27,8 & 61,7 & 10,5 \\
\hline GENERAL LAVALLE & 3.063 & 30,8 & 60,5 & 8,7 \\
\hline GENERAL MADARIAGA & 18.286 & 28,6 & 59,6 & 11,9 \\
\hline GENERAL PAZ & 10.319 & 25,7 & 60,5 & 13,9 \\
\hline GENERAL PINTO & 11.129 & 27,1 & 60,9 & 12,0 \\
\hline GENERAL PUEYRREDON & 564.056 & 23,4 & 62,7 & 13,9 \\
\hline GENERAL RODRIGUEZ & 67.931 & 32,6 & 60,1 & 7,3 \\
\hline GENERAL SAN MARTIN & 403.107 & 23,2 & 63,9 & 12,9 \\
\hline GENERAL SARMIENTO & $/ / /$ & $/ / /$ & $/ / 1$ & $/ / /$ \\
\hline GENERAL VIAMONTE & 17.641 & 24,7 & 60,3 & 14,9 \\
\hline GENERAL VILLEGAS & 28.960 & 27,9 & 60,7 & 11,4 \\
\hline GUAMINI & 11.257 & 23,3 & 62,2 & 14,5 \\
\hline HIPOLITO YRIGOYEN & 8.819 & 25,7 & 59,9 & 14,5 \\
\hline HURLINGHAM & 172.245 & 24,7 & 64,6 & 10,7 \\
\hline ITUZAINGO & 158.121 & 24,1 & 64,5 & 11,4 \\
\hline JOSE C. PAZ & 230.208 & 32,4 & 61,6 & 6,0 \\
\hline JUNIN & 88.664 & 23,1 & 61,2 & 15,7 \\
\hline LA COSTA & 60.483 & 27,3 & 61,2 & 11,5 \\
\hline LA MATANZA & 1.255 .288 & 28,2 & 63,4 & 8,5 \\
\hline
\end{tabular}




\begin{tabular}{|c|c|c|c|c|}
\hline LA PLATA & 574.369 & 23,3 & 65,0 & 11,8 \\
\hline LANUS & 453.082 & 22,1 & 64,0 & 13,8 \\
\hline LAPRIDA & 9.683 & 28,3 & 59,4 & 12,3 \\
\hline LAS FLORES & 23.551 & 24,0 & 61,0 & 15,0 \\
\hline LEANDRO N. ALEM & 16.358 & 26,5 & 59,2 & 14,3 \\
\hline LINCOLN & 41.127 & 24,7 & 61,3 & 13,9 \\
\hline LOBERIA & 17.008 & 26,2 & 59,7 & 14,1 \\
\hline LOBOS & 33.141 & 25,3 & 61,5 & 13,2 \\
\hline LOMAS DE ZAMORA & 591.345 & 25,9 & 63,5 & 10,6 \\
\hline LUJAN & 93.992 & 25,7 & 63,0 & 11,3 \\
\hline MAGDALENA & 16.603 & 25,0 & 64,2 & 10,8 \\
\hline MAIPU & 10.193 & 25,5 & 60,9 & 13,6 \\
\hline MALVINAS ARGENTINAS & 290.691 & 30,4 & 63,0 & 6,5 \\
\hline MAR CHIQUITA & 17.908 & 26,1 & 61,0 & 12,9 \\
\hline MARCOS PAZ & 43.400 & 32,5 & 60,9 & 6,6 \\
\hline MERCEDES & 59.870 & 25,4 & 62,1 & 12,5 \\
\hline MERLO & 469.985 & 30,6 & 62,5 & 6,9 \\
\hline MONTE & 17.488 & 26,2 & 62,5 & 11,3 \\
\hline MONTE HERMOSO & 5.602 & 25,1 & 62,5 & 12,4 \\
\hline MORENO & 380.503 & 33,0 & 61,3 & 5,8 \\
\hline MORON & 309.380 & 20,5 & 64,6 & 14,9 \\
\hline NAVARRO & 15.797 & 28,5 & 59,7 & 11,8 \\
\hline NECOCHEA & 89.096 & 25,4 & 61,1 & 13,5 \\
\hline NUEVE DE JULIO & 45.998 & 25,0 & 60,2 & 14,8 \\
\hline OLAVARRIA & 103.961 & 25,5 & 62,5 & 12,0 \\
\hline PATAGONES & 27.938 & 28,7 & 60,6 & 10,7 \\
\hline PEHUAJO & 38.400 & 26,1 & 60,4 & 13,5 \\
\hline PELLEGRINI & 6.030 & 26,1 & 61,7 & 12,2 \\
\hline PERGAMINO & 99.193 & 24,7 & 61,6 & 13,8 \\
\hline PILA & 3.318 & 27,0 & 61,5 & 11,5 \\
\hline PILAR & 232.463 & 33,9 & 60,7 & 5,3 \\
\hline PINAMAR & 20.666 & 26,9 & 65,3 & 7,8 \\
\hline PRESIDENTE PERON & 60.191 & 35,3 & 59,5 & 5,3 \\
\hline PUAN & 16.381 & 20,8 & 61,4 & 17,7 \\
\hline PUNTA INDIO & 9.362 & 24,8 & 61,6 & 13,6 \\
\hline QUILMES & 518.788 & 25,9 & 63,5 & 10,6 \\
\hline RAMALLO & 29.179 & 26,9 & 61,6 & 11,4 \\
\hline RAUCH & 14.434 & 25,8 & 60,7 & 13,5 \\
\hline RIVADAVIA & 15.452 & 28,4 & 60,1 & 11,5 \\
\hline ROJAS & 22.842 & 23,7 & 59,9 & 16,4 \\
\hline ROQUE PEREZ & 10.902 & 24,5 & 61,1 & 14,4 \\
\hline SAAVEDRA & 19.715 & 23,4 & 61,8 & 14,8 \\
\hline SALADILLO & 29.600 & 24,6 & 60,7 & 14,7 \\
\hline SALLIQUELO & 8.682 & 24,9 & 61,5 & 13,6 \\
\hline SALTO & 29.189 & 25,3 & 60,4 & 14,4 \\
\hline SAN ANDRES DE GILES & 20.829 & 27,7 & 59,7 & 12,5 \\
\hline SAN A. DE ARECO & 21.333 & 25,7 & 61,8 & 12,4 \\
\hline SAN CAYETANO & 8.119 & 24,1 & 61,9 & 14,0 \\
\hline SAN FERNANDO & 151.131 & 25,9 & 63,0 & 11,0 \\
\hline SAN ISIDRO & 291.505 & 21,0 & 65,0 & 14,0 \\
\hline SAN MIGUEL & 253.086 & 29,2 & 62,8 & 8,0 \\
\hline SAN NICOLAS & 137.867 & 26,0 & 63,9 & 10,1 \\
\hline SAN PEDRO & 55.234 & 29,5 & 59,9 & 10,7 \\
\hline SAN VICENTE & 44.529 & 32,2 & 59,5 & 8,3 \\
\hline SUIPACHA & 8.904 & 27,1 & 61,2 & 11,7 \\
\hline TANDIL & 108.109 & 24,0 & 63,1 & 12,9 \\
\hline TAPALQUE & 8.296 & 26,1 & 60,8 & 13,0 \\
\hline
\end{tabular}




\begin{tabular}{|l|c|c|c|c|}
\hline TIGRE & 301.223 & 29,1 & 63,0 & 7,9 \\
\hline TORDILLO & 1.742 & 31,6 & 60,3 & 8,1 \\
\hline TORNQUIST & 11.759 & 23,8 & 62,4 & 13,8 \\
\hline TRENQUE LAUQUEN & 40.181 & 27,9 & 60,3 & 11,8 \\
\hline TRES ARROYOS & 57.244 & 24,3 & 60,5 & 15,3 \\
\hline TRES DE FEBRERO & 336.467 & 21,6 & 64,1 & 14,3 \\
\hline TRES LOMAS & 7.439 & 24,9 & 60,0 & 15,1 \\
\hline VEINTICINCO DE MAYO & 34.877 & 24,9 & 59,4 & 15,7 \\
\hline VICENTE LOPEZ & 274.082 & 18,2 & 65,3 & 16,6 \\
\hline VILLA GESELL & 24.282 & 27,6 & 63,1 & 9,3 \\
\hline VILLARINO & 26.517 & 31,0 & 58,9 & 10,1 \\
\hline ZARATE & 101.271 & 27,9 & 62,1 & 10,0 \\
\hline
\end{tabular}

De acuerdo a los datos obtenidos en la Ciudad de La Plata 13.703 personas viven en instituciones colectivas ${ }^{7}$ y en la ciudad de Chascomús $406 .^{8}$ En el desarrollo del capítulo II trabajaremos sobre lo que nos permiten leer estos datos censales.

Ahora bien, nos encontramos con un distrito que presenta una población envejecida y esta realidad es de intensidad variable en los diferentes partidos. La situación de envejecimiento interpela a la sociedad en su conjunto ya que presenta nuevas necesidades a ser cubiertas. De acuerdo a las características económicas y culturales de cada población las respuestas pueden ser diferentes. En el caso de los escenarios elegidos (dos partido bonaerenses) pareciera ser que la respuesta preponderante es la asilar. Aquí aparece fuertemente uno de los interrogantes ¿Qué características tienen en la actualidad las instituciones de larga estadía para personas mayores en la Provincia de Buenos Aires?

Otra cuestión relevante del envejecimiento poblacional es que no sólo aumenta la cantidad de población de 60 ó 65 y más sino que dentro de este grupo de adultos mayores aumenta el número de los viejos - viejos o de la "cuarta edad". Claro está que cuándo una persona llega a esta etapa aumenta las posibilidades de perder autonomía. Esto no es generalizable, es decir todas las personas mayores de 75 años no presenta deterioro ni se inscriben en la vejez frágil.

Por esto fueron surgiendo otras preguntas a las que se le intentó dar respuestas ¿Cuándo es necesaria la institucionalización? ¿A quién se le da respuesta cuándo se decide la institucionalización? ¿Cuál es la eficacia simbólica y corporal de estas prácticas sociales? Cuándo empezamos a caracterizar el escenario advertimos que una de las particularidades era la existencia de establecimientos que funcionaban sin habilitación, sin control estatal y nos preguntábamos ¿Por qué no están habilitadas? ¿Qué rol cumple el estado en este sentido? En este punto es que advertimos la doble dimensión de nuestro objeto (definición y puesta en acto), quién decide qué debe cumplir un geriátrico, qué intereses se defienden en esta definición ¿Qué se construye como mínimo para los ancianos? ¿Qué sería lo básico para ellos? ¿Qué es un geriátrico? ¿Se configura en un gueto? ¿Cómo son las prácticas sociales de sus agentes? $Y$ nos encontramos con que uno de sus agentes eran los Trabajadores Sociales. Como campo de ejercicio profesional aparecían definidas estas dos

\footnotetext{
${ }^{7}$ De acuerdo al censo se considera instituciones colectivas como el lugar destinado a alojar personas que viven bajo un régimen no familiar, regulado por normas de convivencia de carácter administrativo, militar, religioso, de salud, de reclusión, de trabajo, etc. Fuente: censo 2001.

8 Fuente: Censo Nacional de Población, Hogares y Viviendas 2001. Elaboración Dirección Provincial de estadísticas.
} 
dimensiones, de definición y de puesta en acto (regulación estatal y acciones institucionales al interior de los geriátricos).

\section{CUESTIÓN METODOLÓGICA}

La investigación que se ha llevado a cabo es de tipo empírica y cualitativa en tanto "busca el sentido de los fenómenos sociales que se estudian" ${ }^{9}$ Para el desarrollo de la misma se realizó un trabajo de campo. El escenario elegido para su desarrollo se configura en dos municipios: Chascomús y La Plata. Ambos integran la Región Sanitaria $\mathrm{XI}^{10}$. De acuerdo a los datos extraídos del último censo (2001) el partido de Chascomús tienen una población total de 38.647 habitantes de los cuales el $11,6 \%$ tiene 65 y más años ${ }^{11}$. Y La Plata cuenta con 574.369 habitantes de los cuales el $11,8 \%$ tiene 65 y más años ${ }^{12}$. Estos municipios poseen radicados en su territorio hogares geriátricos privados y también poseen un hogar perteneciente al gobierno municipal.

Los criterios que se han considerado para la selección de la muestra fueron varios. Por una parte las acciones llevadas a cabo por el Municipio tendientes al control prestacional. En la provincia podemos observar que existen municipios que se han comprometido con la problemática de la existencia de instituciones que funcionan sin control alguno y otros municipios se han corrido del lugar de responsabilidad por lo que no han generado ninguna acción. Estos dos municipios, son representativos de este universo. Otro de los criterios es la pertenencia regional, ya que ambos pertenecen a la misma Región Sanitaria y también que ambos tienen un porcentaje de población envejecida similar.

La investigación definió como objeto a las prestaciones brindadas en hogares geriátricos de la provincia de Buenos Aires (los casos de La Plata y Chascomús). Cómo ya hemos planteado estas prestaciones se configuran cómo una de las respuestas sociales frente al envejecimiento, y hemos planteado que la vejez es definida de acuerdo a cada tiempo y cultura en que se enmarque y ambos elementos son interpretados en forma diversa de acuerdo al campo disciplinar de análisis. Por lo tanto este trabajo fue abordado desde un enfoque cualitativo de investigación. Este tipo de estudios no tienen como finalidad la búsqueda de generalizaciones, sino encontrar principios de interpretación que permitan capturar los datos a los que los agentes singulares de este trabajo nos lleven, confrontando con un amplio marco teórico de referencia. Nuestro objetivo va a ser interpretar, caracterizar la prestación pero en una doble dimensión. Señalo esto ya que no será solo interpretar discursos sino inscribirlos en una realidad particular, compleja y totalizadora.

\footnotetext{
9 JOCILES RUBIO, María Isabel "Contexto Etnográfico y uso de las técnicas de investigación de Antropología Social". En: de la Cruz (Comp) INTRODUCCION A LA ANTROPOLOGÍA PARA LA INTERVENCIÓN SOCIAL. Editorial Tirant lo blanch, Valencia, 2002 (pp. 118)

${ }^{10}$ REGION SANITARIA XI es integrada por los municipios de La Plata, Chascomús, Berisso, Coronel Brandsen, Cañuelas, Castelli, Dolores, Ensenada, General Belgrano, General Paz, Magdalena, Monte, Pila, Presidente Perón, Punta Indio, San Vicente y Tordillo.

${ }^{11}$ De acuerdo a las proyecciones efectuadas por la Dirección provincial de Estadísticas para el año 2007 se esperaba que en el Partido de Chascomús el porcentaje de población con 60 y más años sea del $16,35 \%$ (Elaboración propia de porcentajes)

${ }^{12}$ De acuerdo a las proyecciones efectuadas por la Dcción. Provincial de Estadísticas para el año 2007 se esperaba en el Partido de La Plata que el procentaje de población de 60 y más años sea del 16,14 \% (Elaboración propia de porcentajes).
} 
Para el desarrollo de la investigación llevamos a cabo un relevamiento bibliográfico con el objetivo de dar cuenta de los conceptos y categorías de análisis, y realizamos un análisis de las leyes y normativas de habilitación existentes a nivel provincial, nacional e internacional. El trabajo de campo fue realizado durante todo el año 2005 y el primer semestre 2006. Efectuamos observaciones participantes en 8 instituciones geriátricas de gestión privada de la localidad de Chascomús (todas las existentes). Y en la localidad de La Plata observamos 5 establecimientos del ámbito privado habilitadas, 5 clandestinas. El número de establecimientos seleccionado en la localidad de La Plata fue establecido en función al número de geriátricos registrados en el estado provincial, es decir 122 habilitados. De igual forma no es posible dilucidar cuál es el número real. No existe esta información en el Ministerio de Salud ni en la Municipalidad de La Plata. Desde las especulaciones que efectúan algunos funcionarios se cree que el número de establecimientos clandestinos es igual al de los habilitados. La cantidad de establecimientos observados estuvo vinculado al alcance del punto de saturación de la información relevada. Para la observación en los Hogares de personas mayores se tomaron como elementos facilitadores de la evaluación: las actas de inspección labradas por los inspectores sanitarios y se construyeron crónicas sobre lo observado. El observable será el tipo de prestación brindada en cada uno de los geriátricos.

También se llevaron a cabo entrevistas a funcionarios provinciales y municipales, titulares de hogares geriátricos habilitados, titulares de hogares geriátricos clandestinos o en proceso de regularización, profesionales de ambos tipos de establecimientos. Claro está que hemos considerado a los informantes ${ }^{13}$ / interlocutores del trabajo de campo como sujetos constructores de la realidad social y cultural, objeto de determinaciones estructurales, ubicado en una determinada posición social, partícipe de un momento histórico singular.

Las entrevistas fueron semi - estructuradas, es decir con una serie de ejes establecidos previamente que direccionaron las mismas. Se han construido estos ejes comunes a todos los entrevistados para que sea posible efectuar comparación y análisis. Los ejes que constituyeron el instrumento que elaboramos serán trabajados en el Capítulo II.

En el primer capítulo "Algunas referencias a la política de vejez en Argentina". Definimos el concepto de Estado y política de vejez, en tanto posiciones que toma el estado frente al envejecimiento poblacional e individual. Para dar cuenta de la configuración de "políticas de vejez" presentamos un acotado recorrido de las políticas en materia social y de salud pública. Advertimos que las prestaciones de los geriátricos se inscriben en Atención Socio - Sanitaria. Asimismo abordamos un análisis de la dimensión Regulatoria, es decir de la función de control prestacional.

En el capítulo II "Hogares Geriátricos ¿escenarios de violencia? Presentamos una referencia a los porcentajes de población envejecida en la Provincia de Buenos Aires, un análisis de la relación entre ciudadanía y envejecimiento, problematizamos el concepto de violencia y de clandestinidad. Efectuamos un análisis sobre las formas de evaluación de los geriátricos y presentación de la dimensión metodológica de la investigación a partir de la categoría de necesidades básicas.

\footnotetext{
${ }^{13}$ GUBER, Rosana "El informante. Sujeto de la investigación". En: EWL SALVAJE METROPOLITANO. Editorial Legasa, Bs. AS.
} 
En el capítulo III "Caracterizando la prestación brindada en las instituciones de larga estadía: sus dimensiones materiales y simbólicas" presentamos los datos construidos a partir del desarrollo de la investigación.

En el capítulo IV comenzamos caracterizando la cultura institucional y presentamos una síntesis de los hallazgos alcanzados y construidos. Presentamos provisorias respuestas a los interrogantes que habíamos presentado en el desarrollo de la tesis. También realizamos una serie de propuestas que, creemos, deberían orientar la política pública.

Es necesario aclarar que en el desarrollo de los capítulos se observa que se denomina como personas mayores al grupo etario. Sin embargo en varias oportunidades también utilizamos la forma adultos mayores. Ambas formas fueron seleccionadas como una forma de interpelación al lector, recordando que no se pierde la condición de persona ni de adultos cuando se transita la vida en una institución de larga estadía.

Para finalizar advierto a los lectores que la tesis ha sido escrita en primer persona del plural. Si bien se trata de una investigación que fue desarrollada en forma individual, a lo largo del camino recorrido varios fueron los interlocutores que facilitaron y enriquecieron la tarea. Muchos acompañaron el proceso de reflexión, y en virtud de reconocerlos a todos, hablo de nosotros.

Situados en la certeza que es posible cambiar la realidad, presentamos esta investigación deseando que se configure en un aporte. 


\section{CAPÍTULO I}

\section{ALGUNAS REFERENCIAS EN TORNO A LA POLÍTICA DE VEJEZ EN ARGENTINA}

"... la institución de larga estadía es una de las respuestas que da la sociedad al problema de la ancianidad"14 $^{\prime 14}$

El presente capítulo tiene por finalidad presentar algunas referencias del escenario actual e histórico en que se presenta la temática de la internación / albergue de las personas mayores. Por ello es necesario inscribir este tema en el marco de las políticas públicas, por lo que intentaremos aprehender el movimiento histórico en el cual se institucionalizaron las formas de enfrentar la cuestión social destinadas a las personas mayores.

La investigación desarrollada tuvo como objetivo caracterizar la prestación que brindan los establecimientos de larga estadía para personas mayores. Cómo primer paso definimos que esta prestación se inscribe en el marco de la atención socio - sanitaria. "Los cuidados que precisan la mayoría de las personas mayores dependientes no son sólo sociales, tampoco exclusivamente sanitarios. La atención que ha de ofrecerse debe ser de carácter integral, y por tanto, ser socio - sanitaria." ${ }^{15}$ Tras esta definición fue necesario que el recorrido histórico sea efectuado sobre las políticas del ámbito social y de la salud pública.

Siguiendo a Oszlack ${ }^{16}$ definimos al estado como una relación social y un aparato institucional. El autor nos plantea que la existencia del estado se verificaría a partir del desarrollo de un conjunto de atributos que definen la "estatidad". Estos atributos son: capacidad para externalizar su poder; capacidad de institucionalizar su autoridad imponiendo una estructura de relaciones de poder que garantice su monopolio sobre los medios organizados de coerción; capacidad de diferenciar su control, a través de la creación de un conjunto funcionalmente diferenciado de instituciones públicas y capacidad de internalizar una identidad colectiva.

Estado es al mismo tiempo "una relación social en tanto instancia política que articula un sistema de dominación social (sentido abstracto) y también (manifestación concreta) actor social en la medida en que sus múltiples unidades e instancias traducen la presencia estatal difundida en el conjunto de las relaciones sociales y a su invocación de legítima autoridad para encarnar el interés general de la sociedad" ${ }^{17}$ Entonces para comprender

\footnotetext{
${ }^{14}$ FREYSSELINARD; Edgardo; ODDONE, María Julieta, PAOLA, Jorge y PASSADORE, Norma "Hogares de ancianos: una aproximación al estudio de sus características institucionales". En: INFORME SOBRE TERCERA EDAD EN LA ARGENTINA. Secretaria de Tercera Edad y acción Social, Bs. As. 2001 (pp. 393)

${ }^{15}$ RODRIGUEZ RODRIGUEZ, Pilar (Coord) RESIDENCIAS PARA PERSONAS MAYORES. Manual de Orientación. Editorial Médica panamericana, Madrid, 2000 (pp. 51)

${ }^{16}$ OSZLACK, Oscar LA FORMACION DEL ESTADO ARGENTINO: Editorial Belgrano. Bs. As. 1982 (pp. 14/5)

17 FISCELLA, Sergio "Conceptos ordenadores básicos. Marco teórico conceptual". En: ESTADO, CIUDADANÍA Y POLÍTICA SOCIAL. Espacio Editorial BS. As, 2005 (pp. 20) 
las manifestaciones concretas de este estado debemos tener claridad sobre las características del mismo en cada momento histórico particular.

Podemos plantear siguiendo a Giménez que el estado es simultánea e indisociablemente poder y aparato, es un mixto de dominación, autoridad y dirección. "El poder de Estado así caracterizado no es totalmente autónomo, ni autógeno, sino que representa la expresión terminal de las complejas relaciones de dominación y hegemonía que tienen por base y fundamento la estructura de clases de una determinada formación social"18 Por esto es que plantearemos que el estado ejerce su poder entre la coerción y la construcción de consensos, y el interés general de la sociedad no es otra cosa que la expresión de la relación de fuerzas entre las clases.

Ahora bien, a los fines de clarificar la exposición definiremos el concepto de política pública: "las políticas públicas son proyectos y actividades estatales a los fines de satisfacer necesidades sociales, y por tanto que el objeto y finalidad principal debe ser la sociedad."19 Para que una problemática sea abordada por la política pública es necesario que suscite interés público, y se instale en la agenda de gobierno (agenda pública). Siguiendo los aportes de Huenchuan Navarro decimos que "aquellas acciones organizadas por parte del Estado frente a las consecuencias sociales, económicas y culturales del envejecimiento poblacional e individual las denominamos políticas de vejez. ${ }^{20}$.

Para el desarrollo de nuestro trabajo definimos un concepto dinámico de estado y política pública que permitió bucear entre los antecedentes históricos y la génesis de la atención a las personas mayores.

Cómo ya venimos planteando el objeto de nuestra investigación fue analizado en dos dimensiones, una de definición y otra de puesta en acto. El primer plano, de definición se inscribe en las políticas regulatorias del estado. Regulación en tanto generación de "reglas de juego" a ser cumplidas. En rigor, estas acciones de control y fiscalización se inscriben en el escenario de las políticas públicas del Estado. La cobertura por parte de la seguridad social de este tipo de prestaciones sí se inscribiría en el escenario de las políticas sociales en tanto que des - mercantilizan un bien, con un claro fin compensatorio. Pero creímos necesario ampliar la conceptualización a la regulación ya que como veremos más adelante el acceso a estas prestaciones acontece mayoritariamente a través del mercado.

La atención hacia los adultos mayores en nuestro país se trazó en cuatro ejes significativos. El primero vinculado a las prácticas asilares propias de las acciones encaradas a fin de siglo XIX, el segundo vinculado a garantizar la "seguridad económica" a través de la puesta en marcha de políticas previsionales tendientes a garantizar un ingreso a la población que dejaba de pertenecer a los "activos" del mercado de trabajo. El tercero vinculada a garantizar "atención sanitaria" a través de la creación del Instituto Nacional de Servicios Sociales de Jubilados y Pensionados (INSSJyP) y un cuarto momento vinculado a garantizar "seguridad alimentaria" a través de la extensión de políticas alimentarias para este grupo poblacional.

\footnotetext{
${ }^{18}$ GIMENEZ, Gilberto "El Estado". En: PODER, ESTADO Y DISCURSO. UNAM, México, 1986 (pp. 43)

19 GRAGLIA, Emilio DISEÑO Y GESTION DE POLITICAS PUBLICAS. Hacia un moelo relacional. Editorial Universidad Católica. Córdoba, 2005 (pp. 28)

${ }^{20}$ HUENCHUAN NAVARRO, Sandra "MARCO PROGRAMÁTICO SOBRE VEJEZ Y ENVEJECIMIENTO: CONCEPTOS Y ELEMENTOS PARA SU ANÁLISIS Y SEGUIMIENTO." CELADE. Cepal
} 
I -

Primer eje: Asistencia social hacia la vejez

El primer eje que desarrollaremos tiene que ver con la matriz asistencial asilar que dio origen a la configuración de las instituciones de larga estadía como respuesta social y estatal al "problema de la ancianidad". La asistencia social en Argentina desde fines del Siglo XIX y principios del XX era encarada por la Sociedad de Beneficencia, el cual era un organismo laico con un fuerte financiamiento del Estado, pero que imponía sus propios criterios a la hora de hacer efectiva la asistencia. Siguiendo el aporte de Tenti Fanfani " la estrategia típica de intervención propia de la beneficencia se caracteriza por la sanción ejemplificadora (los premios a la virtud) o bien por la internación - segregación"21

"Las poblaciones que son objeto de intervenciones sociales difieren fundamentalmente según sean o no capaces de trabajar. ......Estas poblaciones exentas de la obligación de trabajar son los clientes potenciales de lo social - asistencial." ${ }^{\prime 22}$ En este grupo se incluyen los niños sin padres, ancianos "indigentes", "paralíticos", etc. Es decir aquellos que portan algún tipo de desventaja que no les permite trabajar.

Siguiendo el aporte brindado por Barberena destacamos que "los antecedentes en intervenciones sobre la temática de los "ancianos sin recursos", van a ser pocas. Concluye que "La cuestión social en los ancianos parece casi circunscripta al viejo mendigo"23

Pues entonces estas prácticas destinadas a las personas mayores eran desde una clara intencionalidad política, internar, asilar, excluir al no apto para el trabajo, desterrarlo del escenario público. Desde el campo de la salud también en este momento histórico va a ser el concepto de beneficencia el que rija las intervenciones del Estado. A partir de 1880 se inicia la acción del estado tanto en el aspecto normativo como en el desarrollo de acciones de corte higienista ${ }^{24}$. En este sentido en el período comprendido entre los años 1823 a 1947 la creación de asilos estatales se efectuaron bajo la influencia de la "etapa higienista de la política de salud" en Argentina ${ }^{25}$. En esta etapa "comienza a perfilarse una tendencia destinada a centralizar la política de salud y darle carácter nacional. Por otro lado se tiende a vincular el tema sanitario con las necesidades de desarrollo social y económico. ... se trataba de proteger, a través de la regulación y fiscalización estatal las condiciones de sanidad de puertos y trenes, ambos elementos centrales al modelo agroexportador existente en el país"26

Si bien era el estado el que mayor aportes económicos brindaba a la asistencia social, no le significaba una preocupación central hasta mediados de la década del $\mathbf{4 0}$. En este punto la ruptura con el modelo anterior fue total. Ya no era la sociedad de beneficencia la

${ }^{21}$ TENTI FANFANI, Emilio "Estrategias típicas de intervención". En: ESTADO Y PROBREZA: ESTRATEGIAS TIPICAS DE INTERVENCION/1. Centro Editor de América Latina. Bs As, 1989 (pp36)

${ }^{22}$ CASTEL, Robert "Introducción". LA METAMORFOSIS DE LA CUESTIÓN SOCIAL. (pp. 29)

${ }^{23}$ BARBERENA, Mariano TESIS DE MAESTRIA EN TRABAJO SOCIAL. 2001 (pp. 30)

${ }^{24}$ Para profundizar sobre este tema se puede consultar CARBALLEDA, Alfredo DEL DESORDEN DE LOS CUERPOS AL ORDEN DE LA SOCIEDAD. Editorial UNLP, La Plata, 2000.

25 PAOLA; Jorge Historias FUNDACIONALES DE LAS RESIDENCIAS PARA MAYORES DE LA ARGENTINA. RITUALES INSTITUCIONALES Y EXPERIENCIAS SIGNIFICATIVASS PARA EL CAMPO GERONTOLÓGICO. Actas del III Simposium Argentino de Gerontología Institucional CD- ROM $\mathrm{n}^{\circ}$ de ISBN 987-544-199-6, Mar del Plata, 2005.

${ }^{26}$ PEREZ IRIGOYEN, Claudio "Política Pública y Salud" En: ISUANI, Ernesto y TENTI, Emilio (Comp) ESTADO DEMOCRÁTICO Y POLITICA SOCIAL. Editorial EUDEBA. Bs As, 1989 (pp. 173) 
encargada de esta tarea sino el propio estado. Aparece arraigado fuertemente el concepto de justicia social y de ayuda social y un fuerte rechazo a las actividades caritativas, filantrópicas y de beneficencia. En referencia al grupo etario que nos ocupa, las personas mayores, se establecieron los "Derechos de la Ancianidad" y estos fueron sugeridos ante las Naciones Unidas a través de su embajador. Los hogares de ancianos creados por la Fundación Eva Perón propiciaban "una concepción de hogar para la asistencia integral del anciano superando el hasta entonces criterio asilar"127

En el campo de la salud a partir del año 1946 "se sientan las bases institucionales para el desarrollo de un sistema de salud más complejo. En este período comienza la consolidación de una estructura del sistema de salud basada en tres sectores: público, de la seguridad social y privado"28

En síntesis, ha existido una tradición en las prácticas de asistencia social y de salud pública vinculado al internamiento, al encierro de la población pobre no apta para el trabajo. En el informe sobre tercera Edad en Argentina aparece un análisis en este sentido "el asilo como la forma más práctica de accionar sobre la mendicidad y dar protección caritativa"29. Indican que a fines del siglo XIX surgen instituciones pertenecientes a diferentes colectividades extranjeras con el propósito de brindar protección frente a los riesgos de enfermedad. Estas eran sociedades benéficas, con carácter comunitario.

Podemos vincular esta tradición asilar con los planteos de Michel Foucault y otros intelectuales sobre las tecnologías del poder. "A medida que avanzamos en el desarrollo de una sociedad disciplinaria se van propagando más y más este tipo de instituciones. El encierro cuya funcionalidad se descubre a posteriori de su uso adopta múltiples modos.

Ahora cada institución está especializada en su función y procesan los cuerpos en distintas vecciones. Esta multiplicidad de mecanismos diseminados por toda la sociedad constituye lo que Foucault denomina "la red institucional de secuestro", a través suyo se posibilite una doble funcionalidad de las disciplinas: garantizar la no rebelión de los "ciudadanos" y "desigualar" la "igualdad" ciudadana. ${ }^{30}$ Estas prácticas se han venido reproduciendo históricamente. Han recibido numerosas críticas por lo que se han efectuado esfuerzos en pos de desentrañar las razones de su existir y si realmente eran necesarias. ¿Es necesario que frente a una persona mayor sin cobertura social la respuesta sea el encierro? ¿Es necesario que frente a una persona mayor sin familia (si esto fuera posible) la respuesta sea el encierro? ¿Qué produce el encierro, cual es su eficacia simbólica y corporal?

El encierro de las personas mayores crea y recrea los prejuicios construidos sobre la vejez. La respuesta asilar es una constante a la población envejecida, esto claramente vinculado con la concepción de vejez que opera socialmente. "El edaísmo es "mas que una palabra". Constituye el proceso cultural contemporáneo que se instituye en el espacio de los estilos de vida, tanto en las cosas como en los cuerpos, dando un sentido objetivo y subjetivo a la distinción entre generaciones, y a la lucha entre los protagonistas del pasado, del presente y del futuro. Esta disposición estructura y naturaliza las prácticas

27 PAOLA; Jorge HISTORIAS FUNDACIONALES DE LAS RESIDENCIAS PARA MAYORES DE LA ARGENTINA. RITUALES INSTITUCIONALES Y EXPERIENCIAS SIGNIFICATIVASS PARA EL CAMPO GERONTOLÓGICO. Actas del III Simposium Argentino de Gerontología Institucional CD- ROM n ${ }^{\circ}$ de ISBN 987-544-199-6, Mar del Plata, 2005.

${ }^{28}$ PEREZ IRIGOYEN (Ibidem) pp176

29 FREYSSELINARD, Edgardo, ODONNE, María Julieta, PAOLA, Jorge y PASSADORE, Norma "Hogares de Ancianos: una aproximación al estudio de sus características institucionales". En: INFORME SOBRE TERECERA EDAD EN ARGENTINA. Secretaria de Tercera Edad y Acción Social, Bs. As, 2001 (pp. 393)

${ }^{30}$ NIEVAS, Fabián "Disciplina". En: EL CONTROL SOCIAL DE LOS CUERPOS. Editorial EUDEBA, Buernos Aires, abril 1999 (pp. 82) 
discriminatorias fundadas en las huellas corporales que imprime el paso del tiempo, eufemiza las condiciones objetiva de vida pos jubilatorias y ejerce una influencia condenatoria a la vejez." ${ }^{131}$

\section{Segundo Eje "Seguridad Económica"}

Otra de las preocupaciones que se inscribió en la agenda pública fue la necesidad de garantizar un ingreso "mínimo" para los trabajadores cuándo se retiraban del mercado de trabajo.

Para comenzar a caracterizar el origen de la Previsión Social en Argentina ${ }^{32}$ es necesario situar el origen del incremento de la población envejecida. En esta línea es que vamos a tomar el proceso iniciado en 1880 con una oligarquía a cargo de la administración del estado, conocida como "generación del 80". Su cometido era ordenar el estado nacional en función de los requerimientos del mercado mundial, es decir insertar a nuestro país como agro exportador. Para tal fin era necesario garantizar "orden para el progreso". "Imponer el orden implicaba regularizar el funcionamiento de la sociedad, hacer previsibles las transacciones, regular los comportamientos. El "orden" aparecía entonces, paradójicamente, como una drástica modificación del marco habitual de relaciones sociales. No implicaba el retorno a un patrón normal de convivencia sino a la imposición de uno diferente, congruente con el desarrollo de una nueva trama de relaciones de producción y de dominación social. ${ }^{\prime \prime 3}$ En este marco es que el estado encara un proyecto de convocatoria de población europea, a fin de poblar un país vacío. Un vacío estrecha y dolorosamente relacionado al etnocidio acaecido en los siglos anteriores. La política inmigratoria trajo aparejado para las décadas posteriores (segundo cuarto del siglo XX) un aumento de la franja poblacional mayor de 60 años, sin que haya sido evaluado con anterioridad por las elites gobernantes. Esto se debió al bajo índice de natalidad que presentaban los europeos asentados en el río de la plata y al aumento de la expectativa de vida que se dio en el siglo XX. La cantidad de ancianos que habitaban en Argentina era una de los mayores de América Latina, después de Uruguay. La inmigración modificó la estructura demográfica del país, se incrementó la proporción de población en edad de trabajar y se alentó la urbanización. Lloyd - Sherlock nos plantea que las políticas públicas que alentaron la inmigración eran indirectamente responsables de la caída de la fertilidad y del envejecimiento poblacional en nuestro país.

En este sentido señalamos que el nivel de vida al que acceden los ancianos está estrechamente ligado con la clase de pertenencia y el tipo de trabajo que han realizado, y las condiciones de ejercicio del mismo. El autor mencionado nos plantea que la estructura ocupacional en nuestro país ha variado, de acuerdo a las necesidades que imponía el modo de acumulación. "Los caprichos del funcionamiento económico argentino y los cambios en

\footnotetext{
${ }^{31}$ GOLPE; Laura "Edaísmo y trayactoria vital: una encrucijada en la cultura". EN: GOLPE, BIDEGAIN y ARIAS (Comp.) EDAÍSMO Y APOYO SOCIAL. Editorial suárez, Mar del Plata, 2003. (pp. 33)

32 Previsión social hace referencia al conjunto de programas que cubren las contingencias de vejez, invalidez y muerte cuyas prestaciones son conocidas como jubilación, pensión o retiro según los distintos países. Para ampliar sobre este punto ver: FISCELLA, Sergio "Conceptos ordenadores básicos. Marco teórico conceptual". En: ESTADO, CIUDADANÍA Y POLÍTICA SOCIAL. Espacio Editorial BS. As, 2005 y GOLBERT, Laura y LO VUOLO, Rubén "El sistema Previsional en Discusión". En: ISUANI TENTI ESTADO DEMOCRÁTICO Y POLITICA SOCIAL. EDUDEBA, Bs As, 1989

${ }^{33}$ OZLAK, Oscar LA FORMACION DEL ESTADO ARGENTINO. Bs. As. Editorial de Belgrano. 1982(pp.28)
} 
la configuración de sus mercados de trabajo aumentaron la probabilidad de que una alta proporción de aquellos que habían alcanzado la ancianidad hacia los años 90 hubieran trabajado en varias actividades, incluyendo urbanas y rurales, formales e informales.......... el efecto global ha sido una abrupta caída en el ingreso per cápita desde mediados de la década del 70."134

Durante el último cuarto del siglo XIX y principios del XX las respuestas a la previsión social estuvieron limitadas a programas destinados a trabajadores de actividades específicas. Esto fuertemente vinculado a la capacidad de presión que los sindicatos tenían hacia el estado y la contra respuesta que ejercía la patronal. Aquí se abre un debate entre los historiadores, por un lado algunos plantean que las políticas previsionales (jubilación) fueron otorgadas por el estado a algunos sindicatos a fin de cooptarlos y generar legitimidad, otros en cambio arguyen que estos beneficios se obtuvieron gracias a la presión que ejerció el movimiento obrero. De igual manera, no es un tema que se profundice en este trabajo.

Los primeros en obtener el beneficio de la jubilación fueron los trabajadores del estado en 1904, luego en 1922 el beneficio se extendió para los trabajadores bancarios, recién en la década del 40 se extendió para todos los trabajadores. Por lo que podríamos definir que las políticas de vejez con el objetivo de garantizar la "seguridad económica" se universalizaron en la década del 40.

"Las políticas asistenciales peronistas influyeron en el bienestar económico de los ancianos en diversos aspectos. Principalmente, surgieron los primeros programas de gran escala de pensiones no contributivas............ los programas de pensión y otras actividades de la Fundación Eva Perón brindaron un importante precedente para la realización de programas asistenciales populistas de alto perfil por parte de futuros gobiernos, algunos de los cuales tendrían a los ancianos como beneficiarios directos." 35

Posteriormente a los gobiernos de Perón, durante las décadas del 50 y 60 , no se modificó el marco regulatorio de la seguridad social, pero lo que sí varió fue la situación financiera. En el proceso de implementación de la seguridad social, la relación entre la cantidad de trabajadores en actividad y pasivos era favorable, pero esto fue modificándose con el correr de los años. De igual manera esta desproporción no era causa única de la situación financiera poco favorable, sino que las malas y fraudulentas administraciones de las cajas de previsión tuvieron bastanto que ver. ${ }^{36}$

En 1970 se logra la unificación normativa por lo que de 13 cajas previsionales se pasa a contar con 3: Caja Nacional de Previsión del estado y Servicios Públicos; Industria, Comercio y Actividades Civiles y la de Trabajadores autónomos.

Los cambios más significativos se evidencian a partir de la última dictadura militar profundizándose en los años 90, ligado a la implementación de políticas estatales de corte innegablemente neoliberal. La principal modificación se efectuó en 1994, por Ley 24241 creándose el sistema mixto compuesto por el sistema de reparto y las Administradoras de Fondos de Jubilaciones y Pensiones (AFJP) ${ }^{37}$. Con esta ley se trasladó la obligación de la

\footnotetext{
${ }^{34}$ LLOYD - SHERLOCK ANCIANIDAD Y POBREZA EN EL MUNDO EN DESARROLLO Editorial: Miño y Dávila Editores. Ciepp. Madrid. 1999 (2 edición) (pp. 80)

${ }^{35}$ LLOYD - SHERLOCK. 1999 (pp.96/97)

${ }^{36}$ En este punto Ver Fiscella (pp. 58)

${ }^{37}$ Para ver un análisis de fortalezas y debilidades del sistema mixto ver: Fiscella (op cit)
} 
seguridad social al ámbito privado e individual implementándose el sistema de capitalización individual a través de Administradoras de Fondos de Jubilaciones y Pensiones (AFJP). Esta privatización estuvo acompañada de una estrategia de convencimiento y construcción de consensos en cuanto a lo deficitario de la administración estatal y los beneficios de las administraciones privadas. En este proceso jugaron un rol importante varios medios de comunicación de corte liberal. "Las dos premisas de la propuesta bancomundialista son: que un sistema privadamente administrado es más eficiente que un sistema público y que el ahorro individual obligatorio redundará en un incremento del ahorro global agregado ......... ........no significa ningún avance como instrumento de protección económica en la tercera edad ni para los asegurados ni para el resto de la población ....... los ganadores de la reforma son, sin lugar a dudas, los grupos financieros nacionales e internacionales......... Presenciaremos pues, una acción estatal decidida a crear un nuevo ámbito de acumulación de capital para los grupos financieros, con un esquema en el cual se privatizan las ganancias y se socializan las pérdidas......."138

En síntesis, durante el siglo XX se inscribió en la agenda pública la problemática de la seguridad económica de los trabajadores a medida que envejecen en un escenario signado por un envejecimiento poblacional inédito para el país. En la actualidad sigue siendo un tema de debate, discutiéndose en este momento una modificación a este sistema mixto.

\section{Tercer Eje "Atención Sanitaria"}

Siguiendo los aportes de Perez Irigoyen, las políticas sanitarias, en Argentina, inicialmente no se diferenciaban de las "intervenciones en lo social" ya que estas eran delineadas por la Sociedad de Beneficencia. A partir de 1880 existió una fuerte influencia del higienismo y en la década del 40 las acciones encaradas por el Dr. Carrillo a cargo de la Secretaria de Salud Pública impulsaron fuertemente la capacidad asistencial pública y brindándose un fuerte aliento a la atención de los trabajadores a través de las obras sociales. A partir de 1956 y profundizándose en la década del 70 se facilitó la descentralización de servicios nacionales (muchas veces sin los recursos necesarios) y se facilitó el desarrollo del sector privado restringiéndose el campo de la salud pública. Esto contribuyó a que la atención de la salud se relacione con mayor grado con la lógica del mercado. $^{39}$

En 1971 se crea el I.N.S.S.J. y P. (Instituto Nacional de Seguridad Social para Jubilados y Pensionados) el que brindó y continúa brindando una serie de beneficios ligados a la atención social y sanitaria a los beneficiarios de jubilaciones y pensiones del ámbito nacional. Aquí retomo nuevamente los aportes de Barberena: "Tres cuestiones merecen reflexiones acerca de lo que rodea la creación de lo que será la obra social más grande de Latinoamérica: Una primera reflexión referida al contexto en el que surge, ya que comprender el carácter coyuntural con el que fueron tomadas algunas medidas, las marcas de origen que lleva, sirve para analizar la trayectoria de la cuestión problematizada. La segunda reflexión es acerca de las razones que a manera de diagnóstico socio sanitario

\footnotetext{
${ }^{38}$ LAURELL, Asa "El nuevo sistema de pensiones. De la solidartidad al contrato individual privado". En: LAURELL, Asa LA REFORMA CONTRA LA SALUD Y LA SEGURIDAD SOCIAL.

${ }_{39}$ Para profundizar en este punto ver: PEREZ IRIGOYEN, Claudio "Política pública y Salud". En: ISUANI y TENTI (Comp) ESTADO DEMOCRATICO Y POLITICA SOCIAL. EUDEBA, Bs As, 1989
} 
impulsan la creación del Instituto y una tercera reflexión es que comienza a igualarse la cuestión de la tercera edad a la situación del jubilado. Las políticas de la tercera edad impulsadas por el Estado Nacional están excluyendo a los adultos mayores sin cobertura previsional. ${ }^{\prime 40}$

Centraremos el análisis en la segunda reflexión que refiere Barberena, es decir las razones que a manera de diagnóstico socio - sanitario impulsan la creación de una obra social específica y exclusiva para los adultos mayores. Con esto señalamos que a partir de esta época y gracias al aporte de las Sociedades Científicas se reconoce que este grupo poblacional experimenta necesidades que no estaban siendo cubiertas por el resto del sistema de salud. "La creación del INSSJyP constituyó una respuesta posible a las necesidades insatisfechas de salud de la creciente población anciana argentina. ${ }^{\prime 41}$

Los aires neoliberales comenzaron a soplar por estas tierras a partir del terrorismo de estado, el que posibilitó la implementación de políticas restrictivas en cuanto a la función social del estado. Es necesario vincular la violencia estatal y el achicamiento del rol del estado en cuanto a la seguridad social con los cambios operados en la forma de acumulación.

Y tomando los aportes de Acuña y Chudnovsky ${ }^{42}$ coincidimos que a partir de la década de los años noventa se retoma la política descentralizadora, implicando una doble tendencia: por un lado, el hincapié en la reforma del Estado y por el otro, los cambios en la política social. "En síntesis, podemos sostener que la evolución del sector salud está marcada por tres lógicas convergentes: un primer establecimiento temprano y "débil" del sector con el objetivo de prevenir enfermedades y plagas que lleva a la constitución de un sistema disperso que luego será necesario articular; un fuerte momento de concentración y expansión de la atención médica a la población en el marco del gobierno peronista, que le imprimió al sector características tales como la mayor capacidad asistencial adquirida y el impulso de un nuevo sector (el de Obras Sociales) que luego se convirtió en un actor central del sistema y; por último, un asistemático intento de descentralización de la gestión de la salud de la Nación hacia las provincias, del manejo de los hospitales, etc. que se impulsa, se interrumpe o se debilita según los distintos períodos. Como vemos, del encuentro de estas lógicas imperantes, se desprenden elementos centrales y constitutivos del sistema de salud en la Argentina, tales como la fragmentación, la sobredimensión (en términos de equilibrio sistémico, no de capacidad de movilización de recursos) del subsector de Obras Sociales y los repetidos intentos de descentralización."

Volviendo al Informe sobre Tercera Edad en Argentina $^{43}$ los autores indican otro corte temporal a partir de los años 70 con el surgimiento del INSSJyP y la creación del programa de tercer nivel de atención que demandaba la contratación de establecimientos del ámbito privado para brindar la prestación. Los autores identifican esto como la posibilidad de incorporación de sectores medios como beneficiarios de esta prestación. Marcan como dato relevante que a partir del año 1990 el Instituto contó con su propia normativa lo que permitió un movimiento desde lo asilar a prestaciones más científicas y humanas.

\footnotetext{
${ }^{40}$ BARBERENA (pp. 34)

${ }^{41}$ PAOLA, Jorge "Introducción" En: PAOLA, J, PENAS, L; FERNÁNDEZ, María, PEREZ, Ofelia, MARTINEZ, Laura y DEMARCO, Mónica CONSTRUYENDO EL TRABAJO SOCIAL CON ADULTOS MAYORES. Espacio Editorial. Bs As, 2003 (pp. 9)

42 ACUÑA; Carlos y CHUDNOVSKY, Mariana "EL SISTEMA DE SALUD EN ARGENTINA" Documento 60 Marzo 2002 http://cdi.mecon.gov.ar/biblio/docelec/cedi/dt60.pdf (pp. 28/30)

${ }_{43}$ FREYSSELINARD, Edgardo, ODONNE, María Julieta, PAOLA, Jorge y PASSADORE, Norma "Hogares de Ancianos: una aproximación al estudio de sus características institucionales". En: INFORME SOBRE TERECERA EDAD EN ARGENTINA. Secretaria de Tercera Edad y Acción Social, Bs. As, 2001
} 
En concordancia con lo que venimos señalando de los cambios operados en el sector salud y la profundización de la mercantilización de la vida social, podríamos decir que la generación por parte del Instituto de políticas tendientes a brindar la prestación en Hogar Geriátrico a las personas mayores que así lo requieran nos presenta una des mercantilización de la prestación. En los términos que se presentan en el informe antes citado como posibilidad de acceso a los sectores medios. Paradójicamente esta des mercantilización de la prestación acontece en un momento histórico signado por un incremento de relaciones mercantilizadas. Ahora bien, al mismo tiempo que se des mercantiliza para la persona mayor se instaura un modelo de atención rentable para el mercado. Al mismo tiempo que se genera esta demanda hacia el mercado de generación de establecimientos geriátricos con un alto nivel prestacional, se intensifica la creación de instituciones geriátricas de corte asilar.

Existen Organismos no gubernamentales que se ocupan de la problemática de la vejez empobrecida, pero de igual manera es poco significativo el nivel de cobertura que generan. En el caso de los mayores "sin cobertura previsional con algún tipo de problema de salud físico o psíquico, las "resoluciones" por fuera del Estado, se caracterizan por ser sumamente precarias. Hay una "refilantropización de la política social". En los casos de adultos mayores sin cobertura con problemas de salud psíquicos o físicos al no haber lugares de derivación en la órbita del Estado o éstos contar con muy pocas camas se recurren a otros recursos, que parecen marcar un retorno a la lógica de la caridad. ${ }^{\prime \prime 4}$

Y en cuanto a los mayores que poseen cobertura previsional deben satisfacer sus necesidades básicas a través del mercado. Actualmente existen alternativas de atención pero que presentan un desarrollo variable. Para el caso de la institucionalización en residencias de larga estadía sólo es cubierta por el INSSJyP, a un grupo reducido de beneficiarios, el resto de la seguridad social no contempla su cobertura. Por tal motivo los mayores están expuestos al mercado y a la efectividad (o no) de las políticas estatales de regulación de funcionamiento de los establecimientos privados.

Por último señalamos que "Argentina enfrenta una doble polarización signada por una transición epidemiológica y demográfica vivida de manera muy dispar según los grupos poblacionales y regionales: nos enfrentamos a los riesgos de una población creciente de ancianos y, por otro lado al aumento de los riesgos de accidentes, violencia y a la desnutrición. Es de esperarse que de no tomarse medidas de prevención y de rehabilitación en el sector salud en las próximas décadas la población envejecida presente un alto índice de discapacidad" ${ }^{\prime \prime 5}$

Entonces, volviendo a las reflexiones de Acuña y Chudnovsky, planteamos que"tenemos un sistema de salud conformado por un sector público que pretende dar cobertura médica a toda la población y no logra llegar a los sectores más carenciados, un subsector de Obras Sociales que pretende dar cobertura a los trabajadores pero que no asegura a aquellos que engrosan el creciente grupo de los desempleados $y$, sobre todo, de trabajadores informales. $Y$, por último, un subsector privado, que apunta naturalmente a los estratos sociales con mayor capacidad adquisitiva, pero que -como consecuencia no buscada de la acción/inacción de las Obras Sociales - está logrando una cada vez mayor inserción

\footnotetext{
${ }^{44}$ BARBERENA (pp. 53)

${ }^{45}$ ESQUIVEL, María Laura "La Salud" En: FUNDACION PAR. LA DISCAPACIDAD EN ARGENTINA. Un diagnóstico de situación y políticas públicas vigentes al 2005 . Fundación Par, Bs. As. 2005 (pp. 151) 
como prestador del subsector de OS, por lo que se desdibuja como competidor y,por ende, como fuente de una mayor eficiencia sistémica" ${ }^{\prime 4}$

En síntesis, el sector salud se instala en un lugar estratégico en materia de prevención y resguardo de los derechos de las personas mayores.

\section{Cuarto Eje "Seguridad alimentaria"}

Este eje de intervención se ha desarrollado con mayor énfasis en la década de 1980. Entendemos por seguridad alimentaria como el "derecho de todas las personas a tener una alimentación cultural y nutricionalmente adecuada y suficiente" ${ }^{\prime \prime 7}$

Las acciones estatales durante los años 80 comenzaron a generar políticas de ayuda alimentaria, comenzando a verse beneficiados los mayores. Estas consistieron en: por un lado el otorgamiento de alimentos envasados a aquellos mayores con ingresos mínimos o en situaciones de desventaja significativas, otras en el aporte a la generación de comedores populares o Centros de Día con "componente alimentario". En esta línea el INSSJyP, a partir de los 80 incorporó a los beneficios sanitarios ayuda económica, fortalecimiento de dietas a través del reparto de alimentos y cobertura en establecimientos para el albergue de ancianos sin contención. "En el año 1993 se crea el Programa Probienestar tendiente a brindar una asistencia a los afiliados al Instituto que no podían por medio de sus ingresos satisfacer sus necesidades alimentarias. La Focalización que realiza el Programa preveía la incorporación de aquellos afiliados mayores de 70 años con ingresos mínimos que no contaran con ayudas familiares ${ }^{\prime \prime 4}$. Arias plantea que el programa prevé la incorporación de Centros de Jubilados como efectores del mismo, y que esta inclusión es planteada como un elemento tendiente al protagonismo y la participación de los beneficiarios desde sus comunidades. Lo que bien es cierto, compartiendo el análisis de Arias es que la generación de políticas alimentarias nos señala que para esa etapa se estaba poniendo "profundamente en crisis la función del sistema previsional como un garante de la manutención de los trabajadores finalizada la etapa laboral"49

Los bajos ingresos de los jubilados los expone a un proceso de vulnerabilidad sin precedentes en sus trayectorias. ${ }^{50}$

Es de destacar que los ancianos que no poseen el beneficio de la jubilación están en situación de vulnerabilidad ya que no existen políticas sociales lo suficientemente organizadas y planificadas brindando una cobertura coherente a las necesidades de estos grupos. Existen las pensiones no contributivas a nivel Nacional las que a partir del año 2003 han incrementado significativamente su cobertura, y las del mismo tipo en el ámbito provincial que no logran dar cobertura a la población que la requiere.

\footnotetext{
${ }^{46}$ ACUÑA; Carlos y CHUDNOVSKY, Mariana "EL SISTEMA DE SALUD EN ARGENTINA" Documento 60 Marzo 2002 OPS, pp. 52

${ }^{47}$ AGUIRRE, Patricia "10 años de convertibilidad en la seguridad alimentaria del área metropolitana bonaerense. Una visión desde la antropología alimentaria." En: Sabulsky (Comp) ENFOQUE INTEGRAL DEL DESARROLLO EN LA INFANCIA: EL FUTURO COMPROMETIDO. Fundación CLACYD, Córdoba, 2004.

${ }^{48}$ ARIAS, Ana TESIS DE MAESTRIA "La Centralidad de las Prácticas Asistenciales en Organizaciones Territoriales. Un Estudio de Caso en el Segundo Cordón del Conurbano" Maestría en Políticas Sociales. Facultad de Ciencias Sociales - UBA (pp. 28)

${ }^{49}$ ARIAS, ibidem, (pp. 32)

50 Para profundizar sobre los procesos de empobrecimiento en los últimos años en Argentina, se puede consultar: ROZAS PAGAZA, Margarita INTERVENCION PROFESIONAL EN RELACION CON LA CUESTION SOCIAL. Espacio Editorial, Bs As, 2001 y 
En tal sentido las políticas de vejez, en particular aquellas que están centradas en el papel regulatorio de la vida social y de las prestaciones brindadas en el sector salud deberían contemplar esta realidad. En los capítulos siguientes pondremos en tensión este concepto con la realidad analizada en las prestaciones de albergue de larga estadía en la Provincia de Buenos Aires.

\section{II - REGULACIÓN DEL FUNCIONAMIENTO DE LOS HOGARES GERIÁTRICOS}

La dimensión regulatoria adquiere características particulares en relación con la salud, en tanto que esta se configura en un bien de interés público. A través del poder de regulación el Estado actúa como nivelador, o mejor aún, como re - distribuidor de los bienes sociales en un universo donde coexiste una intensa competitividad entre actores en escenarios altamente fragmentados en términos económicos, culturales, sociales, geográficos, étnicos, etc.

Tal como veníamos señalando en cuanto a las modificaciones en el Rol estatal y la forma en que se particulariza en el sector salud identificamos un crecimiento del segmento privado en la producción de bienes y servicios de salud, incluyendo el financiamiento y provisión de salud y seguridad social. En este marco surge la necesidad de fortalecer la capacidad estatal de regulación analizando sus potencialidades y debilidades, su capacidad técnica y los recursos humanos. En este punto creemos necesario incorporar para el análisis el concepto de Funciones Esenciales de la Salud Publica (FESP). El Concepto de salud pública en el que se basa la definición de las funciones esenciales es el de la acción colectiva, tanto del estado como de la sociedad civil, encaminada a proteger y mejorar la salud de las personas. La salud pública se configura en un derecho humano fundamental. Pues entonces, las Funciones Esenciales son "el conjunto de actuaciones que deben ser realizadas con fines concretos, necesarios para la obtención del objetivo central .... mejorar la salud de las poblaciones ${ }^{\prime \prime 1}$ Las FESP ${ }^{52}$ son 11 , a saber:

1. Monitoreo y análisis de la situación de salud de la población;

2. Vigilancia de salud pública, investigación y control de riesgos y daños en salud pública;

3. Promoción de la salud;

4. Participación social y empoderamiento de los ciudadanos en salud;

5. Desarrollo de políticas, planes y capacidad de gestión que apoyen los esfuerzos en salud pública y contribuyan a la rectoría sanitaria nacional;

6. Regulación y fiscalización en salud pública;

\footnotetext{
${ }^{51}$ OPS-OMS "La Salud Pública en las Américas, Nuevos Conceptos, Análisis del Desempeño y Bases para la Acción", Washington D.C.: OPS, 2002, Publicación Científica y Técnica No 589, Capítulo 6 (pp. 60)

${ }^{52}$ Las FESP fueron definidas en el National Public Health Performance Standards Program en el estudio Delphi de la OMS y el documento inicial de la OPS, ambos de 1998.
} 
7. Evaluación y promoción del acceso equitativo de la población a los servicios de salud necesarios;

8. Desarrollo de recursos humanos y capacitación en salud pública;

9. Garantía de calidad de los servicios de salud individual y colectivos;

10. Investigación, desarrollo e implementación de soluciones innovadoras en salud pública;

11. Reducción del impacto de emergencias y desastres en salud.

Recuperando los aportes trabajados en el texto "Funciones esenciales de la salud pública: un tema emergente en las reformas del sector de la salud"53, decimos que la Salud Pública ha sido descuidada como una responsabilidad social e institucional. En dicho documento de trabajo se plantea que las FESP se han definido como las condiciones que permiten un mejor desempeño de la práctica de salud pública.

El contexto latinoamericano es identificado por Muñoz Porra ${ }^{54}$ como conformado por globalización, políticas de ajuste estructural, nuevos desafíos para el estado, nuevo rol de la sociedad civil, re - definición de la salud tanto como un proceso y un producto social que es un componente fundamental de desarrollo humano $y$, finalmente, por los cambios epidemiológicos en el perfil de las enfermedades. El autor justifica la definición y evaluación de las FESP como una forma de proveer apoyo para el ejercicio de la autoridad sanitaria, como una contribución al fortalecimiento de las políticas inter - sectoriales de salud, como una forma de conciliar las visiones locales, nacionales e internacionales en el desarrollo de la salud y el bienestar y como una forma de facilitar una adecuada infraestructura de salud pública.

Si ponemos en consideración tanto el concepto de política de vejez, en tanto posición que toma el estado frente al envejecimiento poblacional e individual, y el concepto de envejecimiento activo entendido como el proceso de optimización de las oportunidades de salud, participación y seguridad con el fin de mejorar la calidad de vida a medida que las personas envejecen. Consideraremos que las políticas de fiscalización y regulación estatal de los servicios de salud se configuran en centrales en cuanto posibilitan el despliegue de ciudadanía.

La función Esencial de Regulación y fiscalización en salud Pública, contempla:

- Desarrollo y fiscalización del cumplimiento de los códigos sanitarios y/o las normas dirigidas al control de los riesgos de salud derivados de la calidad del ambiente;

- acreditación y control de la calidad de los servicios médicos,

\footnotetext{
${ }^{53}$ MUÑOZ, Fernando; LOPEZ - ACUÑA, Daneil; HALVERSON, Paula, GUERRA DE MACEDO, Carlyle; HANNA, Wade; LARRIEU, Mónica; UBILLA, Soledad y ZEBALLOS, José Luis "Funciones esenciales de la salud pública: un tema emergente en las reformas del sector de la salud" revista Panamericana de salud Pública n a 8, año 2000.

${ }^{54}$ MUÑOZ PORRA, Fernando FORTALECIMIENTO DE LA PRÁCTICA DE LAS FUNCIONES ESENCIALES DE SALUD PÚBLICA. En: http://www.clad.org.ve/anales4/munozpor.html\#arriba
} 
- Certificación de calidad de nuevos fármacos y sustancias biológicas para uso médico, equipos, otras tecnologías y cualquier otra actividad que implique el cumplimiento de leyes y reglamentos dirigidos a proteger la salud pública;

- Generación de nuevas leyes y regulaciones dirigidas a mejorar la salud, así como a promover ambientes saludables.

- Protección de los consumidores en sus relaciones con los servicios de salud; completa.

- Ejecución de todas estas actividades de regulación de forma oportuna, coherente y

Para el caso de los Hogares Geriátricos no existe una normativa que rija a nivel nacional, sino que cada distrito provincial establece su propia norma. En la Provincia de Buenos Aires la fiscalización de los servicios de salud es efectuada por la Dirección de Fiscalización Sanitaria. Esta área se denomina de esta forma desde la década de 1980, aunque en realidad las funciones de control han sido ejercidas desde la creación del Ministerio. En el año 1974 se promulgó la primer normativa de geriátricos en la provincia de Buenos Aires. Para esa fecha eran muy pocos los establecimientos que existían en el territorio bonaerense, y de hecho cuando se promulga el Decreto actualmente en vigencia (Decreto 3280/90) tampoco el número era el de la actualidad.

El Decreto $3280 / 90$ es reglamentario de la Ley $7314 / 67$ y posee una apartado en el que establecen los requisitos para la habilitación de estos establecimientos. Instaura que los hogares geriátricos son aquellos establecimientos destinados al albergue, alimentación, salud, higiene y recreación asistida de personas de la tercera edad de ambos sexos, cualquiera sea el número, estén alojados en forma permanente o transitoria, gratuita u onerosa.

Para el funcionamiento deberán:

$\checkmark \quad$ Poseer la habilitación sanitaria provincial - Ley 7314/67 y Decreto 3280/90

$\checkmark \quad$ Poseer Inscripción como generador de residuos Patogénicos Ley 11347

Decretos $450 / 94$ y $403 / 97$

$\checkmark \quad$ Tramitar la habilitación municipal (comercial).

$\checkmark \quad$ Aprobar el plano ante la autoridad Municipal para la actividad a desarrollar.

$\checkmark \quad$ Garantizar accesibilidad edilicia (acceso liso, agarraderas en baños, pasamanos en circulación, desniveles salvados por rampas, etc.).

$\checkmark \quad$ Contar con un Director Médico (quien será responsable en forma solidaria con el propietario)

$\checkmark \quad$ Contar con personal suficiente (3 auxiliares de enfermería y 3 mucamas para las primeras 20 camas). 
$\checkmark \quad$ Garantizar medidas de seguridad (contar con disyuntor eléctrico y llaves térmicas, sistema contra incendio aprobado por autoridad competente, plan de emergencia, evacuación y catástrofe, calefacción de tipo tiro balanceado, pisos antideslizantes, muros lisos, cielorrasos de yeso.)

Esta normativa ha recibido múltiples criticas ya que la matriz que evidencia en su formulación responde a los valores construidos desde el modelo médico hegemónico. Desde la gerontología se discute fuertemente la obligatoriedad de contar con Director Médico, dando por supuesto que es el único profesional en condiciones de llevar adelante una institución de larga estadía, y que esta obligatoriedad da cuenta de una concepción de vejez como sinónimo de enfermedad. Y al mismo tiempo porque no reconoce explícitamente los derechos de las personas institucionalizadas, no manifiesta que se deben respetar los derechos de los albergados en cada acto prestacional.

Desde el sector de Enfermería se discute fuertemente ya que exige sólo la presencia de auxiliares de enfermería cuando la Ley 12245 establece que los auxiliares pueden trabajar solo bajo la supervisión de un Enfermero Profesional. En el artículo $3{ }^{\circ}$ de la citada Ley se reconocen dos niveles para el ejercicio de la enfermería: a) Profesional: consistente en la aplicación de un cuerpo sistemático de conocimientos para la identificación y resolución de las situaciones de salud - enfermedad, sometidas al ámbito de su competencia. b) Auxiliar: consistente en la práctica de técnicas y conocimientos que contribuyan al cuidado de enfermería, planificados y dispuestos por el nivel profesional y ejecutados bajo su supervisión. Desde la arquitectura se le critica ya que no especifica claramente pautas de accesibilidad dando lugar a libres interpretaciones. Frente a estas críticas el diagnóstico que realizamos es que es una norma con una antigüedad de 17 años y que el desarrollo técnico y científico ha superado ampliamente las concepciones que sustenta la misma. La respuesta mas apropiada será generar una nueva norma con el aporte de los más desatacados especialistas en la materia, pero surge un interrogante ¿Cómo garantizamos generar una normativa que sea factible de ser cumplida? Podemos imaginar tipos ideales de instituciones pero la realidad nos dicta que la Provincia de Buenos Aires es heterogénea regionalmente, signada por la desigualdad social y carente de Políticas de Vejez lo suficientemente articuladas y seriamente planificadas. En cuanto a la falta de reconocimiento de los derechos específicos de las personas institucionalizadas cabría preguntarnos ¿es necesario el reconocimiento de derechos específicos? ¿Acaso a las personas mayores no los contempla los derechos ciudadanos? De igual forma existen algunas normas de nivel internacional que operan en el ámbito nacional, como es el caso de los Principios de las Naciones Unidas a favor de las Personas de Edad. Estos fueron aprobados por resolución 46/91 de la Asamblea General de las Naciones Unidas de fecha 16 de diciembre de 1991. Alientan a los gobiernos a que introduzcan en sus programas nacionales cada vez que sea posible los siguientes principios: Independencia, Participación, Cuidados, Autorrealización y Dignidad.

\section{Independencia}

1. Las personas de edad deberán tener acceso a alimentación, agua, vivienda, vestuario y atención de salud adecuados, mediante la provisión de ingresos, el apoyo de sus familias y de la comunidad y su propia autosuficiencia.

2. Las personas de edad deberán tener la oportunidad de trabajar o de tener acceso a otras oportunidades de generar ingresos. 
3. Las personas de edad deberán poder participar en la determinación de cuando y en qué medida dejarán de desempeñar actividades laborales.

4. Las personas de edad deberán tener acceso a programas educativos y de formación adecuados.

5. Las personas de edad deberán tener la posibilidad de vivir en entornos seguros y adaptables a sus preferencias personales y a la evolución de sus capacidades.

6. Las personas de edad deberán poder residir en su propio domicilio por tanto tiempo como sea posible.

\section{Participación}

1. Las personas de edad deberán permanecer integradas en la sociedad, participar activamente en la formulación y la aplicación de las políticas que afecten directamente a su bienestar y poder compartir sus conocimientos y pericias con las generaciones más jóvenes.

2. Las personas de edad deberán poder buscar y aprovechar oportunidades de prestar servicio a la comunidad y de trabajar como voluntarios en puestos apropiados a sus intereses y capacidades.

3. Las personas de edad deberán poder formar movimientos o asociaciones de personas de edad avanzada.

\section{Cuidados}

1. Las personas de edad deberán poder disfrutar de los cuidados y la protección de la familia y la comunidad de conformidad con el sistema de valores culturales de cada sociedad.

2. Las personas de edad deberán tener acceso a servicios de atención de salud que les ayuden a mantener o recuperar un nivel óptimo de bienestar físico, mental y emocional, así como a prevenir o retrasar la aparición de enfermedades.

3. Las personas de edad deberán tener acceso a servicios sociales y jurídicos que les aseguren mayores niveles de autonomía, protección y cuidado.

4. Las personas de edad deberán tener acceso a medios apropiados de atención institucional que les proporcionen protección, rehabilitación y estímulo social y mental en un entorno humano y seguro.

5. Las personas de edad deberán poder disfrutar de sus derechos humanos y libertades fundamentales cuando residan en hogares o instituciones donde se les brinden cuidados o tratamiento, con pleno respeto de su dignidad, creencias, necesidades e intimidad, así como de su derecho a adoptar decisiones sobre su cuidado y sobre la calidad de su vida.

Autorrealización 
1. Las personas de edad deberán poder aprovechar las oportunidades para desarrollar plenamente su potencial.

2. Las personas de edad deberán tener acceso a los recursos educativos, culturales, espirituales y recreativos de la sociedad.

\section{Dignidad}

1. Las personas de edad deberán poder vivir con dignidad y seguridad y verse libres de explotación y de malos tratos físicos o mentales.

2. Las personas de edad deberán recibir un trato digno, independientemente de la edad, sexo, raza o procedencia étnica, discapacidad u otras condiciones, y han de ser valoradas independientemente de su contribución económica

Con el propósito de aportar al análisis de la tensión existente entre estas normas internacionales, las reglamentaciones vigentes en la provincia y la realidad cotidiana que opera en las instituciones de larga estadía, creemos necesario dar cuenta de la realidad que acontece en los Geriátricos en la actualidad. La investigación que llevamos adelante intenta responder a la pregunta ¿Cómo es la prestación de los geriátricos hoy? Nuestro objetivo ha sido dar cuenta de las dimensiones materiales y simbólicas que operan en la prestación de las instituciones de larga estadía en la Provincia de Buenos Aires.

Y otro de los objetivos es, al mismo tiempo, situar a esta prestación como una más entre otras posibles. Aportar a la batalla cultural contra esta construcción de vejez = enfermedad = respuesta asilar. "La OMS ha definido la asistencia de larga duración como "el sistema de actividades desarrolladas por cuidadores informales, familia, amigos, vecinos o profesionales, para garantizar que una persona que no puede valerse por sí misma, pueda llevar una vida con la mayor calidad posible, según sus gustos personales y con el mayor grado posible de independencia, autonomía, participación, realización y dignidad humana". Por tanto, la asistencia de larga duración incluye ambos sistemas de apoyo: informal y formal. El sistema formal puede incluir una amplia oferta de servicios comunitarios, salud pública, atención primaria, asistencia domiciliaria, servicios de rehabilitación y cuidados paliativos, así como asistencia institucional en residencias y centros asistidos. ${ }^{\prime \prime 5}$

Y por último tomamos las reflexiones de Isuani en cuanto a la dimensión regulatoria que creemos ilumina el camino que decidimos transitar.

"....la regulación es un hecho que precisa capacidades técnicas pero sin duda también capacidad política, esto es fuerza social expresada en el Estado capaz de inducir al cumplimiento de la norma y sancionar su transgresión.

Esto es en definitiva la existencia de actores sociales con proyectos de bienestar colectivo. La regulación de la práctica geriátrica, precisa de actores sociales y políticos que desde la sociedad impulsen y desde el estado plasmen normas y políticas para el bienestar de nuestros mayores............. El estado no es otra cosa que un espacio institucional, una

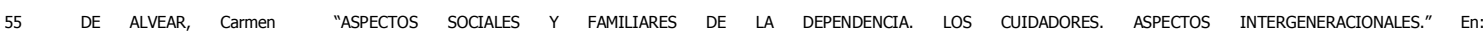
http://www.ceoma.org/vicongreso/ponencias/Ponencia\%205.doc 
arena de lucha y negociación para llevar adelante intereses. En esta lucha y negociación cada uno aporta la fuerza que tiene. Por ello la debilidad del Estado para producir políticas centradas en el bienestar de nuestros ciudadanos en general y de nuestros mayores en particular, no tiene otra explicación que la debilidad de las fuerzas políticas que apuntan a ese norte" ${ }^{\prime \prime 56}$

Por lo que podemos inferir que las políticas de vejez tendientes a regular las prestaciones brindadas en los geriátricos no son otra cosa que el reflejo de la imposibilidad de inscribir en la agenda pública los derechos de las personas mayores allí albergadas.

56 ISUANI, Ernesto Aldo "Regulación estatal y federalismo". EN: I SAGI Primer Simposium Argentino de gerontología Institucional. Facultad de Psicología. Universidad Nacional de Mar del Plata. 2004 (pp. 


\section{CAPÍTULO II}

\section{HOGARES GERIÁTRICOS: ¿ESCENARIOS DE VIOLENCIA?}

En este capítulo presentaremos el escenario en el que transitan las prestaciones brindadas en los Hogares Geriátricos, cuando nos referimos a escenario estamos pensando en el más cotidiano y al mismo tiempo a las regulaciones sociales que se entrecruzan. Por tal motivo aparece nuevamente la posición que toma el Estado.

\section{I - VIEJOS CIUDADANOS}

El número de población adulta mayor que reside en la provincia es de 13,2\% este porcentaje se ha incrementado y la tendencia continúa en ascenso. Sumado a esto se evidencia un proceso de debilitamiento de los espacios de contención social a los mismos. Razón por la cual una persona mayor que reside en esta provincia y que percibe un haber jubilatorio mínimo podríamos afirmar que transita en un espacio de vulnerabilidad. Es decir, está expuesto a padecer deficiencia alimentaria y a no acceder a los servicios básicos de salud. También asistimos a un proceso de fragilización de lazos sociales y a cambios que operan en las dinámicas familiares exponiendo a los mayores a diferentes padecimientos subjetivos (entre ellos la soledad).

Las actuales personas mayores son los hijos del estado de Bienestar, es decir aquellos trabajadores que construyeron una identidad de clase ligada a su inserción en el mercado de trabajo y a un Estado que actuaba como garante de su reproducción y de la manutención de la inserción laboral. Estos trabajadores fueron los testigos privilegiados de las grandes luchas protagonizadas por la clase obrera y encarnaron los logros que se obtuvieron. Hoy padecen los resultados de la reconfiguración del Estado en Neoliberal.

Al configurarse el mercado como satisfactor de necesidades en tanto que todos los sujetos somos "libres" para satisfacerlas, se acrecienta la desigualdad adoptando la forma de polarización social, es decir concentración de la riqueza en un pequeño grupo y expansión de la pobreza en forma generalizada. Esto atraviesa la cotidianeidad de los sujetos y uno de los grupos afectados son los adultos mayores.

Los personas mayores en Argentina presentan un nivel de cobertura previsional del 65 $\%$, cifra relevante si lo comparamos con los niveles presentados en otros países del continente. El poseer cobertura provisional le significa consecuentemente cobertura social (obra social). En este sentido, las personas mayores formalmente poseen cobertura social en salud, pero en la práctica es de difícil instrumentación. Veamos un ejemplo ${ }^{57}$ : una persona mayor que necesita ser intervenida quirúrgicamente en un establecimiento polivalente con internación y prestación quirúrgica (clínica general) a través del I.N.S.S.J.yP. deberá pasar varios obstáculos: 
a) que el médico de cabecera tenga órdenes para realizar la interconsulta

b) que el establecimiento seleccionado para internarse no haya interrumpido el convenio con la obra social.

c) Que el médico no le cobre diferenciado para la consulta y sobre todo para la cirugía. Esto acompañado de la advertencia del profesional: "no debe decir nada en la obra social que le cobro, pero si no puede pagar vaya al hospital"

Aquí aparecen varios elementos a analizar. En cuanto al cobro de diferenciado de los médicos aparece el válido argumento del atraso de la obra social en el pago de las prestaciones efectuadas, que data de 6 meses a un año ¿es la persona mayor la que debe suplir el incumplimiento de la obra social? ¿Pues no deberían ser los médicos los que a través de sus organismos de representación reclamen lo que les corresponde? O acaso ¿es muy alto el costo si los establecimientos, los médicos y el Pami se sinceran y cortan efectivamente los servicios?

\section{Entonces, lo que en lo formal es un bien desmercantilizado para el beneficiario culmina siendo re - mercantilizado en un circuito clandestino.}

En Argentina el albergue en una institución geriátrica no está contemplado en el Programa Médico Obligatorio (PMO). Una de las pocas obras sociales que lo cubren es el INSSJyP (Pami) pero para un porcentaje bajo de sus afiliados. Para este organismo la prestación es de índole social por lo que no está "obligada" a cubrirla. Los mecanismos que operan para la cobertura tienden a evitar la institucionalización. Entonces este servicio es desmercatilizado para unos "pocos" y se mercantiliza para la mayoría en un circuito de ilegalidad. Digo esto ya que un porcentaje importante de los establecimientos que configuraron nuestra muestra eran clandestinos y presentaban la mayoría de las camas ocupadas.

La capacidad de pago de los jubilados y pensionados en general es baja. Y en las prestaciones brindadas en los hogares clandestinos se valoriza el capital en un circuito ilegal ya que es ilegal el prestador (no está habilitado), los trabajadores de la institución están precarizados (en negro) y probablemente los propietarios configuren el hogar en una estrategia de sobrevivencia con lo cual residen en el mismo lugar, comen lo mismo que las personas mayores, los déficits edilicios y alimentarios son socializados. Los propietarios de estos pequeños hogares que hacen las veces de sustitutos podrían ser considerados "cuentapropistas" o trabajadores informales.

"Cuando se piensa la ciudadanía como haz de derechos se resalta su aspecto universal e igualitario. La desigualdad, los procesos discriminatorios y excluyentes de los sistemas sociales reales aparecen como fallas, rémoras o perversiones que obstaculizan el pleno desarrollo de un igualitarismo y un universalismo que serían inherentes a la ciudadanía. Cuando se piensa a la ciudadanía como status se parte del supuesto que los derechos tienen efectos materiales de intensidad variable, y que por ende la desigualdad, los procesos discriminatorios y excluyentes son parte de la propia lógica de la ciudadanía. ${ }^{\prime 58}$ Conjugar lo hasta ahora analizado con el concepto de ciudadanía como status nos permite enriquecer nuestras interpretaciones, ya que visualizamos que "la ciudadanía ha constituido un status excluyente y desigual". Los adultos mayores que residen en los establecimientos

${ }^{58}$ ANDRENACCI, Luciano IMPARIS CIVITATIS. ELEMENTOS PARA UNA TEORÍA DE LA CIUDADANÍA DESDE UNA PERSPECTIVA HISTÓRICA. Bs. As. 2002 (pp3) 
que trabajamos son ciudadanos en términos generales pero que no se concretiza en el devenir de su cotidianeidad.

Asimismo es importante reflexionar sobre los mecanismos que adopta el modo de producción capitalista para convertir las manifestaciones de la cuestión social en espacios de valorización del capital, por ello recurriré al análisis que realiza Margarita Rozas sobre el concepto de necesidad.

"Este proceso de inversión se puede explicar, en tanto el fin de la satisfacción de las necesidades no es el hombre, es la producción de objetos de necesidad que deben ser consumidos a fin de garantizar la valorización del capital. En ese proceso de inversión está la alienación del hombre ya que su relación con la necesidad está mediada por el consumo y la fantasía de la posibilidad de su satisfacción." ${ }^{59}$

Podremos decir sobre la forma de valorización del capital en el área de tercera edad. El Estado posee pocas instituciones de albergue de personas mayores pero la obra social nacional de los jubilados y pensionados, I.N.S.S.JyP (PAMI) cubre la prestación a través de la contratación de instituciones privadas. Esto implica que la última etapa de esta política social es quien garantiza la apropiación de excedente del propietario (empresario) de la institución. Estos hogares deben, por requisito del PAMI, contar entre su equipo a un trabajador social. Este deberá trabajar el vínculo familia - personas mayores, familia institución y los lazos vinculares entre las personas mayores albergadas. Esto implica que el profesional con su intervención garantiza, entre otras cosas, el proceso de valorización del capital. Esto lo constatamos a partir del trabajo de campo.

Podemos inferir que existe una desigual distribución del acceso a los servicios de salud y de los bienes socialmente necesarios que garanticen una vida digna.

\section{II - DE VIEJOS, GERIÁTRICOS, TRAGEDIAS Y ¿VIOLENCIAS?}

En este apartado daremos cuenta de un breve análisis sobre los últimos hechos trágicos en los que aparecen involucradas las personas mayores albergadas en hogares geriátricos, tanto habilitados como clandestinos. Los presentamos ya que durante el desarrollo de la presente investigación se produjeron varios hechos trágicos que influenciaron el proceso analítico. El primero al que a haremos referencia es de México, país en que se produjo un siniestro en el mes de Junio de 2005 en el que fallecieron cuatro ancianos. La nota informaba que el fuego se produjo en un "asilo extraoficial" en la capital mexicana como consecuencia de un cortocircuito en la cocina del lugar. ${ }^{60}$

En Argentina, provincia de Buenos Aires una tragedia que signó un cambio a nivel Ministerial (coyuntural) fue el incendio del Hogar Geriátrico San Agustín de Quilmes el 23 de febrero de 2005. En este caso se trataba de una institución habilitada pero que por no

59 ROZAS PAGAZA, Margarita "Bienestar social en el contexto de la modernidad". En: UNA PERSPECTIVA TEÓRICA METODOLÓGICA DE LA INTERVENCION EN TRABAJO SOCIAL. Espacio Editorial. Buenos Aires. 1998 -

${ }^{60}$ Publicado por Licenciatura en Gerontología de Universidad Maimónides el día: Junio 23, 2005 02:42 PM 
contar con la suficiente cantidad y calidad de personal no logró garantizar la evacuación del lugar frente al inicio del fuego.

En la localidad de Arenasa, partido de Lincoln en el mes de Julio de 2005 aconteció un siniestro. La nota periodística decía "Fuego en el pabellón geriátrico: Un Ilamado al Cuartel de Bomberos Voluntarios de Lincoln alertó a la población que se estaba incendiando el Hospital de Arenaza, un pueblito de dos mil habitantes situado a 35 kilómetros. Inmediatamente, tres dotaciones --con 18 hombres--llegaron a Arenaza y se sumaron a sus colegas del cuartel local y de la vecina localidad de Robert, que luchaban contra las llamas que afectaban todo el edificio del centro asistencial Pedro Lacau" "El fuego se había generalizado. Las llamas ya estaban en el techo colonial y se introducían entre las tejas y la pinotea de las dos aguas, lo que dificultaba la tarea de extinción" relató el jefe del cuartel Lincoln, Fernando Sanz. De acuerdo con los primeros peritajes, el incendio se habría originado por una estufa de cuarzo que prendió fuego prendas de vestir en el pabellón geriátrico, donde se encontraban diez ancianos durmiendo. Los primeros bomberos en llegar al siniestro lograron evacuar a siete de los abuelos que presentaban un cuadro de principio de asfixia, pero la peor noticia llegó cuando, tras combatir el siniestro, se hallaron tres cadáveres de personas mayores que habían muerto asfixiados por el humo, mientras que otra persona falleció carbonizado por las llamas." ${ }^{\prime 61}$

Hicimos una selección de noticias con la finalidad de ilustrar con ejemplos. Solo imaginar la magnitud del fuego, y la desesperación que debe significar morir carbonizado genera desazón y angustia. Y aquí sirve una aclaración, los establecimientos asistenciales de salud dependientes del ámbito municipal no eran fiscalizados ni habilitados por nadie hasta hace cuatro años. Las normas no son muy claras al respecto y a partir de una Resolución el Ministerio de Salud se arrogó esa potestad. Existen discusiones en torno a sí ese instrumento legal es suficiente, pero se sabe que es necesario el control. Entonces, aclaro que este pequeño hospital, el pabellón geriátrico no estaba habilitado. ¿Es relevante que lo estuviera? ¿Esto hubiese evitado el siniestro?.......

Otra información que si bien es de la ciudad de Buenos Aires, y esta no configura el escenario en el que sitúo la mirada para el desarrollo de la tesis, creo que ilustra. El gobierno de la ciudad ha sumado en los últimos años una serie de tragedias vinculadas a adultos mayores y podríamos afirmar a la falta de controles. Claro está no puedo menos que mencionar la tragedia de Cromañon, el "boliche" en el que fallecieron 193 jóvenes el día 30 de diciembre de 2004. "El control estatal sobre la seguridad en los establecimientos geriátricos tiene muchas deficiencias y, aunque el Gobierno de la Ciudad diseñó un área especial de inspectores para ocuparse del tema tras la tragedia de Cromañón, todavía falta mucho para que el escenario esté cerca del ideal. ${ }^{\prime 62}$

Retomo más datos que del Diario Clarín, a los que ellos llaman otras tragedias con "abuelos":

- 23 de febrero de 2005. Tres ancianos murieron y 29 fueron internados con distintos cuadros de intoxicación aquel día, como consecuencia de un incendio que destruyó dos habitaciones de la Residencia Geriátrica San Agustín de Quilmes.

\footnotetext{
61 Diario La Nueva Provincia SRL, Bahía Blanca. 10 de Julio de 2005 (Edición Digital)

${ }^{62}$ Resumen de noticias vinculadas a adultos mayores: http://weblog.maimonides.edu/gerontologia/archives/001608.html
} 
- 25 de julio de 2004. Dos ancianas murieron y otra quedó gravemente herida, al incendiarse una habitación de un geriátrico ubicado en Saavedra 1239, en Balvanera.

- 24 de enero de 2001. En el geriátrico "Los girasoles", ubicado en Superí 2261, Belgrano R, cuatro ancianas murieron ahogadas cuando se inundó un subsuelo. Fue durante una de las peores lluvias que se recuerde en Capital. ${ }^{63}$

Queda evidenciado que el tema de las personas mayores y las instituciones de larga estadía solo se instalan en la agenda pública frente a una tragedia de magnitud. ${ }^{64}$ Por ende, las acciones que se establecen a partir de esto son espasmódicas y a veces irreflexivas.

De esta manera las tragedias cotidianas a las que se ven expuestos nuestros mayores no son advertidas por nadie, pareciera que nadie reclama por ellos. Por esto, nuestra intención es que esta investigación aporte a la desnaturalización de estas tragedias cotidianas. Dicen algunos analistas que la tragedia de Cromañon ha marcado un punto de inflexión en las políticas de control estatal.

Y para culminar este apartado creemos necesario instalar en el proceso de análisis el concepto de violencia. "La violencia es un vínculo, una forma de relación social por la cual uno de los términos realiza su poder acumulado" ${ }^{\prime 65}$ Pensemos las múltiples formas de violencia a las que se ven expuestos las personas mayores en nuestro país. Podríamos identificar a la violencia estructural vinculada a la desigualdad social, es decir a la distribución desigual de la riqueza socialmente producida. La mayoría de las personas mayores que perciben algún beneficio previsional, es con el haber mínimo, por lo que no cubren sus necesidades básicas, lo cual los ubica en un lugar de alta vulnerabilidad. Y aquí podríamos incluir el concepto de violencia generacional que trabaja Golpe "entendemos la violencia generacional hacia los viejos como la forma de dominación naturalizada, que se ejerce sobre estos agentes singulares argumentando las huellas del cuerpo, el egreso de la estructura productiva, el debilitamiento de sus potencialidades y deseos, la caducidad de sus saberes, o la obsolescencia de su estilo de vida, o la vulnerabilidad de su salud para la asignación de servicios sociales" ${ }^{\prime 66}$

Por otra parte, y retomando lo expuesto por Barberena ${ }^{67}$, en Argentina se produjo un proceso de invisibilización de los adultos mayores sin cobertura previsional. Este sector de la ciudadanía ha quedado soslayado y negado tras el proceso de nominar a todos las personas mayores como jubilados. Este último señalamiento se podría vincular al ejercicio de la violencia política, ya que los mayores no logran inscribir en la agenda pública sus necesidades como plausibles de ser abordadas y/o solucionadas.

Y si pensamos específicamente en los adultos mayores que se hallan institucionalizados podríamos afirmar que están expuestos a la violencia cotidiana, entendiendo que este concepto "hace referencia no sólo a aquellas condiciones estructurales

\footnotetext{
63 Diario Clarín, 21 de Julio de 2005 - Edición Digital

${ }^{64}$ Retomo esta línea de análisis de las reflexiones que expresó el Lic. Jorge Paola en el marco del II SAGI Simposium Argentino de Gerontología Intitucional, organizado por Facultad de Psicología Universidad Nacional de Mar del Plata, abril 2005.

${ }^{65}$ IZAGUIRRE, Inés (Comp) VIOLENCIA SOCIAL Y DERECHOS HUMANOS. EUDEBA, Bs as. (pp. 7)

${ }^{66}$ GOLPE, Laura " Edaísmo y Trayectoria vital: una encrucijada de la cultura". En: GOLPE, Laura; BIDEGAIN, Luisa; ARIAS Claudia (Comp.) EDAÍSMO Y APOYO SOCIAL. Ediciones Suárez. Mar del Plata, 2003.(pp. 42)

${ }^{67}$ BARBERENA, Mariano A. Tesis de Maestría en Trabajo Social - Adultos mayores sin cobertura previsional en Argentina: de la negación de su visibilidad a la posibilidad de su construcción como problema social. 2001. Maestría en Servicio Social. Pontificia Universidad Católica de San Pablo.
} 
de sufrimiento vinculadas a la pobreza sino también a la coerción y a la opresión ligadas a la desigualdad de poder y de género, las que en conjunto se imponen en la vida diaria de determinados conjuntos sociales, promoviendo la corporización de sus efectos ${ }^{\prime \prime 68}$. En los procesos de institucionalización, la violencia cotidiana está signada por la imposibilidad de las personas mayores de decidir y por ser su cuerpo garante de rentabilidad. Esta violencia se expresa en forma simbólica, pero existen circunstancias en que se produce una transformación hacia la violencia física. En esta dirección, creemos necesario ilustrar esta violencia cotidiana, y recuperar los procesos que llevaron a los adultos mayores a la institucionalización. Dos características importantes de señalar son que las personas mayores que residen en las instituciones "hogar Geriátrico" son mayormente mujeres y que varias no han tenido hijos, manteniendo una tenue relación con sobrinos, hermanos, vecinos o amigos. Esta fragilidad relacional las expone con mayor desamparo a la violencia cotidiana propia de la institucionalización ya que no hay quien supervise fehacientemente la calidad de asistencia.

Pero ¿por qué afirmamos que los hogares geriátricos constituyen el escenario en el que se ejerce violencia cotidiana? Y aquí es necesario volver a situar la mirada en la violencia generacional que se singulariza en la vida cotidiana de los establecimientos de larga estadía para personas mayores. Golpe en el texto antes citado nos plantea "Cuando en una sociedad sistemáticamente se segrega o ignora a un grupo social sin dejar las puertas abiertas a la vida, se transforma en portadora de una violencia genocida que implementa un síndrome de invisibilidad, dicha sociedad eufemiza y olvida sus necesidades biológicas, psicológicas y sociales. En el caso de los viejos, la incorporación en el cuerpo del sentimiento de invisibilidad puede ser profunda para la pérdida de la illusio en el final de la vida. La violencia generacional se transforma en una ortodoxia que nos impone el mundo contemporáneo." ${ }^{69}$ También podríamos ensayar una respuesta al recuperar los orígenes, la génesis de la constitución de los Hogares Geriátricos. Los antecedentes asilares de la prestación implican coacción por lo que podemos inferir que la génesis de los geriátricos es violenta.

Y para ir cerrando el análisis de la violencia creemos pertinente incorporar el concepto de cronificación del trauma. El ser objeto permanente de ejercicio de la violencia, de desprecio, genera cambios en los sujetos que son de difícil reversión. Cuando Epele trabaja con este concepto en la investigación que ella efectuó menciona "al ser sufridas a lo largo de toda su vida, promueven no sólo la internalización de la opresión sino el sentimiento de culpa por ser pobres y marginalizados. Estos procesos en los que consiste la marginación y la discriminación tienen efectos emocionales negativos, expresados en la aceptación sin mayor cuestionamiento, de los estereotipos negativos acerca de su clase, género y/o minoría étnica." 70 Algo similar sucede con las personas mayores que residen en un hogar, internalizan de tal forma el trato violento que lo transitan como natural e inevitable. El anciano pierde para sí tanto el derecho de ser considerado sujeto como ciudadano.

A partir de lo observado y analizado en el trabajo de campo pudimos constatar que la mayoría de las personas mayores que ingresan a una institución de larga estadía no

\footnotetext{
${ }^{68}$ EPELE, María "Violencias y traumas. Políticas del sufrimiento social entre usuarios de drogas". En: Cuadernos de Antropología Social No 14 - Facultad de Filosofía y Letras. Buenos Aires. 200? - (pp. 120)

${ }^{69}$ Golpe ( op.. cit) pp. 42)

70 EPELE, María "Violencias y traumas. Políticas del sufrimiento social entre usuarios de drogas". En: Cuadernos de Antropología Social № 14 - Facultad de Filosofía y Letras. Buenos Aires. 2001 (pp. 31)
} 
fueron consultadas, y por ende no expresaron su consentimiento. Con la certeza de que el anciano ya no puede cuidarse solo y necesita que un otro (más joven) decida por él, los familiares deciden la internación. Socialmente se ha construido que los mayores ya no pueden decidir, que deben ser protegidos. Esta acción inconsulta pareciera ser el acto fundacional de la cronificación del trauma. Una vez albergado en la institución, el reclamo al familiar iPor qué me trajiste acá! podría significar no ser más visitado. Y cuando el adulto mayor reclama, exige explicaciones, se escucha a los familiares iA mi me hace de mal verlo así! O iMe hace mal venir a estos lugares, yo no nací para esto! Los familiares, en general revisten la decisión de internación de un sentimiento protector. Al mismo tiempo que dictaminan que su viejo no puede vivir solo, efectúan un proceso de desfinanciación del mismo. Es decir, le venden la casa porque ya no va a vivir más en ella, deciden sobre sus bienes. La renta que obtienen por estas transacciones no se destina a garantizar el acceso a bienes de la persona mayor, el dinero no se utiliza para su sostenimiento. Aquí surge la innegable necesidad de complejizar la mirada, ya que al mismo tiempo que la familia aparece como quien se "aprovecha" de sus mayores es el agente social que actúa con mayor frecuencia como apoyo social. La familia también es una construcción histórica y social, este tema será retomado en el próximo capítulo.

Podemos afirmar que cada uno de los agentes institucionales aporta a la consolidación de la violencia y a la construcción del trauma o a revertir estas situaciones. Esta cronificación del trauma está constituido del ejercicio cotidiano de la violencia, de estas tragedias cotidianas, tal como pudimos observarlo en el desarrollo del trabajo de campo.

\section{III - ACERCA DE LA CLANDESTINIDAD}

De acuerdo a los datos censales, solo el 2,3\% de personas de 60 y más años se encuentra institucionalizada. Incorporo el aporte que efectúa la Lic. Adriana Fassio en el artículo publicado en el I Anuario del SAGI $2005^{71}$. La autora plantea que la baja incidencia de internación no respondería a la realidad y que las residencias clandestinas han sido censados como viviendas familiares.

Explica la autora que " las categorías sociales de la variable instituciones colectivas son: hogar de ancianos, hogar de menores, colegio internado, campamento/obrador, hospital, prisión, cuartel, hogar de religiosos, hotel turístico y otros.... En Argentina el $61 \%$ de los mayores institucionalizados residen en hogares de ancianos, el $18 \%$ en hospitales y el $4 \%$ en hogares religiosos y el resto son agrupados en las otras instituciones colectivas. En particular en la provincia de Buenos Aires, según datos censales, 42.876 personas mayores reside en instituciones colectivas. De estos, 27.773 lo hacen en hogares de ancianos."

Fassio afirma que "la falta de información sobre las residencias colectivas conformadas por pocos residentes, no declaradas como tales, es uno de los aspectos que favorecen su ocultamiento y el no cumplimiento de normativa que salvaguarde los derechos y la calidad de vida de residentes y personal que los atiende.

${ }^{71}$ FASSIO, Adriana "'La población de adultos mayores institucionalizada según datos censales". En: GOLPE, L y ARIAS, C (comp.) Cultura Institucional y Estrategias Gerontológicas. Primer Anuario del Simposium Argentino de Gerontología Institucional. Ediciones Suárez. Mar del Plata, 2005. 
En este sentido, una aproximación a ello serían los datos de los hogares compuestos $\mathrm{u}$ hogares no emparentados en los que residen personas mayores. Los datos censales dan cuenta de la existencia de hogares conformados por personas no emparentadas, como una aproximación a fin de dimensionar y aproximarse al fenómeno: 4.029 varones y 7.691 mujeres de 65 y más años habitan en hogares multipersonales no familiares y son no parientes del jefe o jefa de hogar"

Con este aporte se pone en evidencia la existencia de fuentes secundarias disponibles para aportar al hallazgo de instituciones clandestinas. Al mismo tiempo es relevante ya que esta publicación la efectuó en representación de la Dirección Nacional de Políticas Sociales para Adultos Mayores del Ministerio de Desarrollo Social, lo que demuestra que el tema de la clandestinidad comienza lentamente a instalarse en el campo gerontológico y en la política pública.

Cuando hablamos de clandestinidad siempre surge una paradoja, ya que el estado está presente de múltiples formas en los establecimientos que se supone clandestinos. Un claro ejemplo de esto son las casas en las que residen personas con padecimiento mental dados de alta del hospital Dr. Alejandro Korn de Melchor Romero y que son beneficiarios de un subsidio de la Curaduría de Alienados. La curaduría "contrata" o "firma un convenio" con mujeres encargadas de una "pensión", pero pensión creada ad- hoc y deriva allí a sus tutelados. Estas casas no cumplen con medidas de seguridad contra incendios, contra descarga eléctrica. Lo que sí es de destacar cómo han establecido una estrategia que garantiza la atención médica, el control psiquiátrico, y el acceso a la medicación. Los pacientes van a la curaduría, les hacen la receta y van al hospital a buscar la medicación. Van al hospital con el "pase libre" que les permite tomar el colectivo sin pagar boleto.

Este tipo de casas también las encontramos en Bahía Blanca. Si bien los residentes, los habitantes de estas casas no son con exclusividad adultos mayores sería pertinente que se lleve a cabo una investigación social sobre esta realidad. (Recomendación de Investigación). También podríamos inferir que esta es una política que ha definido la Curaduría Oficial de Alienados.

Otra presencia paradójica del estado en las instituciones clandestinas es a través del área Tercera edad del Ministerio de Desarrollo Humano de la provincia de Buenos Aires. Este organismo posee un sistema de becas con las que cubre la "estadía" de adultos mayores sin cobertura provisional en instituciones sin fines de lucro o municipales. Las mismas, en su mayoría, no están habilitadas ergo son clandestinas.

Esto mismo acontece con los Municipios de Nueve de Julio, Pergamino, Arrecifes, Tandil, etc Estos derivan y abonan la prestación en los establecimientos propiedad de particulares, que no están habilitados.

La pregunta que habría que hacerse es ¿por qué no están habilitados? Por un lado porque no cumplen con las medidas estipuladas en las normativas y deciden no exponerse a la valoración. Otras veces por desconocimiento y temor a ser evaluados y no "alcanzar" a cumplir los puntos mínimos. Tal vez podríamos vincular esto con la posesión de capitales sociales diversos. En el caso de los clandestinos propiedad de particulares varias veces no saben que tienen que estar habilitados. $Y$ la respuesta más acertada del por qué no están habilitados tiene que ver con la ineficacia reguladora del Estado. 
Otra paradójica presencia del estado es cuando se produce un despido del personal que trabaja en estos hogares. Las trabajadoras están en negro, cuando el Juzgado Laboral establece la indemnización a los propietarios de estos hogares clandestinos actúa como intermediario entre el trabajador despedido y la patronal. Es decir, el pago de por ejemplo la indemnización en cuotas la hace en el juzgado. Entonces, este patrón que evitó pagar los aportes previsionales termina aportando en otro momento.

Los conflictos laborales son los que le posibilitan al Ministerio el hallazgo de un hogar clandestino, ya que cuando el juzgado libra el oficio para ver si el lugar está habilitado el Ministerio manda una inspección para responder a la justicia.

Entonces cuando analizamos la variable criterios de admisión en realidad empezamos a observar que en la construcción de estos criterios participan los viejos (a veces), los familiares, los propietarios de las instituciones y el estado como agente derivador.

¿Qué criterio gerontológico ha construido el estado? ¿Cuándo es necesario internar a un adulto mayor? La Mag. Silvia Gascón en el "Curso de capacitación en gestión para instituciones y servicios en gerontología" planteaba que albergar en una institución a un anciano solo porque no tiene dónde vivir configura una privación ilegal de la libertad. ¿Por qué se construye el encierro como respuesta a la falta de vivienda?

Y por último es necesario presentar otra de las paradojas que hallamos en el desarrollo del trabajo de tesis. Paradójico en tanto situación de orden material, investido de un significado particular, que envuelve contradicción. Existen consensos técnico científicos que la institucionalización de las personas mayores debe responder a necesidades de atención que no pueden ser cubiertas por otras ofertas prestacionales. Es decir es aconsejable una internación geriátrica en aquellas situaciones en que la persona mayor presenta un grado de dependencia que no le permite el desarrollo de las actividades de la vida diaria en forma autónoma, que no cuenta con vínculos familiares con posibilidad de configurarse en un sistema de apoyo informal y que la figura de un cuidador domiciliario no resulte suficiente. Tal como trabajaremos en otros puntos, de acuerdo a los hallazgos de otras investigaciones las razones que impulsan la decisión de institucionalización no responde a un incremento de las necesidades de la persona mayor sino a un deterioro del cuidador informal / familiar. También sabemos que las instituciones estatales (municipales y las sin fines de lucro con convenio con la Provincia) tienen por norma institucionalizar a personas autoválidas, con el argumento de que no poseen personal suficiente. Pues entonces, volvemos a notar una incongruencia entre este criterio de institucionalizar a aquellos que podrían continuar en su domicilio con un sistema de apoyo fortalecido. Pero lo más paradójico de todo es que es el mercado, la dinámica del mercado, el que respeta los criterios gerontológicos. Como hemos señalado la prestación en Hogar Geriátrico solo es cubierta por el INSSJyP , con un número de camas inferior a la real necesidad de plazas. El acceso a estas prestaciones es garantizada a través del mercado. Para las familias en general les resulta dificultoso decidir la internación de uno de sus miembros por lo que extiende en el tiempo esta decisión. Por lo tanto, como se trata de un bien mercantilizado, se "compra" cuando es necesario. Las familias, los particulares, los ciudadanos ponen un juego un criterio gerontológico en pos de minimizar gastos. Por lo que se desdibuja el derecho a la protección que tenemos todos los ciudadanos.

\section{IV - ¿ QUÉ EVALUAMOS CUANDO FISCALIZAMOS?}


Retomando los aportes de Potyara Pereira incorporamos la discusión sobre las necesidades mínimas y las necesidades básicas sociales. Estas concepciones se ponen en juego cuando se analiza la pertinencia de permitir el funcionamiento de hogares que no cumplen la totalidad de requisitos. La autora plantea que "... en el marco de la reciente valorización del estatuto de ciudadanía, el concepto de necesidad básica asumió un papel preponderante en la justificación de los derechos sociales y de las políticas públicas que les corresponden. ${ }^{172}$

La autora nos plantea que las necesidades básicas son objetivas porque su especificación teórica y empírica no depende de preferencias individuales, son universales porque la concepción de pérdidas serias que derivan de su inadecuada satisfacción es la misma para todos los individuos en cualquier cultura. Refiere que dos conjuntos de necesidades básicas se configuran en pre - condiciones para alcanzar objetivos universales de participación social: Salud Física y Autonomía. La salud física es una necesidad básica porque sin la debida provisión para satisfacerla los hombres estarían inclusive impedidos de vivir. Y la autonomía nos la presenta como la capacidad del individuo de elegir objetivos y creencias, valorizarlos con discernimiento y ponerlos en práctica sin opresiones.

Potyara Pereira instala en forma muy interesante la discusión sobre lo oportuno de hablar de necesidades básicas en vez de necesidades mínimas. En este sentido, retoma un trabajo efectuado por dos autores ingleses Doyal y Gough "... sostienen que todos los seres humanos, en todos los tiempos, en todas las culturas, tienen necesidades básicas comunes .... afirman que hay un consenso moral, perfectamente verificable en diferentes visiones de mundo, de que el desarrollo de una vida humana digna solo ocurrirá si ciertas necesidades fundamentales (comunes a todos) fueron atendidas."

Aquí se establecen varios nexos con la situación de los adultos mayores, en particular con los que están institucionalizados. A la hora de fiscalizar los hogares de ancianos se evalúan las condiciones edilicias, el recurso humano e indirectamente la prestación brindada. Para este fin se ha construido una mirada que examina y pondera todos estos elementos. Esa mirada evalúa entre cuestiones consideradas previamente como relevantes o como aleatorias. El fundamento de este discernimiento reside en qué se considera de mínimo de cumplimiento.

El análisis efectuado por Potyara Pereira ilumina la mirada a la que hicimos referencia, ya que no solo la preservación de la salud física es relevante sino también la autonomía. En general desde el sentido común, que a veces direcciona el discurso y las prácticas oficiales, se considera que si los viejitos tienen dónde dormir, están abrigados y comen es suficiente. Esto conlleva una concepción de necesidades mínimas a ser satisfechas, por lo que no cabría la pregunta sobre la calidad de vida ni sobre la autodeterminación de los adultos mayores.

En primer lugar nos gustaría puntualizar sobre la cuestión de la autonomía. Los autores mencionados plantean que lo que perjudicaría el libre ejercicio de la autonomía serían la presencia de déficit en alguno de estos tres atributos: salud mental, habilidad cognitiva y oportunidad de participación. En varias oportunidades observamos que los viejos son

\footnotetext{
72 PEREIRA, Potyara "La contribución del concepto de necesidades humanas básicas para la formulación de políticas sociales". En: NECESIDADES HUMANAS. Cortez editora. San Pablo, 2002 (pp. 45)

73 PEREIRA, Potyara "Especificación de necesidades humanas básicas a partir de teorías recientes". En: NECESIDADES HUMANAS. Cortez editora. San Pablo. 2002 (pp. 78 y 79)
} 
tratados como si tuvieran déficit en su salud mental o en las habilidades cognitivas. Colocándolos en este lugar poco importa si se avasalla su autonomía. Un claro ejemplo es que generalmente los ancianos no deciden su internación en un hogar, sino que esto se hace en forma compulsiva tal como lo constatamos en el trabajo de campo.

Aquí es importante señalar lo que sucede en los hogares de ancianos que cuentan con un número elevado de camas, cuando se hallan en presencia de adultos mayores que conservan un alto grado de autovalimiento, es decir que están en condiciones de efectuar las actividades de la vida diaria sin ser asistidos. En tal caso, en general, se le coarta la posibilidad de ejercer el autovalimiento. Vale decir, en aquellas instituciones en las que lo que prima es la organización, la rigidez en la planificación, un anciano autónomo molesta, desorganiza. Al mismo tiempo se observa la presencia de adultos mayores que requieren asistencia permanente y lo único que reciben es "contención" (atados a la silla), colocación de pañales y aseo. Otro de los grandes temas son los ancianos que padecen alguna patología psiquiátrica de tipo demencial y que no reciben controles periódicos ni les garantizan la realización de actividades terapéuticas o recreativas adecuadas, esto es común en los hogares grandes y en los más pequeños.

Aquí se entremezclan los dos elementos fundantes de las necesidades básicas, es decir la salud física y la autonomía.

En el caso de los hogares clandestinos se observa que las personas mayores no cuentan con asistencia médica en la misma institución, pero las propietarias suelen encargarse de llevar a los ancianos a la consulta médica. En general establecen un trabajo en red con los médicos de cabecera de PAMI o con algún referente del hospital público. En otras oportunidades la falta de capacitación de las encargadas de los hogares hace que no adviertan cuando un anciano requiere asistencia y no trabajan en forma preventiva (Ej: prevención de escaras, alimentación acorde a las patologías prevalentes de los residentes, etc.) Y también observamos en estos hogares que la planta física no reúne condiciones de seguridad ni de accesibilidad, es decir no poseen dispositivos de seguridad contra descarga eléctrica, la instalación de gas es insegura, la calefacción no garantiza condiciones de seguridad, no poseen equipamiento para la detección y extinción del fuego, el personal no está capacitado para actuar eficazmente frente a una emergencia. Los accesos al edificio son por escalones o diferencia de pisos sin salvar mediante rampas por lo que los mayores están expuestos a caídas, los baños no son accesibles ni seguros en cuanto carecen de dispositivos que permitan el uso de los sanitarios en forma autónoma y sin riesgos.

En referencia al tema de decidir la continuidad del funcionamiento de las instituciones que no garantizan el cumplimiento de la totalidad de requisitos que contempla la norma, son varios los puntos que se ponderan. En uso del sentido común la autoridad sanitaria evalúa que "si los ancianos comen bien, están al abrigo y asistidos" no hay mayor impedimento para permitir su funcionamiento. Convengamos que los ancianos que viven en los hogares clandestinos son aquellos que poseen un ingreso muy bajo, y de vivir solos ni siquiera garantizarían una ingesta diaria. Asimismo en necesario señalar que es muy dificultoso hacer efectivas las clausuras. Uno de los motivos que ya hemos señalado es la carencia de lugares de derivación para los ancianos que están institucionalizados, y a la vez porque tal vez no existe una fuerte voluntad política vinculado a la imposibilidad que hemos tenido de instalar este tema en la agenda pública.

Frente a todo esto surge un interrogante ¿Qué se construye como mínimo para los ancianos? ¿Qué sería lo básico para ellos? 
No podemos acotar la discusión a lo legal o ilegal del funcionamiento de los hogares clandestinos, debemos aportar a la construcción de miradas superadoras que contemplen la autonomía de los adultos mayores. El estado provincial deberá re pensar varias de sus intervenciones. Por un lado deriva a través de los servicios sociales hospitalarios y desde el poder judicial a los hogares clandestinos, considerándolos un recurso válido para que vivan los mayores que carecen de cobertura social o cuentan con ingresos indignos. Por otro lado controla el funcionamiento de estos hogares que a todas luces escapan a la lógica de la reglamentación, con una pretensión de adecuación y encuadre a la norma.

Frente al tema de lo dificultoso de hacer efectiva la fiscalización en todos los hogares geriátricos existe un consenso generalizado en la provincia vinculado a las propuestas de descentralización, es decir delegar el ejercicio del poder de policía sanitaria al ámbito municipal. Como equipo venimos advirtiendo que en una provincia de la magnitud de la nuestra, que cuenta con 134 municipios, que son muy heterogéneos entre sí, es necesaria la realización de un análisis de situación en cada lugar a fin de examinar si los mismos están preparados para abordar un tema tan complejo. Con esto último se pone en evidencia que nuestra intervención deberá tender a instalar en la agenda pública, algo así como hacer visible lo que pareciera no tener visibilidad. El desarrollo de esta tesis está orientada en este sentido.

\section{V - ANÁLISIS DE LOS INSTRUMENTOS METODOLÓGICOS}

El desarrollo del trabajo de campo nos permitió ir comprendiendo los significados que se construyen en los escenarios institucionales. $Y$ el proceso analítico nos permitió profundizar esta comprensión, sorprendernos, angustiarnos y continuar interrogándonos.

Nos apropiamos de la categoría de necesidades básicas y la pusimos en tensión con la realidad de un Hogar Geriátrico. A partir de allí definimos cuál era nuestro objeto de investigación y definimos que eran las Prestaciones brindadas en los Hogares Geriátricos. Desde allí empezamos a preguntarnos qué dimensiones de este objeto nos permitirían caracterizarlas. Recuperando el saber acumulado sobre la vida cotidiana de los geriátricos que poseía desde mi intervención profesional y rescatando los hallazgos de otras investigaciones definimos que las Variables que nos permitirían dar cuenta de la prestaciones tanto en su plano material como simbólico eran:

- Alimentación ya que proveer alimentación a los albergados es una de las acciones definidas como constitutivas de la prestación. "Son los establecimientos destinados al albergue, alimentación, salud, higiene y recreación asistida de personas de la tercera edad de ambos sexos, cualquiera sea el número, estén alojados en forma permanente o transitoria, gratuita u onerosa" ${ }^{74}$

\footnotetext{
${ }^{74}$ Artículo $69^{\circ}$ Decreto 3280/90 Publicado en el boletín Oficial el 20/9/1990
} 
- Atención Sanitaria: ya que al mismo tiempo que es definido desde el marco legal esto nos permitiría dar cuenta de las acciones de prevención de la salud o recuperación que se desarrollaban y al mismo tiempo como eran significadas por los agentes sociales.

- Admisión: En este punto se produjo mucha discusión ya que uno de los supuestos que teníamos era que los establecimientos clandestinos no poseían "criterio" de admisión y mucho menos "criterio" gerontológico. Esta dimensión puesta en juego en el desarrollo del trabajo de campo nos permitió romper algunos supuestos erróneos.

- Autonomía: Esta dimensión nos permitió interpelar a nuestros informantes y muchas de las respuestas estuvieron signadas por una clara voluntad de revisión de las propias acciones.

- Integración: esta dimensión nos permitió recuperar los múltiples lazos que contruyen los mayores.

El tipo de entrevistas que desarrollamos fue semi estructurada por lo que se trabajó con una serie de items que ordenaban el desarrollo de la misma. Este instrumento fue ampliamente superado en el trabajo de campo ya que surgieron otras dimensiones de la prestación que prima facie no se habían tenido en cuenta. De igual forma la construcción de esta guía nos permitió ordenar el trabajo e iniciar una puesta en juego desde marcadores similares.

Variable alimentación:

- ¿Qué Comen? (Variabilidad del menú)

- ¿Quién decide lo que se come?

- ¿Existe concordancia entre la alimentación y las patologías prevalentes?

Variable atención Sanitaria

- Frecuencia de visita a los médicos de cabecera

- Frecuencia de atención con médicos especialistas

- Cumplimiento en la administración de medicación prescripta.

- ¿Los revisa el Director Médico?

- Quién efectúa los controles de enfermería, con qué frecuencia?

Variable Admisión

- ¿Quién decide la admisión?

- ¿Se pondera el autovalimiento como restrictivo para el ingreso?

- ¿Se evalúa servicio brindado con las necesidades del viejo?

- ¿Se consulta el deseo / decisión del viejo?

Variable autonomía:

- Nivel de decisión de la persona mayor en el cotidiano

- Participación del adulto mayor en la decisión de salir y a donde

- Participación en la decisión de internarse en el hogar.

- ¿Administra dinero el anciano?

Variable Integración:

- Los residentes conservan vínculos con familiares.

- Los residentes conservan vínculos con vecinos de su barrio.

- Los residentes visitan a sus familiares o a sus vecinos, habitualmente. 

externos.

- Los residentes mantienen correspondencia o comunicación telefónica con agentes hogar.

- Los residentes establecieron algún vinculo especial con alguno de los trabajadores del

- Los residentes establecieron algún vínculo especial con otros residentes.

Estas dimensiones nos permitieron dar cuenta del plano material y simbólico de la prestación brindada en los Hogares Geriátricos. En el capítulo siguiente compartiremos los hallazgos encontrados. Cabe señalar que al configurarse el trabajo de campo en una estrategia etnográfica fueron recuperados los saberes de los agentes sociales a los que se entrevistaron por lo que en la exposición presentada en el capítulo III se estableció otro orden y se incorporaron otros ejes de análisis. Los informantes claves fueron considerados interlocutores, tomando los aportes de Miguel Bartoloméc5 en tanto que se generó una relación social igualitaria y no solo una extracción de información. Ellos señalaban una centralidad de las personas mayores como "objetivos de la prestación". Por lo tanto, las variables construidas nos permitieron dar cuenta de las características de la prestación a la luz de su "beneficiario".

Es oportuno plantear que las cuatro características de la descripción etnográfica "es interpretativa ya que lo que interpreta es el flujo del discurso social y la interpretación consiste en rescatar lo dicho en ese discurso de sus ocasiones perecederas y fijarlo en términos susceptibles de consulta.... la descripción etnográfica tiene una cuarta característica, por lo menos tal como yo la practico: es que es microscópica" ${ }^{\mathbf{7 6}}$

Asimismo queremos compartir las reflexiones construidas sobre el proceso analítico, en particular en cuánto a la necesidad de construir una posición de extrañamiento en este escenario que creía conocer. En el desarrollo del trabajo aparecía fuertemente como objetivo a alcanzar la generación de un producto de investigación propio del Trabajo Social. Pero nos preguntábamos ¿Qué caracteriza a la producción de conocimiento desde el Trabajo Social? En este punto tomamos el aporte de la Profesora Susana Cazzaniga quien refiere que la intervención profesional del Trabajo Social conlleva Comprensión, Explicación, Nominación y Transformación. Tomando el aporte de la Antropología podríamos decir que para lograr la comprensión y explicación es necesario tomar una "posición de extrañamiento". Esto permitiría convertir lo familiar en exótico. De esta forma se buscaría conocer la realidad en la que se interviene sin imponer nuestra propia forma de ver la misma. Nos permitiría recuperar las diferentes racionalidades que operan en la intervención y a partir de allí comenzaríamos a nominar. Ya no encasillando al otro en mis nominaciones previas. Una vez recuperada la trama de significados que operan y sus modos de producción material y de sentidos, podemos operar, intervenir, desde un lugar de conocimiento más certero, validado, mas argumentado y desde ahí, tal vez, transformar.

Con lo expuesto queda claramente en evidencia el valor político del proceso de construcción de conocimiento en Ciencias sociales en general y del Trabajo Social en particular. El trabajo desarrollado en esta tesis tiene una clara intencionalidad de denuncia, de hacer visible la situación de vulnerabilidad en la que se encuentran las personas mayores institucionalizadas. Es nuestro objetivo dar cuenta de las paradojas de lo real.

\footnotetext{
75 BARTLOMÉ, Miguel "En defensa de la etnografía".

${ }^{76}$ BOIVIN, Mauricio, ROSATO, Ana ARRIBAS, Victoria "La observación participante". En CONSTRUCTORES DE OTREDAD. Una introducción a la Antropología Social y Cultural. Editorial Antrpofagia. Tercera Edición, segunda reimpresión. Bs. As. 2006 (pp. 171)
} 
Volviendo a lo característico de la producción de conocimiento en Trabajo Social tomaremos el aporte de Nora Aquín quien sostiene que "La intervención determina a la investigación en Trabajo Social, le señala su finalidad. En Trabajo Social investigamos para intervenir. La intervención determina modos específicos de ver". ${ }^{77}$

Si articulamos esta dimensión política y estos modos específicos de ver desde la intervención profesional podemos decir, coincidiendo con Barberena que "Este hacer ver lo que no se ve como primer paso, reconocer un sujeto para que éste pueda ser sujeto de políticas. .... la visibilidad es el primer paso para la producción de conocimientos. Estimo que la relevancia tiene que ver con la puesta en escena, con hacer subir al escenario un actor que está oculto; y que mientras esté oculto no hay derechos sociales posibles. Entonces planteo la intervención como posibilidad, .....como constructora y sostenedora de la cuestión. En la medida que se hace visible lo que está invisible se va constituyendo alguien con características de ciudadanía"m8

Pues entonces la producción de conocimiento en Trabajo social tiene como punto de partida la intervención profesional ${ }^{79}$, construye una decisión política de denuncia, de hacer visible, de inscribir en la agenda pública una cuestión. Por lo tanto es necesario un ejercicio de problematización constante "la realidad socio - histórica es una realidad mutante, la posibilidad de comprenderla en su movimiento deviene de la capacidad de establecer con ella una relación de conocimiento dirigida a la centralidad de la pregunta" 80

El sentido de esta tesis está centrado en una clara pretensión de comprensión, explicación, nominación y transformación.

\footnotetext{
77 Nora Aquín."La especificidad del Trabajo Social y la Formación Profesional". ENCUENTRO ACADÉMICO NACIONAL DE F.A.U.A.T.S. Editorial Espacio, Buenos Aires, 1996

${ }^{78}$ BARBERENA, Mariano "Tesis de Maestria" pp. 71

${ }^{79}$ Para la conceptualización de Intervención profesional tomamos los aportes de Margarita Rozas Pagaza quien la define como "un proceso que se construye a partir de las manifestaciones de la cuestión social y dichas manifestaciones son las coordenadas que estructuran el campo problemático." "Intervención como campo problemático en la medida que ella se constituye en el escenario cotidiano donde se objetivan las manifestaciones de la cuestión social y que atraviesan la vida cotidiana de los sujetos" En: "La cuestión social contemporánea y la intervención profesional como campo problemático". En: LA INTERVENCIÓN PROFESIONAL EN RELACION A LA CUESTION SOCIAL. Espacio Editorial, Bs As, 2001 (pp. 219/220)

${ }^{80}$ CAZZANIGA, Susana "La formación de los Trabajadores Sociales en el actual contexto". En: Revista Escenarios n 0 Escuela Superior de Trabajo Social, 2004 (pp. 90)
} 


\section{CAPÍTULO III \\ CARACTERIZANDO LA PRESTACIÓN BRINDADA EN LAS INSTITUCIONES DE LARGA ESTADÍA: SUS DIMENSIONES MATERIAL Y SIMBÓLICA.}

"Uno quiere mirar los ojos de aquellas personas que miró siempre"

Fiscalizador

En el proceso analítico de las entrevistas y crónicas de observaciones efectuadas durante el desarrollo del trabajo de campo hemos identificado varios vectores o puntos comunes que creemos necesario dejar sentados como constitutivos de las prestaciones de hogar geriátrico en la provincia de Buenos Aires.

Cómo ya hemos explicado anteriormente la definición del protocolo de entrevistas estuvo guiado fundamentalmente por la categoría de necesidades humanas. $Y$ esta fue operacionalizada con los conceptos salud física y autonomía. Del relato de los entrevistados y de las observaciones surgieron otros elementos significativos que necesariamente se fueron incorporando. Esta flexibilidad metodológica es lo que nos ha permitido bucear en la trama de significados que se tejen alrededor de las prestaciones brindadas en los hogares geriátricos y consecuentemente en referencia a las personas mayores, a sus derechos y al rol del estado.

Las variables, vectores o puntos significativos que aparecieron y serán desarrollados a continuación son:

- Historia Institucional - Trayectoria institucional - Mito de origen: Este punto en particular surgió como dato relevante y en todas las entrevistas. Todos los agentes sociales entrevistados ataban una referencia a su trayectoria personal para dar cuenta del origen de las instituciones.

- Residentes - Personas Mayores - Población objetivo de la prestación (Dimensión alimentaria, atención sanitaria, admisión, autonomía, integración) En este punto hemos condensado las variables construidas en el proceso de operacionalización. En todas las respuestas aportadas por los entrevistados aparece una centralidad de los residentes a la hora de dar cuenta de las dimensiones de la prestación. Por tal motivo hemos escogido para la exposición respetar esta "centralidad" de los residentes a para dar cuenta de la prestación.

- Familia de los residentes Cuando trabajamos la variable Integración aparece una clara referencia a la familia de los residentes por lo que creíamos necesario que trabajemos con este concepto que opera fuertemente en la realidad institucional de los geriátricos. 
- Casos paradojales: en este punto se intenta ejemplificar a partir de la presentación de algunos casos las prácticas y significados que se construyen sobre las personas mayores institucionalizadas y al mismo tiempo algunas paradojas sobre las acciones del estado.

- Caracterización de los propietarios caracterizar a los propietarios ya que este nos prestacionales.

El desarrollo del trabajo de campo nos permitió ir comprendiendo los significados que se construyen en estos escenarios institucionales. $Y$ el proceso analítico nos permitió profundizar esta comprensión y sorprendernos, angustiarnos, y continuar interrogándonos.

Muy pocas certezas hemos podido construir en este proceso, ya que las mismas las expusimos a la problematización permanente. Esto fundamentalmente porque tuvimos que configurar una posición de extrañamiento en este escenario que creía conocer.

\section{I - HISTORIA INSTITUCIONAL - TRAYECTORIA INSTITUCIONAL - MITO DE ORIGEN}

"La analogía con la racionalidad de la producción de mercancías es total. Se trata del mismo modo a los pacientes y a la salud misma que a los automóviles en la línea de producción; las diferencias, el pathos, y el problema ocasional atestiguan que, al contrario de los automóviles, los pacientes sí piensan y sienten y que la enfermedad es tanto una relación de interacción humana como una cosa en sí misma." 81

Los ancianos que residen en instituciones privadas de larga estadía garantizan con su cuerpo la rentabilidad. Una mayor renta se obtiene si se reducen costos, una manera es acortando la cantidad de personal, reduciendo la calidad y cantidad de alimentos dispensados y sobre - facturando los servicios brindados. Pero, por sobre todas las cosas, la rentabilidad será garantizada a largo plazo por lo que la mejor manera es conservando a los clientes.

El Médico Director del hogar geriátrico Marítimo cuando trabajamos en la entrevista sobre las razones en la elección de trabajar en este tipo de institución y con esta población refiere:

"Nunca tuve en mente trabajar con abuelos. Siempre tuve atracción por ellos cicómo te puedo decir?... Las circunstancias se dieron que trabajara en un geriátrico. Yo trabajé en clínicas psiquiátricas durante 15 años, y bueno, tenía abuelos. Y en el hospital, cuando estaba en clínica con los abuelos era una atracción que tenía. Sí, siempre me decían "Che, a vos que te gustan los viejos atendelos" Director Médico hogar Marítimo

Aparece un reconocimiento de la elección de trabajar con personas mayores y al mismo tiempo aparece esta certeza de que a la mayoría no le gusta. En varias producciones

${ }^{81}$ TAUSSING. Op. Cit. (pp. 131/2) 
gerontológicas trabajan esta idea de que cuando se trabaja con población que no es valorada, las especialidades que le corresponden tampoco lo son ${ }^{82}$.

En una entrevista con dos propietarias de un hogar cuando se las interroga sobre el origen institucional refieren por un lado a la necesidad de trabajo de una de ellas, y la continuidad del proyecto lo vinculan al haberse enamorado de lo que hacen.

"Yo le propuse : Eros, no te gustaría poner una casa para cuidar abuelos? Ella se fue y me dijo Bueno, dale buscate una casa para cuando yo vuelva...... Y así fue, cuando ella volvió - capaz que ni se lo esperaba- cuando volvió a los tres días le digo que ya tengo la casa. Y bueno - me dice - vamos a verla. Fuimos a ver dos y nos decidimos. Pasamos un mes haciendo cortinas, pintando rasqueteando camas, que la cama de mi hermano, que la del hermano de ella. ¿Me entendés? Que la cama mía de cuando era chiquita. Compramos colchones, trajimos colchones nuevos, almohadas. Así armamos la casa.... y después estuvimos como una semana... que ya teníamos cortinitas, era una casa chica. Yo iba a las 6 de la mañana a coser porque me llevé la máquina a esa casa, yo cocía y después a las siete y media entraba a trabajar a un hogar"

"Yo es como que me enamoré de lo que hacía"

En la entrevista efectuada a Zeus, propietaria del Hogar Soberano surge en el relato sobre el origen la mercantilización que opera tanto en el campo de la salud como de la política pública y como esto se singulariza en la prestación de los hogares geriátricos. Al mismo tiempo aparece en el discurso una referencia al sentido "altruista" de las acciones por parte de los propietarios.

"Sí, tesoro sí. Bueno, empecé porque mirá. Mi historia es muy larga, mi historia es, yo en el año 84 perdí mi casa. Tuve un juicio, perdí mi casa y tuve que ir a una pensión, con los chicos. Y bueno, y después mi hermana tenía también en ese tiempo un geriátrico $\boldsymbol{y}$ me vendió, digamos, la mitad de las personas y la mitad de todo, de los muebles, todo. Lo único que yo tenía que conseguir era dinero para alquilar era lo más, este ......"

"Mi primer época, te digo del ochen, del 90 que yo empecé con esto (.......) No,no, no,no, vivía en otra casa, si, con gente mayor, que te dá mucho más trabajo. Porque tenés que ponerle pañales, que (...) a veces no caminan, son gente con más. Pero te digo son más bien pagos que esta gente. Pero este...

P: Y a vos qué te gusta más, trabajar con viejitos $0 . .$.

No,no, no, con gente así. Sí, porque vos lo hablás, lo retás y se terminó el drama. En vez el viejito aunque le hables y re hables, no, no te entiende. Yo tuve muchos viejitos, si, en, cuando estaba en la calle 12 teníamos y cómo 16. Pero un trabajo era, pero había."

"En el año ochenta y, cuando perdí la casa, que me piré, en una palabra (Risas de ambas) y el Dr. me internó ahí. Y bueno, ahí veía, las enfermeras, porque yo estaba bien, cómo trataban a la gente enferma. Que se yo, cómo es posible que un ser humano trate a otro ser humano tan mal. Entonces yo hago todo lo contrario"

Dionisio, propietaria del Hogar Vinicultor refiere sobre el origen institucional: "Yo había comprado con 15 pacientes...compré con 15 pacientes, entré el 4 de mayo de 1988"

\footnotetext{
${ }^{82}$ SALVAREZZA, Leopoldo LA VEJEZ: UNA MIRADA GERONTOLÓGICA ACTUAL. Editorial Paidós. Bs, As. 1998
} 
Aparece claramente diferenciado el origen de las instituciones privadas con mayor capacidad de camas y habilitadas de aquellas que han surgido en forma más "espontánea" y sin planificación empresarial ni sanitaria. Pero en ambos casos aparece claramente que el leit motiv es la maximización de la ganancia. Algunos con matices más de tipo solidario y con un anclaje en el "amor".

Una de las características comunes que se hallan es la consideración de que esta actividad es sencilla, que las capacidades necesarias para iniciar la actividad es el "amor al prójimo". Surge con total claridad que la construcción de la población objetivo de la prestación brindada, es decir las personas mayores, está arraigada fuertemente desde una óptica asilar. Aparece el viejo como objeto de cuidado.

" la primera concepción que encontramos en las políticas de vejez es la construcción social de la vejez como asunto de pobreza. El origen de esta concepción se encuentra en las sociedades industriales de finales del siglo XIX y principios del XX..... el modelo asistencialista diseñado para los viejos pobres en este período no es diferente al diseñado para los jóvenes pobres: el asilo" ${ }^{\prime \prime 3}$

Entonces podríamos identificar que la respuesta asilar es una constante a la población envejecida, esto claramente vinculado con la concepción de vejez que opera socialmente. Por lo que más adelante desarrollaremos como concepto de edaísmo.

Sumado a esto identificamos que la tendencia mercantilizada que aparece en las prácticas y discursos de los agentes sociales tiene que ver con los cambios operados en el campo de la salud en los últimos años:

" El proceso de implantación de la nueva política de salud permite constatar que no estamos ante el simple retiro del Estado, sino ante un cambio profundo en el tipo de intervención ............................... la nueva política en salud es, en realidad una política económica de promoción de los negocios privados en el ámbito de salud y obedece al propósito de construir a este campo en un terreno de acumulación. El segundo eje de intervención estatal es la adecuación del marco legal para institucionalizar la nueva política de salud." 84

Tal como plantea Laurell se produjo una modificación en la forma de operar del campo de la salud que posibilitó la ampliación de espacios de rentabilidad, en particular este tipo de prestación, como fuera planteado en el capítulo I.

\section{II - RESIDENTES - PERSONAS MAYORES - POBLACIÓN OBJETIVO DE LA PRESTACIÓN}

A partir del análisis efectuado sobre las entrevistas y particularmente sobre las observaciones efectuadas podriamos afirmar que los residentes de las instituciones geriátricas ocupan un lugar de sumisión. Deben acatar las reglas de juego que ya fueron

\footnotetext{
83 HUENCHUAN NAVARRO, Sandra "Definición de la cuestión en las políticas de vejez:pobreza e integración" En: MARCO LEGAL Y DE POLÍTICAS A FAVOR DE LAS PERSONAS MAYORES EN AMERICA LATINA. CEPAL, Santiago de Chile, 2004. (pp. 34)

${ }^{84}$ LAURELL, Asa "La reforma del sector salud. Hacia la mercantilización de los servicios". En: LA REFORMA CONTRA LA SALUD Y LA SEGURIDAD SOCIAL. Fund. Friedrich Ebert, México. 1997 (pp 103) 
creadas por otros. La institución no se presenta como flexible dispuesta a prestar atención a las demandas de los residentes.

La persona mayor institucionalizada aparece como un objeto de cuidado, por lo que no es pensado como portador de derechos. $\mathrm{Y}$ al mismo tiempo aparece como objeto garante de rentabilidad.

Antes de avanzar sobre el análisis de las entrevistas es necesario aclarar la manera en que nominaremos a los viejos. Cuando comenzamos a definir esto, nos surgieron varios interrogantes. Por un lado, porque desde mi intervención profesional los llamo Viejos, obviamente no desde un sentido despectivo sino porque en realidad cuando me refiero a cada uno de ellos los llamo por su nombre, nombre que lo viene acompañando desde toda la vida. Desde la gerontología, se propone hablar de adulto mayor en respuesta a la tendencia a infantilizar a los viejos, se recuerda desde la forma de nombrarlos que son adultos. También se los llama gerontes, pero esto es un tecnicismo. También se los llama personas de edad, esta nominación ha sido propuesta por la Asamblea de la ONU cuando declaró el año 1999 como año internacional de las personas de edad. En el presente trabajo hablaremos de personas mayores, por que creemos necesario recordar desde la nominación que los sujetos que están albergados en instituciones de larga estadía no pierden su condición de personas, a pesar de acumular años en su trayectoria.

Volviendo al carácter de objeto de protección / cuidado que reviste la persona mayor institucionalizada, lo podemos observar en varias dimensiones, a saber:

a) - Dimensión Admisión: Cuando comenzamos con el trabajo de tesis creíamos que los geriátricos clandestinos no poseían criterios de admisión ya que no efectuaban valoración geriátrica de los "postulantes" para el ingreso. Después comenzamos a observar que este no elegir al futuro residente era claramente un criterio de admisión, anclado en el objetivo institucional (ocupar la cama, maximizar ganancia). Por lo tanto la admisión en tanto que evaluación de la persona, análisis pormenorizado de los servicios que requiere y evaluación institucional frente a la demanda, no aparece.

"No se evalúa. Se toma ... digamos, se empieza a conocer al abuelo si necesita atención psiquiátrica por ejemplo" - Eros, propietaria de hogar amoroso.

Aparece claramente que en los geriátricos privados tanto habilitados como clandestinos se albergan a personas mayores dependientes (según índice de Katz). Este punto creo que se configura en un hallazgo de esta investigación, ya que pudimos analizar el proceso de acceso a los servicios de apoyo para las personas mayores en la Provincia de Buenos Aires. $^{85}$

Ratificamos lo expresado en algunas investigaciones que la razón de la institucionalización está centrada en el agotamiento del cuidador. Entendiendo por dependencia a la necesidad de cuidados personales e instrumentales para realizar las actividades vitales de la vida cotidiana que requieren aquellas personas con algún tipo de discapacidad. ${ }^{86}$

"Ya no es el viejo común, es el viejo patológico. No sé cual es la palabra justa, eh pero ya viene deshecho, deshecho, deshecho, demencia senil, alzheimer...." - Poseydon

\footnotetext{
${ }^{85}$ Ver capítulo II de esta Tesis.

${ }^{86}$ Universidad de Alcalá " La protección social de la Dependencia". Organización Iberoamericana de Seguridad Social.
} 
"Mirá si hay cama acepto" (Zeus)

"Frente a tener la cama desocupada, me conviene. Me conviene, viste nenita, porque eso me ayuda a poder solventar el alquiler y todo lo demás." - Dionisio

Pudimos advertir que en los dos geriátricos municipales a los que accedimos han construido un criterio de admisión. Uno de ellos admite entre sus "pensionados" a personas mayores autoválidas ya que por razones presupuestarias no está en condiciones de atender a personas que requieren mayor asistencia. El otro hogar inscribe el criterio de admisión en una política de vejez. El equipo evaluador no es el del hogar sino que depende del área de tercera edad por lo que buscan la puesta en juego de varias alternativas de atención superando la mirada asilar.

En los hogares que trabajan para el INSSJyP, el criterio es establecido por la obra social. La institución no posee espacio de discusión sobre la pertinencia del ingreso de determinada persona, se coloca el saber por fuera de la institución. Es otro el que conoce, el que es capaz de evaluar y dictaminar. De igual forma, una vez que la persona ingresa a la institución es evaluada por el equipo conformado por médico, trabajador social, enfermero profesional y nutricionista. A partir de la evaluación cada profesional establece las líneas de intervención, existen experiencias en instituciones que la planificación la efectúan en forma interdisciplinaria. No es el caso de los hogares que configuran el escenario de esta investigación. Por lo que podríamos afirmar que en los hogares que poseen varios profesionales se produce un proceso de escisión del sujeto, algo así como una especie de "depostación".

"Tenemos un caso, Alfredito, se llama Alfredo $S$, le digo subí Alfredo Ja, ja! Ochenta y cuatro años, claro, a vos te llega la orden, eso le recalco a la gente de Pami, diciéndole que a nosotros nos quieren utilizar como variable de ajuste. Digo, a nosotros nos llega la orden, nosotros lo primero que hacemos es comunicarnos con el familiar. $A$ mi no me dejan hacer una previa para decir, bueno, dejame analizar el caso, ver la documentación, y ver todos los estudios que ustedes hicieron para saber cómo es el entorno familiar, por qué lo internan, y todo este tipo de cosas. Por ahí hay violencia y vos no te enterás, te enterás al tiempo cuando te dicen uy! tal persona no había que dejarla salir porque .. la hija le pegaba a la madre y bueno, escuchame (....) Y cosas así, y en este caso eh, llega la orden, y ..yo llamo, y bueno sábado a la noche, 8 y media Yolanda me avisa, porque cuando no está Susana Yolanda es la encargada del turno tarde. Eh, me dice mirá Miguel una señora para internar a(...). Bueno,. Yo vengo, eh, le dije mirá Yolanda después de las 8 de la noche no se puede recibir. Porque la gente mayor, por mas que sea mayor tienen que saber dónde se la lleva, que venga mañana. $Y$ bueno, llego aquí y me encuentro con un señor todo desalineado, todo barbudo, todo coso, y una persona que señora digo es un poco tarde, se podría haber echo durante el día. Claro, agarra levanta la blusa y dice mire!. Claro, yo veo un bombo, eh, Digo pucha, que desconsiderado que soy entonces le digo, es su papá? No. Es mi marido. Le digo, enseguida lo internamos......Cincuenta y dos años, ahora, después de dos meses el tipo está re piola, ella también está re piola, porque él acá no toma más, lleva una vida sana." POSEYDON

Volviendo al lugar que le asigna la institución a la persona mayor, este reviste carácter de objeto. Esto no solo acontece en el hogar es también la familia quien aporta a la construcción de este lugar para el viejo. 
"En general no se los consulta. Yo creo que se consulta entre los familiares, qué hacemos con fulano en estas condiciones" - Fiscalizador

La familia, una vez que toma la decisión de institucionalizar a "su viejo" pretende que quien notifique esto sea la institución. Existe un temor a la verdad, y de esta forma se fortalece esta idea de "todo presencia institucional".

"Cuando le dicen te dejo quince días hasta que te recuperes está contando los días para irse ...... eso es medio cruel ¿viste? Eros, propietaria de Hogar Amoroso

En este punto es necesario dejar sentado un interrogante en cuanto a la dependencia de las personas mayores institucionalizadas que será retomado en el apartado "Trayectoria de las personas mayores en estas nuevas condiciones materiales de vida".

La persona mayor experimenta un sentimiento de desarraigo muy fuerte, esto agravado con la falta de participación activa en la decisión. Se lo excluye de participar sobre su propia vida, y este es algo así como el acto inaugural. Este acto inaugural genera sentidos que posteriormente se expresarán en las prácticas cotidianas.

Aquí es pertinente retomar la expresión de "rito de pasaje" que traen Francisco Suarez y Natalia González. Los autores plantean que "Si bien no existen rituales establecidos para el ingreso en una residencia, se puede trazar la analogía con el pasaje simbólico de la adultez a la muerte. Separados de sus vidas pasadas en la comunidad, los residentes han de adecuarse a la vida residencial en una diversidad de maneras. Los límites resultan bastante imprecisos, ya que no se los considera más como adultos responsables, pero tampoco están desprovistos totalmente de capacidades" ${ }^{87}$

Y aquí recuperamos "La peor exclusión es la que priva al ser humano de sus rasgos, su cultura, su identidad, lo que lo deja en el autismo personal y colectivo"188

b) - Dimensión Alimentaria: En pocas instituciones aparece claramente un trabajo profesional que guíe la elaboración de menúes. Si aparece con cierta centralidad esta idea de la "panza vacía" a llenar (objeto). Solo aparece la alimentación integrando una estrategia prestacional en los hogares dependientes del municipio y en uno de los que trabaja para el INSSJyP.

"la verdad que comen mejor de lo que yo como en mi casa. Mejor porque comen carne, comen pollo, comen pescado." (Profesional hogar Guerrero)

"Acá el personal de cocina es exclusivo del área y es supervisado por la nutricionista, Pami se fija mucho en eso" (Poseydon, titular de Hogar marítimo)

De los relatos surge un orden en la alimentación que se podría creer vinculado a una planificación, pero esto es fácilmente desmentido por lo constatado en las observaciones. Aparece claramente que la decisión de la comida se toma cotidianamente, como en una "casa". No hay una evaluación seria de la población y sus necesidades nutricionales. Se define con el criterio de "ama de casa".

\footnotetext{
${ }^{87}$ SUAREZ, Francisco y GONZALEZ, Natalia "Cultura Institucional y Estrategias de Vida de los Adultos Mayores en la Argentina en la población inserta en residencias geriátricas" En: PRIMER ANUARIO DEL SIMPOSIUM ARGENTINO DE GERONTOLOGÍA INSTITUCIONAL. Ediciones Suárez. Mar del Plata, 2005 (pp. 31)

${ }^{88}$ Artículo "La máscara y el rostro" en Revista (Antro II)
} 
Sin embargo los horarios de comida son percibidos por los agentes institucionales como los grandes reguladores del tiempo. Tanto las personas mayores como el personal orientan sus acciones con los "mojones" de horarios de comida.

c) Dimensión Atención Sanitaria: En todas las instituciones aparece centrado en el control de signos vitales diarios por parte del personal de asistencia y la administración de medicamentos. Cuando digo personal de asistencia me refiero a auxiliares de enfermería, mucamas y asistentes geriátricos. Estas últimas, son "mucamas" que adquieren el "status" de asistente tras contar con un año de antigüedad en el puesto de trabajo. De acuerdo a las leyes que regulan la actividad del personal de la salud en el ámbito privado no es necesario un proceso de aprendizaje sistemático para ser asistente geriátrico. (ATSA).

En el hogar, el médico centraliza la información y decide qué estrategia tomar y la propone. La decisión la toma el propietario. En los casos en que no cuentan con médico de la institución pareciera que nadie ocupa este rol de centralizar la información. La persona mayor ocupa un lugar de objeto de registro que ni siquiera es utilizado. Aquí podríamos enriquecer con los aportes de Matusevich quien siguiendo a Goffman refiere "la actividad principal del personal que trabaja en estas instituciones es la vigilancia: controlar que todos hagan lo que se les exige y evitar que se perturbe el clima de sometimiento general". ${ }^{89}$

"Todos los días el enfermero le toma la presión, el pulso, la temperatura, los signos vitales. Bueno, y análisis les hago aproximadamente cada 6 meses" - Dionisio

"Tenemos tres médicos, la Directora que viene todas las tardes, un médico viene a la mañana y la otra médica cubre los baches de horarios,. Tenemos médico desde las 8 de la mañana hasta las 8 de la noche" Poseydon

De acuerdo a las observaciones, la mayoría de los geriátricos carecen de personal de enfermería. En general este rol es cubierto por mujeres que anteriormente se desempeñaban como servicio doméstico. Pasan de mucamas de una casa de familia a "asistentes geriátricos" sin haber mediado un tránsito por espacios de formación. Aquel que no ha sido formado para la tarea que desempeña es probable que no logre desarrollar convenientemente la misma. El que opera es el sentido común. Aquí se pone en juego la construcción social de vejez que posea la persona. Al mismo tiempo que al no tener la mirada entrenada, puede no advertir signos de deshidratación, de descompensación de la persona mayor, lo cual se configura en un riesgo. Sumado esto, a que varias instituciones clandestinas carece de Director Médico (es la figura vigente en la normativa) la persona mayor es instalada una vez más en un espacio de vulnerabilidad. Esta afirmación la efectuamos porque de acuerdo a lo constatado en las dos ciudades elegidas para el trabajo de campo alrededor del $\mathbf{8 0} \%$ de las personas mayores que residen en las instituciones privadas son dependientes o semidependientes.

Lejos de presentar a la vejez como sinónimo de enfermedad, pero es un dato tangible que la persona mayor institucionalizda es aquella que se ubica en la "vejez frágil". Y aquí es necesario complejizar la mirada y revisar las acciones institucionales. Varias veces hemos observado que ingresa a una institución una persona mayor incluída en el "índice $C$ " de Katz, es decir independiente en todas las actividades de la vida diaria excepto lavado y otra

${ }^{89}$ MATUISEVICH, Daniel "Envejecimiento o institucionalización geriátrica". En: ENVEJECIMIENTO Y VEJEZ. Editorial Atuel, Bs. As. 1998 pp. 124 
actividad. Luego de algunas semanas, o meses esta persona comienza a abandonar funciones, deja de ir al baño sola, deja de vestirse sola o de elegir su ropa, deja de caminar o lo hace con menor frecuencia, comienza a usar pañales. ¿Podríamos decir que la institucionalización genera en la persona un deterioro vertiginoso? ¿O estamos frente a los efectos de las prácticas institucionales? Volveremos sobre esta idea de la construcción de una biología particular de las personas institucionalizadas.

En los hogares el recurso humano con el que cuentan está caracterizado por la impronta del modelo médico hegemónico ${ }^{90}$ el cual obviamente direcciona al Decreto $3280 / 90$. Con esto se quiere señalar que el personal que cumple una función fundamental es el enfermero y el médico. En algunas instituciones incorporan a otros profesionales como psicólogos, trabajadores sociales, terapistas ocupacionales, profesor de educación física o Kinesiólogo, y a veces se trabaja con perspectivas más amplias, intentando rupturas con el modelo asilar.

En el caso de los hogares sustitutos algunas veces se cuenta con la presencia de un enfermero, o la propietaria es auxiliar de enfermería o entendida en la materia por haber transitado alguna experiencia anterior de cuidado de ancianos. Existen experiencias de mujeres que tras haber dedicado un tiempo al cuidado de un anciano de su familia decide dedicarse a tal actividad por considerar que es apta para tal fin. La mayor falencia que aparece en estos hogares es la ausencia de preparación específica para el cuidado de adultos mayores. Cuando un anciano comienza un proceso de deterioro significativo, es necesario que sea asistido por personal capacitado. Aquí tomaré una frase del propio Marx "El camino del infierno está empedrado de buenas intenciones" ${ }^{\prime 11}$

d) - Dimensión Autonomía: El lugar que se ha construido para la persona mayor en las instituciones privadas observadas no es de autonomía. En el trabajo de campo pudimos advertir cómo se le negaba la capacidad de decisión. Tanto la familia como la institución no cree en la capacidad del viejo para tomar sus propias decisiones.

"Yo creo que el viejo no toma decisiones. No sé en otros hogares con gente más joven, lo desconozco. Sería lo ideal decir: bueno, puedo charlar con él usted está decidido a quedarse acá, a firmar un documento de que él viene por su propia voluntad. Eso,no! Es la voluntad de los familiares que cuando no lo pueden contener en el hogar o cuando sale después de un accidente clínico o cerebral ya dicen iNo lo podemos! Se juntan, resuelve la familia. Y resuelven que no lo pueden cuidar. Entonces van a hacer los trámites y se resuelve que vengan al hogar. Es así. " - Director Médico hogar marítimo.

"La palabra autonomía muchas veces no se dá porque a la gente le resulta más cómodo en los geriátricos hacer la cama y dejar todo hecho y después mantener a los ancianos en una estructura de tipo militar" - Fiscalizador

\footnotetext{
${ }^{90}$ Se entiende por modelo médico hegemónico lo que plantea Eduardo Menéndez "..el conjunto de prácticas, saberes y teorías generadas por el desarrollo de lo que se conoce como medicina científica, el cual desde fines del siglo XVIII ha ido logrando dejar como subalternos al conjunto de prácticas, saberes e ideologías que dominan en los conjuntos sociales, hasta lograr identificarse como la única forma de atender la enfermedad, legitimada tanto por científicos como por el Estado..."

${ }^{11}$ MARX, Karl "Producción del plusvalor absoluto". En: EL CAPITAL: TOMO I VOLUMEN 1. Editorial: Siglo XXI Editores Argentina S.A. Bs. As. 2002 (pp. 232)
} 
Aquí es necesaria una aclaración. En las dos instituciones municipales aparece con mucha claridad el criterio de admisión y las pautas institucionales de funcionamiento. Todos los agentes institucionales saben fehacientemente que, parafraseando a una entrevistada se trabaja por el "interés superior del viejo". Agentes sociales de ambas instituciones refieren que "el hogar es abierto, el que quiere salir, sale"

Con el manejo del dinero aparece una fuerte diferencia. En un privado me dijeron:

"no, no manejan dinero" (Dionisio)

$Y$ en general les aconsejan a los familiares que no les dejen, solo en aquellos que tienen teléfono público le piden al familiar que deje moneditas. $Y$ en los casos en que los residentes manejan dinero, son sometidos a un prácticas de control más severas que lo vulneran más aún.

"Nosotros no le permitimos porque entra mucha gente.... Hay una sola abuela que bueno, ella cobra y guarda el dinero. Pero las chicas, por ejemplo en cada turno cuentan el dinero que tiene y dejan escrito. Y así van de turno en turno.." (Eros)

En cambio en uno de los municipales, los residentes manejan dinero:

"Entonces vamos con un remisse, yo voy con ellos a la cola. Ellos van a la ventanilla. Ellos cobran su plata. Ellos la llevan en su cartera. Llegan al hogar, hacen su colaboración voluntaria, con un recibo que le da la cooperadora y se quedan con la diferencia". Minerva, profesional del Hogar Guerrero)

En ambos municipales han reconocido que la cuestión del manejo del dinero genera algunos contratiempos, pero de igual forma han creado diferentes estrategias que garanticen prácticas de autovalimiento y eviten la vulnerabilidad de la persona mayor.

En el uso y administración del dinero aparece un desplazamiento del adulto responsable, ya no lo es la persona mayor sino su hijo/a, o familiar "a cargo". Se produce un proceso de infantilización. En este proceso se construye al otro mayor como niño. Eduardo Menendez nos plantea que el proceso en el que se infantiliza, al otro, se lo cosifica se le quita la categoría de persona es racismo. "el racismo debe ser referido a las formas de relaciones sociales y culturales que implican negación, discriminación, subordinación, compulsión y explotación de los otros en nombre de pretendidas posibilidades y disponibilidades, ya sean biológicas, sociales o culturales ${ }^{\prime 92}$

e) - Dimensión Integración Podríamos pensar la integración en varios niveles. Por un lado se produce integración de los residentes y sus familias de origen que lo analizaremos en el siguiente punto, por otro la vinculación que opera entre el personal y los residentes y en tercer lugar el vínculo que establecen los residentes entre sí. Y en este punto creo que opera una especie de mecanismo de compensación. Este en varias direcciones ya que los vínculos se construyen con otro y este otro se modifica tanto como uno.

\footnotetext{
92 MENENDEZ, Eduardo "Racismo, colonialismo y Violencia Científica" En: Revista Transformaciones, Buenos Aires, Centro Editor de América Latina, 1973.(pp.1)
} 
"Formó como su familia, cómo te puedo decir... creo que la gente también , a pesar de que todos tenemos fallas.

La gente que es enfermero y que por un accidente viene a trabajar ahí porque necesita el trabajo (...) los demás quedan porque sí., porque hacen una relación afectiva, porque lo veo, lo compruebo que a veces me dicen "Sí porque me trajo tal la crema para las manos" Viste? $Y$ es un enfermero o un asistente que le trajo la crema que ella le pedía. $Y$ esa persona no gana tanto para regalarle una crema, pero se la trae. Pero también esa abuela le tejía un par de medios de lana o algo, porque lo he visto. Tal vez ese es el lazo afectivo. Con el transcurrir del tiempo más, más, mas.." - Director Médico hogar marítimo.

"Hoy hay 10 empleadas que son las 10 iguales. O sea, le dan todo al abuelo! No faltan nunca! Si tienen franco y es un cumpleaños van. Entendes? Eros

"Porque es tanto el cariño que ellos ven ahi, que nos ha pasado casos que han entrado llorando los abuelos porque no entienden por qué motivo.... y a los tres días a los 4 días, el hijo los llama por teléfono para preguntarles si quiere ir a almorzar a la casa y le dicen no, me quedo acá porque estoy bien. Me entendés? - Eros

"Y reconocer que vos con las viejas ya tenés afectividad, una vez que estuvieron acá, ya parece que fueran de tu familia., perdoname que te diga, y no están y las extrañás." Dionisio

Los residentes entre sí también establecen estrechos vínculos, así aparece en las entrevistas:

"Sí, ese grupo inseparable si se me va una se me van las tres. Después el otro caso que te dije de López, de C. López. Se lo llevaron el 23 de diciembre de acá porque se había fracturado y el 24 le dieron el alta y se la llevó para un geriátrico de City Bell del Dr. Dela. Bueno, que queda en City Bell. Entonces lo llevaron y lo trajeron en Enero, en Enero, viste. $Y$ el otro señor Cortez que te dije que pasó un fin de año. Que se lo llevó la esposa a la casa, ella se lo llevó el 24 y lo tuvo hasta el día 3 de enero. Según ella lo tenía en la casa y no, lo había llevado a otro geriátrico, bueno, y lo sobremedicaron, se ve, porque el tipo estaría inquieto que no lo trajeron acá y lo trajeron en sillón de ruedas. Viste que yo después lo tuve que hacer suero todo, para desintoxicarlo. Bueno, después que lo trajeron a este señor en sillón de ruedas estaba entrando en una depresión porque le faltaba López, porque están hechos uno, cómo hermanos, toman mates juntos entonces me preguntaba constantemente por López, si López va a venir. Yo le dije que estaba acá enfrente, que está internado todavía acá, venir va a venir. Unos días que casi me vuelve loca. Entonces, viene López o y el hombre se serena y López también se serena, porque (confuso) Hace 4 años que están juntos, viste mamita, y se hacen esa especie cómo si fueran hermanos. Con los demás se contactan y todo, pero este Lázaro y Córtez son inseparables

\section{P: Comparten la habitación?}

Dionisio: Comparten la habitación. Bueno, esos son dos casos y después que también son inseparables son Amalia $Z$ y Mara, que esas vos no las podés separar ni un rato que se están preguntando constantemente. $A$ ver (se fija en un cuaderno en el que tiene anotado los nombres de los residentes) 
Este es un libro de (...) en dónde anoto todas las cosas, este, cómo te voy a decir, después lo paso al otro, viste. Esta, es Amalia $Z$ una, y la otra son casos como una simbiosis que no pueden estar la una sin la otra. (Pasa las hojas del libro) Bueno, estas otras tres son, espérate, Yoly Pérez, Ibañez María y la otra Nelly Gimenez. Son los casos esos inseparables, viste, las demás se contactan y todo pero no es esa amistad tan fuerte." - Dionisio

Tanto en los discursos como en las observaciones surgen la manera en que operan las relaciones entre los residentes. Recuerdo en uno de los hogares haber visto en una de las mesas a tres señoras. Una estaba pintando, la otra leyendo el diario y la tercera cebaba mates. Cuando me acerco me cuentan que ellas eran muy amigas, que sin embargo discutían todos los días pero que sabían que podían contar una con la otra. La señora que pintaba padecía artritis deformante y relataba que había descubierto su capacidad para esta actividad a partir de vivir en el hogar. Sus amigas le buscaban imágenes en el diario y el personal también. (Diario de campo)

Con esta imagen aparecieron varias cuestiones en juego, a saber, el reconocimiento de las prácticas del otro, la escucha de la palabra del otro, el sentirse escuchado y la certeza de la mirada que cuida. Y por sobre todo el reconocimiento de que la capacidad de aprendizaje no se extingue y que a pesar de haber cambiado sus condiciones materiales de vida pueden generar otras prácticas.

\section{III - FAMILIA DE LOS RESIDENTES}

"..en nuestros países se suele considerar que la atención de personas mayores en situación de fragilidad y dependencia es un problema de índole privado que se resuelva dentro del ámbito familiar" ${ }^{93}$

"Hablar de familia es hablar de estructura y dinámica. La característica que adopten ambos componentes del concepto, ayudan a dibujar la identidad de un grupo co- residente, en torno a la subsistencia y la reproducción social. En tanto estructura, la organización familiar constituye un campo de posiciones e intereses, que asume a una morfología contingente (histórica social) en el que se articulan las distintas posiciones de sus miembros de un sistema de uso, transferencia y control del poder en torno a actividades cotidianas. En tanto dinámica, la organización familiar va construyendo históricamente determinadas "reglas de juego" en base a las cuales explican la comunicación, el afecto, la insatisfacción, etc. ......la dinámica familiar se estructura en un tiempo y espacio articulando a sus miembros desde el género y la generación"194

Del trabajo de campo surge que el cliente a satisfacer en las instituciones geriátricas es la familia. Y esa satisfacción pareciera que pasa en el intento institucional de suplirla. La imagen que surge es que la ausencia familiar es cubierta con una "todo presencia"

\footnotetext{
${ }^{93}$ GASCON, Silvia y REDONDO, Nélida "Marco de referencia para la programación de servicios integrados de cuidados de larga duración para personas de edad frágiles y dependientes en Argentina, Chile y Uruguay". OPS Dosumento Preliminar Argentina, 2005 (pp.1)

${ }^{94}$ GATTINO, Silvia, AQUIN, Nora "LAS FAMILIAS DE LA NUEVA POBREZA". Espacio Editorial, Bs. As. 1999 (pp. 14/5)
} 
institucional. Institución que regula horarios, lugares, deseos. Y al mismo tiempo se arroga la potestad de mediar en la relación persona mayor - familia.

"Sí, reemplazás a la familia. Porque te dicen: "vos sos como mi mamá, como mi hermana. Yo te quiero, yo te adoro". A las dos, ¿no? Nos abrazan! Una abuela que no está muy bien de la cabeza, pero ella a nosotras nos registra porque... yo cuando la veo muy nerviosa, le digo: "Bueno, vamos al auto Vamos a dar una vueltita". Y la llevo a la casa de mi hija, a ver a mis nietos, porque los familiares están en el campo, vistes? - Eros

Los agentes institucionales construyen un significado particular sobre las familias y este lo ponen de manifiesto a través de diferentes acciones y palabras.

"El otro día le dije vos tenés que entender que tu hija tiene su vida" (Director Médico Geriátrico Marítimo)

"La familia no existe, es muy poca la gente que dice bueno voy, me voy a buscar a mi hermano.... se desentienden completamente, ni llaman por teléfono" (Zeus)

"Las llamadas son esporádicas" .........." A veces ellos piden comunicarse, viste, que tienen sueños que al hijo le pasó tal cosa. Entonces antes que se descompense llamo al hijo y lo hago hablar para que vean que está bien"

"...de vez en cuando, pero vienen, y bueno, algunos vienen una vez al mes. No asiduamente, cada 15 días. (Dionisio)

En la construcción de las actuales instituciones coexisten las formas asilares por lo que el "afuera" institucional no tiene espacio qué ocupar. Y las familias constituyen posiciones de transferencia y control de poder que pareciera que el "viejo" no ocupa. Las reglas de juego que construyen las familias permiten la "expulsión", la salida de la persona mayor. La familia construye un discurso social que valida la decisión del ingreso a un geriátrico. Y el discurso y las prácticas sociales instalan a las familias en un lugar de toma de decisión sin un soporte de política pública que abra las alternativas. Históricamente la práctica asilar estuvo dispuesta para los pobres, viejos y discapacitados por lo que se ha naturalizado esta oferta como la única posible.

Como ya hemos planteado anteriormente en varias investigaciones se ha identificado que las razones de la institucionalización tiene que ver con el agotamiento del cuidador. En general se acuerda que las razones que motivan un ingreso están dadas por el perfil patológico del anciano y básicamente por el desgaste del cuidador. Es decir, en varias oportunidades no sucede una agudización de patología de la persona mayor sino un agotamiento de la familia 0 grupo de cuidado que lo asistía ${ }^{95}$ La tarea de cuidador habitualmente es desempeñada por hijas o nueras, ya que la familia ha construido que esta tarea de asistencia de la persona mayor dependiente le corresponde primordialmente a las mujeres.

Pues entonces, al ser la familia quien toma la decisión de la internación las instituciones establecen como cliente a sastisfacer a las mismas. La familia es una construcción social que responde a variables políticas, económicas, religiosas y culturales. La prestación en hogar geriátrico también es una construcción social que responde a una necesidad que se ha construido y hoy podríamos afirmar que consolidado.

${ }^{95}$ DE LOS REYES, María Cristina "Institucionalización de ancianos y cuidadores familiares". En: Revista margen no 19 año 2000. 
Uno de los entrevistados refiere: "Los podemos criticar pero de última sabemos que posiblemente estén mejor, con todas las falencias que tienen, que en el lugar de dónde ellos provienen. Por el maltrato, por la imposibilidad de asistirlos convenientemente bien, de alimentarlos, de asearlos. En esos lugares por una u otra causa donde algunas veces la gente se ha empujado por necesidades económicas que por vocación, pero la gente le brinda algunas cosas que en la casa no se las brindan" - Fiscalizador

Este planteo vinculado a que el establecimiento brinda "cosas que la familia no brinda" se hegemoniza con frecuencia y lo podemos analizar en términos de "todo presencia institucional". La institucionalización modifica el vínculo con la familia, lo dificulta. Es necesario aprender una nueva forma de vincularse, por lo que se requiere flexibilidad.

"La desvinculación se debe hacer porque el familiar así lo quiere, desvincularse. Es un poco decir al viejo lo dejo ahí y lo veo una vez al mes" Fiscalizador

"Uno quiere mirar los ojos de aquellas personas que miró siempre" Fiscalizador

Podemos enriquecer el análisis con el concepto de madurez filial, entendiéndola como "la disposición de los hijos de dar testimonio de responsabilidad filial" ${ }^{\prime \prime 6}$. Esto nos permite problematizar lo que acontece. Lo retomaremos en el apartado sobre la intervención del Trabajo Social.

"En casa mientras sea posible, en la residencia cuando sea necesario" sostiene una autora española, esto debería ser lo que guíe la política pública. Una de las ciudades que configura el escenario investigado generó una política de vejez. Si bien en la actualidad presenta "altibajos" se viene sosteniendo. Una de las funcionarias me decía: "Ya te digo la ansiedad que trae el familiar cuando llega a pedir la internación es muy alta, con lo cual por eso te digo desandar a veces esta ansiedad y poder empezar a mostrarles este abanico de alternativas, es bastante difícil"

En el desarrollo de una entrevista, la trabajadora social nos decía "Nosotros atendemos la decisión del viejo, la familia es la que demanda pero nosotros sabemos qué intereses debemos defender"

Ese municipio cuenta con el SIPE - Servicio Integral para Personas de Edad- este se trata de una política de orientación prestacional para las personas mayores. Efectuando una intervención interdisciplinaria tendiente a dar respuesta a las necesidades de la persona mayor.

\section{IV - TRAYECTORIA DE LAS PERSONAS MAYORES EN EL NUEVO ESPACIO}

"El hogar es en sí mismo, una expresión del valor de la independencia"

Rubinstein $1989^{97}$

\footnotetext{
${ }^{96}$ FORNOS ESTEVE, Monserrat "La persona mayor en el modelo familiar" Clase dictada en el marco de Programa de Seminarios por Internet Clase no 5 http://psiconet.com/seminarios (pp.30)

97 SANCHEZ SALGADO, Delia "'La vejez y las situaciones cambiantes en la vida". En: GERONTOLOGIA SOCIAL. Espacio Editorial, Bs. As, 2000 (pp. 156)
} 
El hogar, la casa propia, el espacio físico en el que transitamos nuestra vida cotidiana, durante mucho tiempo es el que nos proporciona abrigo y protección configurándose en una expresión de independencia. Cuando se envejece continuar ocupando el mismo espacio sin lugar a dudas será expresión de independencia. Para que esto suceda es necesario un sistema de apoyo y/o sostén adecuado a los requerimientos de las personas mayores. Cuando estos fallan, o no son suficientes se produce la internación geriátrica. Esta es identificada por algunos autores como muerte social "Frente a la destrucción física propuesta por la muerte biológica la muerte social responde con el anonimato, impersonal, la cosificación y la supresión del papel social por degradación." ${ }^{98}$ Aquí podríamos retomar los aportes de Eduardo Menéndez con el concepto de racismo, pero el objetivo de este apartado es recuperar las trayectorias de las personas mayores en este nuevo espacio.

De los relatos y observaciones surge que las personas mayores tras haber transitado el rito de pasaje, comienzan a reconocerse en este nuevo lugar. Se produce un proceso de apropiación del espacio. La dinámica institucional pareciera que ya tiene un lugar pre asignado para la persona mayor, pero como lo social es dinámico, complejo y contradictorio acontecen otras cosas.

Por un lado en los geriátricos observamos la presencia de población dependiente, por lo que como ya he planteado anteriormente nos generaba ciertos interrogantes. Esto llevó a elaborar la idea de construcción de una biología particular de las personas mayores institucionalizadas. Comenzamos a trabajarla cuando sistematizábamos las crónicas de las observaciones efectuadas en el desarrollo del trabajo de campo. Encontraba cierta regularidad en la disposición de los cuerpos en las instituciones, en los movimientos acotados que presentaban los mayores y en el silencio. No es extraño ingresar a un hogar y ver a personas sentadas alrededor de una mesa sin hablarse durante horas. Tampoco nos asombra que una persona esté sentada en el mismo sitio desde las 8 de la mañana hasta las 13 , hora en que la llevan a dormir la siesta y vuelva al mismo sitio por 5 horas más. A los agentes sociales que trabajan en las instituciones no les sorprende que una persona que ingresó caminando a los pocos meses ya no lo haga y lo mismo con el control de esfínteres. Pareciera que es natural que los cuerpos que habitan los geriátricos sean poco flexibles, que requieran de otro para el desarrollo de las actividades de la vida diaria y que hablen poco. El deterioro es innegable durante la vejez, pero existen prácticas que pueden retardar la aparición de la dependencia.

"Una persona que se aburre experimenta como un vacío interior y una tristeza sin objeto concreto que describe a menudo manifestando que "el tiempo no pasa aprisa" o que "los días son largos". Estas expresiones populares son exactas; expresan bien lo que es en realidad el tedio como experiencia vivida. El tedio, el fastidio, es un sentimiento que resulta de una alteración de nuestra relación subjetiva con el tiempo.

El tedio puede definirse como un sentimiento de reducción del movimiento del tiempo. En el límite, está la muerte que se percibe como la absoluta detención del movimiento del tiempo. ${ }^{\prime \prime 99}$

Los discursos que recogí en referencia a la poca movilidad de "los cuerpos" están cargados de cuestiones vinculadas al cuidado y al temor de las caídas. Pues entonces la práctica habitual es la de "sujetar", "contener", es decir atar a la persona a la silla, a la

\footnotetext{
${ }^{98}$ MUTUSDEVICH "Envejecimiento o institucionalización geriátrica". En: ENVEJECIMIENTO Y VEJEZ. Editorial Atuel, Bs. As. 1998 pp. 123

${ }_{99}$ LAFOREST, J "'Crisis de pertenencia". En: INTRODUCCIÓN A LA GERONTOLOGÍA. Editorial Herdes, España, 1991 (pp.160/1)
} 
cama. Esta contención varias veces no es supervisada por ningún profesional, es más la decisión no fue tomada con un criterio "técnico", "científico".

"si se cae es peor, se puede quebrar la cadera y sufren muchísimo. Además después hay que aguantar al familiar" -

\section{Enfermera de geriátrico Marítimo (nota de campo)}

Normativamente correspondería que frente a la decisión de "contener" a una persona debe existir un criterio médico que lo justifique y el mismo debe estar documentado, es decir asentado en la historia clínica. Debe estar pautado de antemano cada cuánto tiempo se va a "desatar" a la persona, acompañarla al baño, ayudarla para que camine, etc

Volviendo al tema de los pocos movimientos, a esta espacie de quietud inherente a la cotidianeidad de los geriátricos podemos observar lo nocivo que es la pérdida de masa muscular para los mayores. No ejercitar la marcha y la movilidad implica una pérdida de funciones que varias veces son irrecuperables.

Todo indica que las prácticas de los geriátricos no son azarosas, pareciera que se busca orientar al viejo para que ocupe una posición de pasividad, de inmovilidad cligadas a lo inerte?

"La sobre prestación no sólo puede constituir un abuso moral o simbólico al subvaluar las capacidades de las personas para controlar por si mismas sus vidas y decidir sobre sus actos, también resulta un gasto ineficiente e irracional..." ${ }^{\prime 100}$

La imagen que intentamos transmitir de la cotidianeidad vinculado a lo inerte, el silencio puede ser modificado. El autor citado plantea que el tedio es causado por carencia de estímulos adecuados por lo que las prácticas institucionales pueden ser modificadas.

Por otro lado, si bien planteamos que lo asilar es constitutivo de las prácticas institucionales, no es lo único. Como ya se sabe no todas las personas envejecemos de igual forma, por lo que existe una distribución desigual y diversa de las formas de envejecimiento. Para algunas personas mayores la institucionalización es vivida como una tragedia en cambio para otros es una oportunidad, el inicio de un nuevo proyecto de vida.

Un punto revelador de este complejo proceso es el tema de las salidas al exterior, al afuera institucional. Algunos autores refieren que cuando pasa mucho tiempo sin que la persona salga de la institución se produce una "situación de extrañamiento y temor que hace que al viejo le sea cada vez más difícil trasponer el umbral de la institución." ${ }^{\prime 101}$

Pero por otra parte a nivel discursivo los residentes plantean que no desean salir. El salir los enfrenta a ratificar el desplazamiento "social". Si van a su casa observan como su habitación fue desarmada, cómo sus muebles fueron desechados (vendidos, tirados, etc). Si salen a cobrar son sometidos a los tiempos escasos del familiar por lo que los llevan corriendo, aprisa, sin respetar sus tiempos. El salir de la institución los expone a recrear el duelo, a re transitar el rito de pasaje. El desafío es que las salidas dejen de ser una

\footnotetext{
${ }^{100}$ GASCON, Silvia y REDONDO, Nélida MARCO "Marco de referencia para la programación de servicios integrados de cuidados de larga duración para personas de edad frágiles y dependientes en Argentina, Chile y Uruguay". OPS Dosumento Preliminar Argentina, 2005 (pp.4)

${ }^{101}$ MUTUSEVICH op. Cit (pp. 130)
} 
excepción, que las instituciones tengan un programa articulado de salidas, que la institucionalización no sea impedimento para el consumo de bienes culturales (ir al cine, al tetro, a pasear, etc). Esto lo podemos relacionar con los aportes de Antequera-Jurado y Blanco Picabia ${ }^{102}$ sobre los motivos que permiten dar cuenta de las causas del descenso del autoconcepto de los ancianos cuando son institucionalizados: disminución del sentimiento de poder controlar sus vidas; interpretación de la institucionalización como demostración de rechazo y la institucionaización como el momento de enfrentamiento con la propia muerte.

"E.2: No, porque no hay abuelos como para sacarlos a todos juntos, entendés? iHay abuelos que no quieren salir afuera!, que van a decir: "Yo de acá no me muevo". Y no se mueven, viste? Están los otros que se los llevan el hijo o la hija todo el fin de semana.

\section{E.1: Hay algunos que se los lleva el familiar y les hace mal.}

E.2: Les hace mal. Después están unos días mal. No les hace bien.

\section{P.: Qué, por la sensación de que tuvieron que volver o que?}

E.2: Y sí...los pone mal, porque ellos quieren estar con su familia. Y te lo dice el abuelo: Yo estoy muy bien acá y me atienden muy bien. Estoy recontento!, pero yo quiero estar con mi hijo!". Y es entendible. Y te explica para que no te ofendas que no es el lugar, ni como la tratan...

\section{P.: Si no que quiere estar en el lugar que estuvo toda la vida.}

E.2: Exactamente! Es entendible lo que dicen, pero les hace mal. Por ahí van una semana al campo, por ejemplo, y cuando vuelve, después llora y llora.

\section{E.1: No, a parte dicen disparates...}

P.: A parte se desubican con el tiempo y el espacio...

\section{E.2: Sí, si... (EROS Hogar Amoroso)}

En el punto II E planteábamos la situación de varios residentes y los estrechos vínculos que establecen con el personal y con sus co - habitantes. Decíamos que esto se configuraba en algo fundamental ya que implicaba el reconocimiento de las prácticas del otro, la escucha de la palabra del otro, el sentirse escuchado y la certeza de la mirada que cuida. Y por sobre todo el reconocimiento que la capacidad de aprendizaje y de amor no se extinguen y que a pesar de haber cambiado sus condiciones materiales de vida pueden generar otras prácticas.

Creemos que es necesario incorporar al análisis una referencia a la sexualidad de las personas mayores. Esto obviamente no es algo dicho en el discurso institucional y es más, pareciera que no es algo que acontezca. "La situación de los geriátricos carga con los estigmas de la asexualidad atribuidos a la vejez. Uno de los sentidos más fuertes que

102 ANTEQUERA-JUARADO, Rosario; BLANCO PICABIA, Alfonso "Percepción de control, autoconcepto y bienestar en el anciano". En: SALVAREZZA, Leopoldo (Comp) LA VEJEZ: Una mirada gerontológica actual. Editorial Paidós Bs. As., 1998 (pp. 106) 
emergen en relación a esta temática es la falta de derechos sexuales dentro de esta institución"103

"Desde el psicoanálisis, la sexualidad es el eje a partir del cual se conforma lo subjetivo. Según la formulación adoptada por Lacan, el sujeto "es" en su relación al deseo". ${ }^{104}$ En el trabajo de campo recuperé algunas referencias a la cuestión de la sexualidad, a saber.

"P.: Claro. Y me quedé pensando...el tema de la sexualidad? De los varones? ¿Notan diferencia con las mujeres? [unos segundos de silencio]

E.1: No...se habla.

E.2: No...con las chicas se hablan.

E.1: Todo en broma, ¿vistes?

P.:Ah...

E.2: Sí, sí. Porque por ahí a uno cuando lo van a acostar, una se le acuesta en el costado y le dice: "te voy a violar, te voy a hacer esto...". Y el otro le dice: Por qué no venís acá? Y la otra le dice: "Bueno. Dale", y entonces se empieza a desprender el pañal. Por ejemplo, al que lo cargan tiene sonda. - Eros

Las prácticas aparecen erotizando al otro envejecido. Un dato a tener en cuenta es que esto acontece en un geriátrico clandestino, de igual forma creemos que estas prácticas también son constitutivas de la vida cotidiana de los geriátricos habilitados.

"Diversas investigaciones apuntan a mostrar una noción de la sexualidad más rica en tanto no se limita a la genitalidad, sino que se asocia a la búsqueda de placer y de afecto, lo que recupera un sentido más abarcativo al erotismo" ${ }^{105}$

"E.2: ...como pasan las abuelas, porque son vagos viste?

E.1: ríe.

E.2: Entonces cuando pasan las abuelas...

E.1: (la interrumpe) La que es pechugona, la que es...

P.: ríe.

E.2: Ellos ven todo...

P.: Las piropean o...?

E.2: No! Las miran y después les dicen a las chicas, viste?

${ }^{103}$ IACUB, Ricardo "De los mitos a los goces. El pluralismo sexual" En: ERÓTICA Y VEJEZ. Editorial Paidós. Bs. As. 2006 (pp. 182)

${ }^{104}$ IACUB, Op cit. Pp 157

${ }^{105}$ IACUB, op cit, 169 


\section{E.1 [habla riendo] Mandan los mensajitos..." Eros}

La vida cotidiana de estas instituciones conlleva prácticas de erotización. Al mismo tiempo que las personas mayores son "cosificados" y pensados como meros cuerpos a conservar despliegan estrategias de seducción y arraigo.

"En las piezas no hay intimidad. El abuelo que está al lado del que usa pañal vé cómo le cambian el pañal al otro" Trabajadora Social Hogar Guerrero

\section{E.1: ... y la abuelita de cien años y el abuelo N?}

E.2: (la interrumpe) Está enamorada la abuela!

E.1: (se ríe) Él mide como dos metros y ella es petisita. Y cuando pasa para su habitación pasa por un pasillito donde están los abuelos. Pero si vieras con que encanto lo saluda! Es tan amorosa! "Hasta mañana" [la imita]

\section{P.: Y él le da bolilla?}

\section{E.1 y E.2: [en simultaneo] Sí, sí.}

E.1: Es muy respetuoso! La saluda: "Hasta mañana". Entonces las chicas le dicen: "Que pasa si esta noche se te aparece?". "Y...le hago un lugarcito" [ríen todas] Así dice. EROS

"Hay un noviazgo. Es entre Dora y Enrique: había otro entre Josefa y Pepe, pero Pepe falleció" Trabajadora Social Hogar Guerrero

Pues entonces, la institución geriátrica puede configurarse en una institución total pero esto no es inexorable. Seguramente el tránsito por estas nuevas condiciones materiales de vida va a depender del capital social que posea la persona mayor, de las experiencias vividas previamente, de cómo haya transitado su sexualidad, de cual haya sido su posición en el espacio social.

\section{$V$ - CASOS PARADOJALES ${ }^{106}$}

Aquí presentaré algunos de los casos que a mi juicio son paradojales. Paradójico en tanto situación de orden material, investido de un significado particular, que envuelve contradicción.

La historia de Nelly es paradojal porque nos presenta el discurso y las prácticas que se construyen en las instituciones, es decir la contradicción en el proceso de construcción del otro envejecido y el rol del estado.

"La historia mía comienza cuando esa asistente social me llama para decirme qué tenía una pacientita así, así, con una demencia moderada; si me interesaba. Este es el papel del

\footnotetext{
${ }^{106}$ Todos los nombres de las personas mayores fueron modificados en pos de preservar su identidad.
} 
policlínico (me lo exhibe), tiene la fecha de cuándo me la traje. La estuvieron por internar en Romero, pero no había lugar. Pero las asistentes sociales del Policlínico no sé como hicieron para saber que era Nelly. . E incluso le tramitaron el documento y el carnet de IOMA. Todo eso hicieron las asistentes sociales del policlínico. Entonces tuvimos una reunión para saber que hacer con esta señora y me dijeron yo sé que a vos te gusta la psiquiatría, la vas a saber manejar, tiene un ingreso de $\$ 600$. Y ya vinieron con el carnet de IOMA y todo, y me dice vas a tener que tratar con el Tribunal de Familia $N^{\circ} 2$.

Bueno, este y pero te tenés que ocupar de todo alimentación, alojamiento, trato afectivo porque esta mujer está sola, y no hemos podido contactarnos con ningún familiar, viste gracias que pudimos sacarle esto. Bueno, entonces yo agarro y presento en el Tribunal de Familia la nota viste, fulano de tal ingresó al hogar en fecha tal. $Y$ me dice, cobraba 550 era pensá la paridad eran 550 dólares. Ahora me sigue pagando 550. Ja, jas! 550 para alojamiento atención médica, vestido, medicamentos, todo. $Y$ bueno, presento, ingreso armo un expediente y me presento a ver si estaba el cheque $y$ nunca estaba. Entonces, la nota la había hecho yo. Y entonces me voy a mi abogado, Dr. Masa andá a averiguar qué pasa yo necesito la plata. $Y$ Nelly seguía recuperando poco a poco. Pobrecita, pobrecita, mirá esa Nelly. . Después que averigua mi abogada, no me iban a pagar nunca porque estaba declarada por muerta. Entonces, había que desarchivar el expediente, demostrar que estaba viva. No sabes lo que trabajó y lo que yo pagué de mi plata. Y tardó mucho, tarde como tres años y me pagaron todo junto. "DIONISIO ${ }^{107}$

Por un lado aparece esto de ofrecer un "pacientito", desdibujándose condición de ciudadano de la persona mayor. Por otro aparece una institución geriátrica privada asistiendo por 3 años a una persona sin remuneración y el estado no dando otras respuestas. En este mismo sentido aparece el caso de María Clara. El estado no dando respuestas y las instituciones privadas otorgándolas. Seguramente el fin de estas no es altruísta y de una u otra manera le conviene, pero ¿no es paradójico que sea el sector privado el que termine defendiendo los derechos de las personas mayores que alberga? ¿O tal vez lo paradójico es que el Estado sea el que vulnere los derechos?

"Y también tenemos casos de gente que ha quedado sin cobertura. Nosotros tuvimos un caso que es María Clara. . Falleció, el familiar nunca, nunca aportó de los pañales. Yo en un momento me cansé y me fui hasta Las Flores a buscar al hijo. Y bueno, me vine a enterar que tenía una hija ee que estaba internada en la San Juan y que había sido internada a los 18 años y que ahora tiene 50. Y que .. la primera internación la hizo en (.........), ahí fue violada, tiene una hija de 22 años y yo cometí la estupidez de decir que para que conociera a la hija la conociera en este lugar. Entonces Susana se encargó de buscarla, eee, para decir bueno, planteamos el caso porque esa persona en su momento iba a ser derivada a Romero porque habían perdido la prestación. La mamá había fallecido y la gente de Pami no le supo hacer el trámite de la pensión. Io iniciamos con Luis después Nadia se reintegró. Le dije mirá Nadia tenemos que dedicarle con todo a obtenerle la obra social Pami pero primero tenemos que completar el trámite del Anses. Tuvimos que hacerle discapacidad, tuvimos que mandar al médico porque le dio el $70 \%$. Le hicimos todo el trámite del Anses, metimos la discapacidad del $70 \%$, obtuvimos la obra social. Ahora queremos la, digamos, la internación geriátrica. Porque desde el 22 de setiembre del año pasado está a "cargo mio"???. Cuarenta y ocho, 49 años. Esas son, para qué sirve esto. Bueno, va el que se toma el trabajo a pecho. A la gente de Pami le molesta (POSEYDON) 
También aparece este tema, que ya fue analizado, sobre el rol del Estado en la configuración de criterios de admisión.

"Lleva tanto el trámite de, de pedir un traslado el único que hemos logrado como excepción de un cuadripléjico que le tuvimos que dar, que nos cayó 42 años, se había separado de la mujer, el hijo tuvo un brote psiquiátrico, el quedó cuadripléjico, pero claro, 42 años entonces el Rossi en un momento dado dijo "necesito la cama". Bueno, y ha dónde y los estúpidos del Marítimo. Entonces tenía una alimentación nasogástrica, toda la alimentación iba por sonda, la medicación iba por sonda, entonces había que permanecer, mantener los conductos limpios durante todo el día , porque con la medicación se le podía .. Entonces la gente del Hospital Rossi decía que era cuestión de preparar alimentación clara de huevo, no sé tal cosa, eh, cuando ellos por ahí le daban el preparado especial acá nos aconsejaban que nosotros le hiciéramos cualquier cosa, pero ellos por las dudas usaban el del laboratorio. Entonces, dije nosotros no estamos en condiciones de hacer ese tipo de trabajo. $Y$ bueno, mientras elevábamos eso y que fuera un centro de rehabilitación y todo pasó 4, 5 meses. Es el único caso que conseguimos derivar, pero mientras tanto lo tuvimos que tener acá. La persona empezó después a hablar, recuperó el habla, eh, porque hay cosas que el ,mismo organismo reacciona en base al trato que tiene. Eh. Eh .... se encuentra entre pares y claro, no se manda tanto la parte, es más la persona. POSEYDON

Podemos afirmar que la prestación brindada en los hogares geriátricos en varias oportunidades pone en evidencia la "ineficacia" del estado. O tal vez la falta de coordinación entre las múltiples tomas de posición del estado frente al envejecimiento.

Y aquí queremos compartir una obra de Galeano ${ }^{108}$ llamada "Paradojas" que sintetiza el objetivo por el que trabajamos este punto:

"Si la contradicción es el pulmón de la historia, la paradoja ha de ser, se me ocurre, el espejo que la historia usa para tomarnos el pelo.

Ni el propio hijo de Dios se salvó de la paradoja. Él eligió, para nacer, un desierto subtropical donde casi nunca nieva, pero la nieve se convirtió en un símbolo universal de la Navidad desde que Europa decidió europear a Jesús. Y para más inri, el nacimiento de Jesús es, hoy por hoy, el negocio que más dinero da a los mercaderes que Jesús había expulsado del templo.

Napoleón Bonaparte, el más francés de los franceses, no era francés. No era ruso José Stalin, el más ruso de los rusos;y el más alemán de los alemanes Adolfo Hitler, había nacido en Austria. Margherita Sarfatti, la mujer más amada por el antisemita Mussolini, era judía. José Carlos Mariátegui, el más marxista de los marxistas latinoamericanos, creía fervorosamente en Dios. El Che Guevara había sido declarado completamente inepto para la vida militar por el ejército argentino.

De manos de un escultor llamado Alejandrinho, que era el más feo de los brasileños, nacieron las más altas hermosuras del Brasil. Los negros norteamericanos, los más oprimidos, crearon el jazz que es la más libre de las música. En el encierro de una cárcel fue concebido Don Quijote, el más andante de los caballeros. Y para colmo de paradojas, Don Quijote nunca dijo su frase más celebre. Nunca dijo: Ladran Sancho, señal que cabalgamos.

108 GALEANO, Eduardo "Paradojas". En: EL LIBRO DE LOS ABRAZOS: Editorial Catálogos, Bs. As, 2003 (Duodécima edición argentina), pp.114/5 
"Te noto nerviosa" dice el histérico. "Te odio" dice la enamorada. "No habrá devaluación" dice, en vísperas de la devaluación el ministro de Economía. "Los militares respetan la Constitución", dice, en vísperas del golpe e Estado el Ministro de Defensa.

En su guerra contra la revolución sandinista, el gobierno de los Estados Unidos coincidía paradójicamente con el Partido Comunista de Nicaragua. Y paradójicamente habían sido, al fin y al cabo, las barricadas sandinistas durante la dictadura de Somoza: las barricadas que cerraban la calle, abrían camino"

Siguiendo a Galeano nos preguntamos ¿A quién le toma el pelo la historia con las paradojas presentadas? ¿Quién se debería sentir interpelado?

\section{VI - CARACTERIZACIÓN DE LOS PROPIETARIOS Y LAS INSTITUCIONES}

En este punto identificaremos en primer lugar a los propietarios de geriátricos que funcionan sin habilitación, clandestinos, por fuera del control estatal y por otro a los propietarios de los emprendimientos que funcionan con habilitación.

Los propietarios de los "clandestinos", generalmente son mujeres, jefas de hogar. Obviamente no eran jefas de cualquier hogar sino que pertenecían a estas familias que la literatura sociológica llama nuevos pobres 0 pauperizados. $Y$ los establecimientos clandestinos eran casas que condensaban en su estructura la historia de una clase obrera que alguna vez ejerció derechos y tuvo la posibilidad de movilidad social. En la conformación de los hogares "clandestinos" encontramos y analizamos la centralidad del trabajo.

En la constitución de los hogares por parte de familias pauperizadas subyace la búsqueda de trabajo. Trabajo entendido como base de sustento para la reproducción, como posibilidad de objetivación del hombre a través de sus obras, de sus productos. En este caso la obra versa sobre cuidar a ancianos. Estos hogares albergan a aquellos ancianos que cuentan con un ingreso mensual, sea esta jubilación, pensión por viudez, pensión no contributiva, subsidio por alta psiquiátrica, etc. Todos las formas de ingreso mencionadas implican una retribución de \$200 a 470 por lo que estos ancianos engrosan las filas de la pobreza e indigencia. A esta población les ha sido negada la cobertura por parte de la obra social, a la que aportan, del servicio de albergue. Con esto queda graficado fielmente que la población asistida por los hogares "clandestinos" son aquellos que quedan por fuera de la cobertura de las políticas sociales específicas.

En algún momento del desarrollo de la tesis habiamos optado por no denominar a los hogares que carecen de habilitación sanitaria provincial como clandestinos, ya que creía que esto impedía constituir una mirada amplia que escape a la disyuntiva legal / ilegal. Los denominamos hogares sustitutos ya que creimos que efectivamente eran una alternativa de albergue para los adultos mayores, que conserva los rasgos propios de una casa familiar. Pero con el desarrollo del trabajo de campo y del proceso analítico advertimos que en el devenir institucional se ejercen prácticas asilares tendientes a la conservación de cuerpos. Y que nominarlas como "clandestinas" me permite afianzar en el plano discursivo la "fuerza del problema".

En estos tiempos de globalización de la economía, flexibilización laboral, desempleo estructural, políticas sociales focalizadas surge como alternativa para muchas jefas de 
familias (la mayor parte son mujeres) iniciar un emprendimiento productivo vinculado al cuidado de ancianos. Casi siempre se trata de mujeres pertenecientes a las ex clases medias, con maridos o compañeros que han sido excluidos del mercado de trabajo y con pocas posibilidades de re ingreso al mismo. Estas mujeres se reconocen trabajadoras apelando a un rol que siempre les fui atribuido (cuidar al débil, asistir). Por lo tanto esta situación está también fuertemente atravesada por la cuestión de género.

"La informalización del trabajo no solo significa menores ingresos sino también - dada la relación entre empleo y seguridad social - falta de protección mediante las instituciones de la seguridad social." ${ }^{109}$

En este sentido se puede afirmar que los propietarios de estos emprendimientos familiares se ubican en un espacio de alta vulnerabilidad, no solo porque carecen de cobertura previsional sino que ejercen una actividad que es considerada ilegal. En contrapartida señalamos que en varias oportunidades estos sujetos contratan a otros trabajadores para que colaboren en el desarrollo de las tareas inherentes al albergue de los ancianos. La contratación obviamente es informal, irregular, es decir ellos explotan a otros trabajadores. Cabe indicar que en general las trabajadoras que se desempeñan como sub empleadas (sin cobertura social, ni previsional) son consideradas como inempleables, población sobrante para el mercado formal de trabajo.

Asimismo es necesario encuadrar estas prácticas en los procesos de mercantilización que evidencia el campo de la salud. Los ancianos que residen en instituciones privadas de larga estadía garantizan con su cuerpo la rentabilidad. Una mayor renta se obtiene si se reducen costos, una manera es acortando la cantidad de personal, reduciendo la calidad y cantidad de alimentos dispensados y sobre - facturando los servicios brindados. Pero, por sobre todas las cosas, la rentabilidad será garantizada a largo plazo por lo que la mejor manera es conservando a los "clientes".

".. la cultura médica y curativa también sucumben al lenguaje de los negocios.. Pues la nuestra es la cultura de los negocios, que pone al negocio como el objetivo de la cultura"110

Las propietarias de los hogares sustitutos plantean abiertamente que la garantía de su emprendimiento reside en que "los viejitos no se mueran". Saben que lo que garantiza sus ingresos es la conservación.

"... esto sólo es posible en una sociedad donde la forma de mercancía es la forma general que adopta el producto del trabajo, y donde, por consiguiente, la relación entre unos y otros hombres como poseedores de mercancías se ha convertido, asimismo, en la relación social dominante." ${ }^{111}$

Con esto queda expresado claramente el grado de vulnerabilidad en el que se hallan los adultos mayores institucionalizados. Aquí surge otra paradoja ya que se trata de una actividad ilegal vinculada al bienestar de los adultos mayores.

\footnotetext{
${ }^{109}$ AUYERO, Javier LA POLÍTICA DE LOS POBRES. Editorial Manantial. Bs. As. 2001 (pp. 57)

110 TAUSSIG, M. "La reificación y la conciencia del paciente". En: Un gigante en Convulsiones: el mundo humano como sistema nervioso en emergencia permanente. Editorial Gedisa. España. 1992 (pp. 135)

${ }^{111}$ MARX, Karl "Mercancía y dinero". En: EL CAPITAL. TOMO I. LIBRO 1. Editorial Siglo XXI Editores Argentina S.A. Bs. As. 2002 (pp. 74)
} 
Queda evidenciado que estamos en presencia de varias manifestaciones de la cuestión social, ya que son los ancianos los que ameritan asistencia urgente por parte del estado pero también los "ilegales" emprendedores también son "merecedores" de política social.

Los hogares sustitutos desarrollan una actividad mano de obra intensiva, con una división del trabajo sumamente simple o nula. Son un emprendimento familiar centrado en el desarrollo de trabajo por parte de las mujeres jefas de hogar en el que varias veces desarrollan todas las tareas, siendo esto riesgoso ya que en general no se cuenta con la capacitación adecuada.

En segundo lugar presentaramos algunas reflexiones sobre la particularidad de los propietarios de los geriátricos que configuraron la muestra de la investigación. No es pretensión de esta producción realizar generalizaciones sobre el particular, ya que el diseño de la investigación no lo permitiría. De igual forma creo que aportará a la comprensión del escenario.

Cómo ya había mencionado efectuamos observaciones en 18 geriátricos de gestión privada radicados en los distritos de la plata y Chascomús. Y efectué entrevistas a agentes de esas instituciones, de fiscalización y de las residencias de gestión municipal.

Los establecimientos que configuraron la muestra fueron:

\begin{tabular}{|r|l|l|}
\hline \multicolumn{1}{|c|}{$\mathbf{N}^{\mathbf{1}}$} & \multicolumn{1}{|c|}{ NOMBRE PARA TESIS } & \multicolumn{1}{c|}{ PROPIETARIO PARA TESIS } \\
\hline 1 & BELLO HOGAR & AFRODITA \\
\hline $\mathbf{2}$ & HOGAR AMOROSO & EROS \\
\hline 3 & HOGAR CAZADOR & ARTEMISA \\
\hline 4 & HOGAR ARTÍSTICO & ATENEA \\
\hline 5 & HOGAR TITÁNICO & CRONOS \\
\hline 6 & HOGAR CEREALERO & DÉMETER \\
\hline 7 & HOGAR PROFÉTICO & APOLO \\
\hline $\mathbf{8}$ & HOGAR VINICULTOR & DIONISIO \\
\hline 9 & HOGAR TERRESTRE & GAYA \\
\hline 10 & HOGAR DE CACOS & HERMES \\
\hline $\mathbf{1 1}$ & HOGAR MARÍTIMO & POSEIDÓN \\
\hline 12 & HOGAR CELESTIAL & URANO \\
\hline $\mathbf{1 3}$ & HOGAR SOBERANO & ZEUS \\
\hline 14 & HOGAR MADRECITA & REA \\
\hline 15 & HOGAR SOMNOLIENTO & HIPNOS \\
\hline 16 & HOGAR PROTEGIDO & HESTIA \\
\hline 17 & HOGAR FÉRTIL & HERA \\
\hline 18 & HOGAR CELESTIAL & SATURNO \\
\hline 19 & HOGAR GUERRERO & MINERVA \\
\hline 20 & HOGAR DESEOSO & VENUS \\
\hline
\end{tabular}

De los datos obtenidos surge que varios de los propietarios de los geriátricos presentan "fragilidad relacional" y muchas veces el vínculo más fuerte que poseen es con el personal 
de la institución y con los residentes. Este vínculo no es horizontal sino que obviamente aparece una relación asimétrica que en algunas oportunidades opera y en otras se desdibuja.

En el caso de Afrodita es una trabajadora de la salud con más de 20 años de experiencia, actualmente y desde hace más de 5 años trabaja exclusivamente en el hogar. Vive en un departamento al fondo del mismo y de acuerdo a lo manifestado por ella no sostiene una vida social activa. Podríamos decir que Afrodita está institucionalizada, asilada tanto como los residentes a los que "cuida".

"Vos no podés estar 24 horas, tres personas viviendo con los abuelos y no me digas que los podes atender bien, porque no es así. Yo viví dos años y medio con los abuelos, y ... me hizo mal. Llegó un momento que era eso nomás, y no ves otra cosa. Perdés hijos, perdés nietos, no disfrutás nada, porque era todo ahí. ¿ Vistes? i No se puede atender bien! Entonces ahí van a hacer dinero, porque todo lo que entran, no tienen ningún gasto." (EROS)

Eros son dos mujeres familiares entre sí que comenzaron con la tarea de "cuidar abuelos" hace 10 años, el trabajo era efectuado exclusivamente por ellas dos solas. Una de las dos decidió comenzar con esta actividad tras quedar viuda, refiere que era en el único momento que no estaba angustiada. Actualmente las dos se han desvinculado un poco del cotidiano y han contratado personal (sobrinas y otros familiares suyos) para la atención de los residentes. De igual forma aperece la relación entre ellas dos como el vínculo más significativo que poseen.

E.2: "Somos primas, pero nunca nos separamos. Vivimos muy...bueno, después se dio que trabajamos juntas, pero siempre estuvimos juntas. $Y$ ahora, bueno, separarnos ni locas porque...como que todo. Cada una se va de vacaciones y yo ya no sé que hacer cuando se va de vacaciones...

\section{E.1: (la interrumpe) iSe pone loca!}

E.2: ...en las vacaciones me pongo re mal....

[Paula ríe]

E2.: ...porque como que me falta! Es como...no sé si a ella le pasa lo mismo, pero a mí me falta ella. Es el apoyo, ¿vistes? Cualquier cosa que pasa ella tiene que estar cerca mío o saber. Aparte nos llevamos bien, por que, Porque todo lo consultamos. Ahora que se hizo más grande, hay más problemas. " (EROS)

"E.2: Yo lo que tengo del hogar es...satisfacción. Sentirme realizada. Haber hecho algo...y estar haciendo por alguien...Muchas cosas hemos hecho con ella. Ahora que están las chicas hay ciertas cosas que no. Pero el comprar algo para la casa de los abuelos...vamos a cobrar y a pagar y se nos ocurre...!Ay, es una satisfacción!" (EROS)

Atemisa comenzó a trabajar porque se le presentó una oportunidad. Ella refiere que la convocaron para cuidar a una señora que tenía una casa grande y ella les propuso que en lugar de pagarle un sueldo le presten la casa para cuidar a otras personas mayores. Así comenzó, actualmente tiene albergadas a 10 personas. Algunos son adultos mayores y otras personas con discapacidad mental. Una de las características de Atemisa es que emprende 
varios "negocios" al mismo tiempo por lo que además de "administrar" un hogar posee una "feria tipo americana", un vivero, etc.

Atenea comenzó con la actividad hace 7 años, comenzó en una casa con serias falencias y trabajó esforzadamente para adecuarla. Con el desarrollo de esta actividad solventaba los gastos de toda su familia. Después de lograr poner medianamente en condiciones la casa, el propietario del inmueble le rescindió el contrato por lo que tuvo que cerrar. Intentó continuar con la actividad en otra casa y finalmente desistió.

Cronos es el titular de un geriátrico habilitado, no es una persona con formación gerontológica, ni de salud. El hogar lo administra como cualquiera de sus otros negocios reduciendo costos y maximizando ganancias. Está vinculado a sectores políticos locales por lo que en varias oportunidades ha albergado en el hogar a familias sin recursos derivadas por la Municipalidad, mezclados con los residentes del hogar.

Démeter es una ex trabajadora sexual que ayudaba a su madre en el desarrollo de tareas vinculadas al cuidado de personas mayores. Posteriormente decidió independizarse y generó su propio emprendimiento. Intentó adecuarse a la normativa vigente, pero nunca lo lograba. Asimismo al carecer de formación adecuada, pareciera que no podía discernir entre cuestiones importantes y aleatorias. Durante el desarrollo del trabajo de campo otros entrevistados hicieron referencia a que Démeter alquilaba las habitaciones del hogar que eventualmente tenía desocupadas para ser utilizadas por parejas como "casa de citas". Desde el Ministerio le otorgaron plazos para su adecuación y finalmente en el mes de Julio 2005 fue Clausurado.

Apolo es una sociedad familiar propietaria del geriátrico hace muchos años. Funciona en un edificio en el que había funcionado una clínica hace 30 años. El lugar es funesto, ediliciamente malo, sucio. Son varios hermanos y cuñados, aproximadamente 10 personas. Desde el Ministerio siempre se ha intentado Clausurarlo pero nunca se efectiviza.

Dionisio es una profesional, médica. Funcionó en forma clandestina por 15 años, actualmente su establecimiento está habilitado. No posee vínculos extra - muros, sus únicos lazos son con los residentes y el personal. Posee familia pero no tiene trato, aparentemente originado por su problema de alcoholismo.

"Viste que no estaban López y Córtez. Sabía que a Córtez lo habían llevado este, a un geriátrico donde no conocía a nadie y que iba a pasar el 24 y 31 con gente desconocida, lloraba. Lloraba madre, menos mal que me lo trajeron. Y por el otro señor también, vá más lo quería a López porque a López lo veo más desprotegido. " Dionisio

Gaya es una señora de 50 años de edad. Funciona en forma clandestina hace más de 15 años. Hace caso omiso a todas las exigencias que viene recibiendo. Incrementa constantemente el número de camas, no respeta un menú acorde a las patologías que padecen los mayores o ella misma. También presenta fragilidad relacional, el vínculo más estable con el que cuenta es el que genera con el personal de la institución y con los residentes.

Hermes es un hombre de unos 35 a 40 años. Posee tres establecimientos geriátricos. A uno de ellos lo está adecuando de acuerdo a la normativa vigente, tramita su habilitación ante el Ministerio de Salud y la Municipalidad. Pero a la fecha no ha obtenido autorización de funcionamiento. Los otros dos son más precarios, no respetan ninguna 
norma. De estos últimos, uno es administrado por su pareja actual, un hombre de unos 30 años. El otro es "dirigido" por una señora de unos 60 años a la que él llama tía.

Poseidón es un empresario, profesional. La firma es una sociedad familiar, aunque en realidad el que toma las decisiones es este profesional. La institución posee convenio con el INSSJyP desde hace aproximadamente 15 años. Este señor posee una relación sumamente conflictiva con su familia y cuándo estos llegan a un punto significativo él se va a dormir al hogar.

Urano es otra institución que posee convenio con el INSSJyP, también desde hace aproximadamente 15 años.

Zeus es una señora de 50 años de edad, propietaria de una casa con "convenio" con la Curaduría General de Alienados. Es una paciente psiquiátrica, actualmente compensada. $\mathrm{Ha}$ incorporado a sus residentes a la dinámica familiar o tal vez ha incorporado a su familia a la dinámica institucional.

Rea es una empresa que posee vínculo contractual con el INSSJyP. Quizá como característica común a las instituciones con convenio con el Instituto se trata de una sociedad familiar. Tras 15 años de convenio las 3 instituciones están en proceso (más o menos conflictivo) de traspaso a sus hijos de las responsabilidades.

Hipnos es un señor de unos 55 años que posee la institución hace 10 y no hemos recuperado mayor información sobre él.

Hestia es una sociedad familiar, pero dirigida funcamentalmente por una profesional con una vasta trayectoria en el campo gerontológico. La institución funciona desde hace más de 20 años, la población que es asistida posee un amplio poder adquisitivo.

Hera es una sociedad dirigida por un profesional médico. Se trata de una institución con una antigüedad de 10 años aproximadamente. Su propietario es muy reconocido en su especialidad.

Saturno es otra institución que trabaja para el Instituto. Se encuentra en el centro de la ciudad. El propietario es un profesional, pero habitualmente deja un "encargado" en la institución.

Minerva y Venus son los Municipios titulares de los dos geriátricos Municipales que configuraran la muestra. Ediliciamente no los conozco ya que no tuve oportunidad de ir, pero sí en el desarrollo del trabajo de campo entrevisté a profesionales que trabajan en dichas instituciones.

Hemos presentado una referencia general de los propietarios a fin de aportar al análisis de las diferencias prestacionales. En el caso de aquellos propietarios que se configuran en mano de obra intensiva y que obstruyen en esto su vida social, extra muros, aparece un vínculo distinto a aquellos que se instalan en un lugar empresarial, "patronal". El desgaste que habitualmente transitan los cuidadores informales se ve incrementado nocivamente en el caso de aquellos propietarios de geriátricos que efectúan la tarea sin colaboración. $Y$ en ambos casos, los que trabajan solos y los que recurren a la contratación de empleados aparece como claro objetivo prestacional la generación de 
excedente. Obviamente el margen de ganancia es significativamente diferente entre unos y otros.

Creemos que hemos logrado presentar una respuesta a la pregunta ¿Cómo es la prestación del geriátrico hoy? Con sus contradicciones, paradojas, sus dimensiones materiales y simbólicas. Decíamos en este capítulo que socialmente no se desea ver la vejez frágil, socialmente no se quiere ver el "deterioro". Tomando el aporte de Wacquant y Auyero afirmamos que las instituciones hogar geriátrico no pueden explicarse por sí solas y parafraseando a Auyero decíamos que llevar a Wacquant al "geriátrico" sugiere entenderlo como una relación entre la economía, el descuido estatal y la acción de los actores políticos dentro y fuera del "geriátrico". Esta producción ha sido un intento de respuesta a este interrogante con el claro objetivo de generar prácticas y significados diferentes sobre las necesidades y derechos de las personas mayores que transitan su vida en estas instituciones.

\section{CAPITULO IV}

\section{A MODO DE COROLARIO}

\section{I - CONSTRUCCIÓN SOCIAL DE LA PRESTACIÓN. CULTURA INSTITUCIONAL: "estrategias de vida y de muerte en las prácticas institucionales"}

"La imagen de la residencia de tercera edad viene a resultar la imagen especular de las personas que residen allí."112

Una de las cuestiones que más nos sorprendió fue la manera parecida de proceder en las instituciones. Nos preguntábamos de qué forma los agentes institucionales sabían cómo proceder si nunca habían sido capacitados y nadie les había "enseñado". Y ahí apelamos al aporte de Pierre Bourdieu con los conceptos de habitus y prácticas. Entendiendo al habitus como "... un sistema socialmente constituido de disposiciones estructuradas y estructurantes, adquirido mediante la práctica y siempre orientado hacia funciones prácticas." ${ }^{113}$ Evidentemente existe una construcción histórica - social de la prestación y al mismo tiempo de la vejez que permite esta similitud en las prácticas. Existiendo un patrón común en las acciones.

Aquí es pertinente traer el concepto de cultura institucional que colectivamente se ha discutido en el II Simposium Argentino de Gerontología Institucional (SAGI 2005) "La cultura institucional es la personalidad de una institución, si su estructura puede considerarse como su cuerpo, su personalidad o alma es la manera en que la gente se relaciona entre sí y los valores y creencias dominantes. Determina las convenciones y reglas no escritas de la institución, sus normas de cooperación y conflicto, y sus canales para ejercer influencia." ${ }^{114}$

\footnotetext{
112 BAZO, María Teresa "Institucionalización de personas ancianas: un reto sociológico" En: REVISTAS ESPAÑOLA DE INVESTIGACIONES SOCIOLÓGICAS. No 53, CIS (Centroi de Investigacionsines Sociológicas) Enero - Marzo 1991 (pp.158)

${ }_{113}$ BOUDIEU "RESPUESTA SPOR UNA ANTROPOLOGIA REFLEXIVA." Pp. 83

${ }^{114}$ SUAREZ, Francisco, GONZALEZ, Natalia "Cultura Institucional y Estrategias de Vida de los adultos mayores en la argentina en la población inserta en residencias geriátricas". En: CULTURA INSTITUCIONAL Y ESTRATEGIAS GERONTOLOGICAS. PRIMER ANUARIO DEL SIMPOSIUM ARGENTINO DE GERONTOLOGIA INSTITUCIONAL. Ediciones Suárez. Mar del Plata, 2005. (pp. 36) 
Las instituciones atribuyen significados a su accionar. "Un pensar que se manifiesta desde la particularidad de matrices culturales y hace a la forma y el modo en que los sujetos interpretan, reflexionan y actúan sobre su propia realidad existencial. Una perspectiva inserta en la cultura como principio organizador de la experiencia que posibilite actitudes y comportamientos a partir de nuestro posicionamiento en redes de relaciones sociales constituyéndose en un sentido práctico de la vida." ${ }^{115}$

"...cumplen una función social que el resto de la sociedad no la cumple. Innegablemente ese gueto de ancianos aparece allí porque hay alguien que no quiere tenerlos en otro lado.....seguramente no están disconformes desde el momento que lo han dejado como estaba funcionando eso" - Fiscalizador

Las instituciones producen prácticas inscriptas en significados singulares que retomando a los autores mencionados podremos llamar cultural institucional. Ahora bien, ¿̇El geriátrico se configura en un gueto? Aquí es necesario revisar este concepto. De acuerdo al diccionario gueto significa barrio o suburbio en que viven personas marginadas por el resto de la sociedad. $Y$ otra de sus acepciones es situación o condición marginal en que vive un pueblo, una clase social o un grupo de personas. ${ }^{116}$ Por lo que la imagen que aparece es la de un espacio de relegación, de apartamiento, de ocultamiento a la mirada. No se desea ver la vejez frágil, socialmente no se quiere ver el "deterioro". ¿Las instituciones de larga estadía para personas mayores están efectivamente apartadas? Aquí retomamos el aporte de Wacquant que nos dice "La separación del gueto estadounidense del resto de la sociedad es sólo aparente: es una separación de "mundos vividos", no de "sistemas".

Esta distinción se refiere a las experiencias y relaciones concretas de sus ocupantes, no a los lazos subyacentes que los anclan con firmeza al conjunto metropolitano, si bien en la modalidad de la exclusión. En efecto, ..., hay nexos causales y funcionales profundamente arraigados entre la transformación del gueto y los cambios en la estructura de la economía, la sociedad y el gobierno...."117

Entonces afirmamos que las instituciones hogar geriátrico no pueden explicarse por sí solas. Parafraseando a Auyero decimos que: llevar a Wacquant al "geriátrico" sugiere entenderlo como una relación entre la economía, el descuido estatal y la acción de los actores políticos dentro y fuera del "geriátrico". Y agregamos que todo esto ha sido investido de una dimensión simbólica que le otorga sentido.

Tal como hemos planteado en los capítulos anteriores no podemos entender la prestación de Hogar Geriátrico si no ponemos en consideración los cambios producidos en la economía, los cambios políticos y las formas diversas de relación que establecen las familias.

"La cultura institucional va a depender también, en parte, de las estrategias de vida y de muerte que tengan los residentes, las autoridades y el personal." 118 En una entrevista surgió cómo sucumbe el personal ante el hecho fáctico de la muerte, de hecho durante el desarrollo de esta entrevista el informante se quebró y tuvimos que suspender por un rato el desarrollo de la misma.

\footnotetext{
${ }^{115}$ AMEGEIRAS, Aldo "El pensar popular: Entre la memoria popular y el imaginario colectivo en la cotidianeidad del ámbito barrial". En: FORNI, Floreal (comp.) DE LA EXCLUSIÓN A LA ORGANIZACIÓN. HACIA LA INTEGRACIÓN DE LOS POBRES EN LOS NUEVOS BARRIOS DEL CONURBANO BONAERENSE. Ediciones Ciccus. BS As, (pp. 92)

${ }^{116}$ Biblioteca de Consulta Microsoft $\circledast$ Encarta $® 2005$. (C) 1993-2004 Microsoft Corporation. Reservados todos los derechos.

${ }^{117}$ WACQUANT, Loïc "La nueva línea de color urbana: Estado del gueto en la Norteamérica posfordista". En: PRIAS URBANOS. Editorial Manantial, BS. As. 2001 (pp. 39/40)

${ }^{118}$ Ibidem, pp. 38
} 
P.: claro. ¿Qué pasa con la muerte? (silencio)

E.: La muerte en ellos...es algo que la presienten y la tienen elaborada.

P.: ¿Si?

E.: Sí. Cuando...cuando se derivan, lo primero que te preguntan es: "Doctora, ¿volverá?". Eso te preguntan.

P.: ¿Y vos?

E.: Y después miran todos los días el diario (silencio). Es así.

P.: Y a vos $A$, ¿qué te pasa con eso?...con la muerte? Bah, yo te pregunto porque hace tantos años que estás y yo que trabajé menos años y me conmueve...

(.............)

E.: Sí, sí. Yo creo que es una sensación de que...eh...como te puedo decir, hay abuelos que fallecieron ahi, ¿no es cierto? Primero porque el calor que se les daba y sabíamos que no tenían...era irreversible y se decidió que los últimos días iban a quedar acá en el hogar. Por lo menos van a tener el calor. Van a tener una mano. (silencio) Esas cosas los abuelos la ven... porque la ven muy mal, la van a ver, se asoman. Y después cuando están las oraciones los miércoles, piden por tal persona, que se mejore, o...rezan por los muertos. Se acuerdan. Es todo una historia distinta (silencio). Sí, es así. - Directora Médica Hogar Marítimo

Y conjugando el tema de la muerte, aparece la posición de la familia frente a esta.

E: "pero la señora Lola hacía cuatro, cinco días que presentía que al marido algo le iba a pasar, porque: "Soñé con Federico, que lo agarraba un auto, murió". Decía dormida, medio delirando: "llamá a mi hijo, porque a Federico lo agarró un auto y le cortó las piernas" decía.

P.: Mh.

E.: Y después llaman y nos dicen que había fallecido. Así que mirá, fijate vos, como son estas historias, no? (silencio) Al final a Lola hasta ahora no se le dijo.

P.: capaz que ya sabe.

E.: No se. Vamos a esperar que venga el hijo, comentar con el hijo que forma hay de decírselo. Es muy viejita...

P.: A partir de lo que me decís, me aparece como imagen esto del reemplazo de la familia - Director Médico Hogar Marítimo

Aquí un necesario señalamiento, no existe un modo unívoco de cultura institucional. Las distintas instituciones van construyendo significados diversos sobre la muerte y sobre el espacio que le otorgarán a la familia para la "administración de la muerte" 

¿no?

"P: Y en general cuando alguno fallece $o$ se va, el resto que dice frente a la muerte

Dionisio: Sí, e, y bueno le decimos que sigue internado, no le comunicamos que falleció . Que sigue internado y bueno, con el tiempo se olvidan, viste mamá. Se olvidan, se le habla de otras cosas viste

P: ¿Por qué, tenés miedo que se depriman?

Dionisio: Claro, claro, entonces no le decimos que fallecieron, que está ahí internado que ya va ha venir, se le dice siempre lo mismo

\section{P. Hasta que no preguntan}

\section{Dionisio: Hasta que no preguntan más. " DIONISIO}

Es inadmisible que la muerte sea reemplazada con una desaparición, en esto la historia nacional nos ha enseñado vastamente. La mentira sobre la muerte descansa sobre la certeza de que "los viejos ya no sienten, ya no pueden construir vínculos nuevos". Y por otra parte, considerando que los propietarios y el personal de los hogares se configuran en los responsables de administrar la muerte y la angustia que genera esta. Noticiar a los residentes de las muertes supondría asumir por parte de la institución un nuevo rol. Muchas veces es tal el grado de "informalidad" que opera en las instituciones, y al mismo tiempo una omnipresencia tan asfixiante la que asume la institución de internamiento que evade esta administración del dolor que produce la muerte. Al mismo tiempo no es solo administrar el dolor que produce en el resto sino los efectos que produce en cada uno de ellos.

Pareciera que algunas instituciones, sus agentes le temen a la idea de finitud. $Y$ al mismo tiempo este temor los empuja a generar prácticas nocivas como el ocultamiento.

"E.2: (la interrumpe) Tenemos que contenerlas a las chicas ahora. Pero al principio para nosotras era terrible...cuando fallecía un abuelo... yo le contaba antes...

E.1: (la interrumpe) La última vez que falleció un abuelo, fue a parar al hospital, porque había una abuela que la queríamos mucho y otra también... Yo todavía la sigo...

E.2: Sí, si. Yo me agarré una angustia total, que fui parar al hospital. O sea, es como que es algo muy mío...

E.1: (la interrumpe) Sí, porque digamos que una de las abuelas de estas, se sabía que no había tratamiento.., pero eran tan cariñosas, eran tan especiales. Una era una gorda que estaba cuadripléjica, viste? La hija la quiso llevar a Pila, porque la iba a tener más cerca y la tuvo 20 días. Se enfermó de tristeza, o no se de que...

\section{E.2: (la interrumpe) De tristeza. Nos Ilamaba. El hijo nos contaba que nos llamaba}

\section{E.1: (la interrumpe) Eso era para nosotras...}

E.2: ...que por favor, que fuéramos. Yo me quedé con Eros...viste? Entonces es como...y murió, ien 20 días!. Era, era...este... ella tenía problemas de azúcar. Cómo es? Diabetes. A mi no me entraba en la cabeza. No lo podía creer, viste? Hasta el día de hoy, 
que la familia haya tomado esa decisión, porque era como matarla, vistes?" (EROS Propietaria del Hogar Amoroso)

Esta omnipresencia que construye la institución hace que la narrativa que explica la muerte de un residente con el que se generó un vínculo importante adjudique a las decisiones de la familia la causa del deceso. Esta certeza de que si "el abuelo" hubiera seguido con nosotras no se habría descompensado.

Recordemos que uno de los marcadores de esta "cultura institucional" es su omnipresencia, junto a la construcción de un lugar para alojar a la persona mayor de protección / cuidado/ heteronomía/rentabilidad y la institución como parte de su cultura establece para sí la responsabilidad la administración de la muerte y la generación de vínculos con un fin compensatorio y construye una biología particular de la persona mayor institucionalizada signada por la quietud y la pérdida de funciones. Asimismo en este escenario acontecen prácticas de erotización.

Y agregaremos un nuevo hallazgo de esta investigación, las Instituciones Hogar Geriátrico generan prácticas a las que podremos llamar como censoras del amor filial. La institución al mismo tiempo que establece como cliente a satisfacer a las familias de los residentes las somete a un proceso de evaluación y ponderación de la intensidad de su amor familiar. Para esta tarea se convoca a un profesional específico, es decir a los Trabajadores Sociales. Podremos inferir que en la intervención Profesional del Trabajo Social somos interpelados para cumplir la función de "Censores del amor filial"

"Bueno, ahí por ejemplo, más allá de que yo me re - caliento cuando la hija no viene. La hija no se calienta, pero de hecho yo creo que también pasa porque tiene una imposibilidad muy grande.." Trabajadora Social Hogar Marítimo

Aparece en el ejercicio de la intervención profesional una carga valorativa muy fuerte.

"Entrevistada: Claro. Ahí no. Pero me tocó con Juana una vez, era una ínter consulta de ginecología, y me tocó incluso ayudarla de acostarla en la camilla. Sí.

\section{P.: ¿Y que te pasa ahí a vos?}

E.: Y a mí...yo siempre esto siento, de que si por ahí no estoy yo, no hay nadie... Pasó por ejemplo con Juana, con el tema de la vista. Juana tiene cataratas muy avanzadas. Las tiene muy avanzadas, eh...entonces, salió todo el tema también: se la opera, no se la opera, con la edad que tiene, o sea...las cataratas. Bueno, yo hice todo lo posible para que a Juana se la opere. Incluso ahora estamos a la espera de las lentes que va a dar PAMI. ¿Qué pasa? Por una cuestión de estar tan avanzada la diabetes de ella, no se sabe si con la operación va a ver, pero no importa. Se hace todo lo posible. Acá estamos hablando de que corre el tiempo; o sea, que PAMI te puede dar la prótesis...lentes mañana como puede dártelo en un mes. O sea, vos tenés que hacer todo lo posible para llevarla a los controles, todo. ¿Qué pasó? La llevé yo, la acompañe, la vio el médico, todo. Yo le expliqué quien era al médico... siempre les explico quien soy a todos los médicos. Entonces me dice el médico: Sí, pero lamentablemente por más que vos pongas toda tu buena voluntad de venirla a acompañar, la que tiene que dar...no tanto la autorización, pero la que tiene que estar en pleno conocimiento de lo que se le va a hacer a Juana es la hija, porque la hija en realidad está. Entonces, ¿qué pasó? Me dijo: "comunicate con ella y tratá de decirle por favor que venga a hablar conmigo, porque yo le voy a explicar como va a ser la operación, que se le va a hacer 
y demás". Esto fue un lunes. No, creo que fue un viernes. La llamé cuando llegué al Hogar inmediatamente a la hija, le expliqué la situación. iLa hija fue después de 15 días!...(silencio) ¿entonces que me pasa? Eso. Yo trato de hacer todo lo posible para que el residente esté bien. Trabajadora Social Hogar marítimo

Las instituciones catalogan de "abandónicas" a aquellas familias que no responden a los mandatos socialmente construidos, a sus obligaciones civiles propios de la responsabilidad filial.

"Las familias, yo creí que no era así! Son 18 residentes que tienen familia iNo quieren saber, no quieren querer y no quieren hacerse cargo! ¿Vos sabés las veces que van, que voy y les digo? La mirada de un familiar, la caricia de un familiar, el hecho de comer, en lugar que el auxiliar de enfermería le dé en la boca, hace a una persona. Es no querer, no saber, no comprometerse ¿Viste? Es eso. Es lamentable pero es así. Yo choqué, choqué y choqué y me di cuenta que es asi" Trabajadora Social Hogar Guerrero

Y tal como habíamos señalado las instituciones se sitúan en un espacio de generación de vínculos con un claro fin compensatorio.

"Yo los veo tan desprotegidos que yo hago todo lo contrario. A la hora del almuerzo voy, ayudo a servir. Hay 2 o 3 que hay que darles de comer en la boca, ayudo y les hago chistes." Trabajadora Social Hogar Guerrero.

Para ir culminando creemos oportuno ilustrar con el aporte de la literatura la idea de que construcción social de la prestación se conjuga con el ejercicio de la violencia generacional:

"Prosiguió el camino y en la Plaza Güemes consiguió por fin un taxímetro: un coche viejo, manejado por un hombre viejo. Este escuchó atentamente la dirección, bajó la bandera y dijo:

Hace bien, señor. Pasada cierta edad, no hay que subir a taxímetros de jóvenes.

¿Por que? - preguntó Vidal.

¿No se ha enterado, señor? Por deporte roban viejos y después los tiran por ahí. comentó.

Vidal estaba casi recostado en el asiento. Se enderezó y acercándose al hombre,

Que no vengan a decirnos que detrás de esta guerra hay una gran necesidad científica. Lo que hay es mucha compadrada.

Dice bien, señor. El criollo es compadre. La muchachada hace de cuenta que sale a cazar peludos y nos caza a nosotros.

Y uno vive en la inseguridad. Lo peor es temer siempre una sorpresa.

A eso voy - convino el conductor- Supóngase que realmente sobre el viejo inútil. ¿Por qué no lo llevan a un lugar como la gente y lo exterminan por métodos modernos? abuso.

¿No será peor el remedio que la enfermedad? - preguntó Vidal. Yo le digo por el teléfonos." ${ }^{119}$

Ahí me la ganó. - admitió el hombre- El gobierno es muy abusador. Sino fíjese en los

\footnotetext{
${ }^{119}$ BIOY CASARES, Adolfo. DIARIO DE LA GUERRA DEL CERDO. Editorial Altaya. Barcelona, 1999 (pp. 146/7)
} 
En esta obra el autor nos presenta esta guerra en que los jóvenes salen a "matar viejos". En la cita anterior refleja el sentir de las personas mayores frente a la amenaza. Y nos dice:

"La juventud espresa de desesperación - repitió Faber-

En un futuro próximo, si el régimen democrático se mantiene, el hombre viejo es el amo. Por simple matemática, entiéndame. Mayoría de votos ¿Qué nos enseña la estadística, vamos a ver? Que la muerte hoy no llega a los 50, sino a los 80 años, y que mañana vendrá a los 100 . Perfectamente. Por un esfuerzo de la imaginación ustedes dos conciban el número de viejos que de este modo se acumulan y el peso muerto de su opinión en el manejo de la cosa pública. Se acabó la dictadura del proletariado, para dar paso a la dictadura de los viejos." ${ }^{120}$

En este apartado el autor refleja los argumentos que sostienen los que desataron esta guerra y cómo son recepcionados y replicados por los "amenazados". En esta obra el autor ha plasmado los discursos que ha construido la sociedad, en esto que se denomina edaísmo.

\section{II - MIRADA DE LOS AGENTES SOCIALES SOBRE LA REGULACIÓN ESTATAL}

Hemos trabajado la dimensión regulatoria de los establecimientos inscribiéndola como una función esencial de la salud pública, y hemos problematizado la condición de clandestinas de los geriátricos. En este punto decidimos presentar qué plantean nuestros entrevistados sobre esta dimensión.

Aparecen dos cuestiones centrales en las referencias que hacen los propietarios de los establecimientos frente a la fiscalización. Por un lado reclaman que solo se mira el edificio, si hay madera o cerámico "nadie mira a los abuelos" (Eros). Este es un común denominador, platean que los inspectores no le hablan a los residentes, a veces ni los miran, parecería que no se tiene claridad sobre quién es el sujeto de nuestra práctica ¿para qué fiscalizamos? ¿Para quién? El punto central es la falta a coordinación entre las inspecciones que reciben. Plantean que depende quién venga es la evaluación: "el último inspector que vino me dijo que estaba todo mal, y el anterior no dijo nada. Siempre están 5 minutos y el último estuvo como dos horas" (Entrevistado)

"Después no sé que había pasado mamita, y empezaron con el asunto de los pisos de madera, los pisos de madera. Pero yo pensé que arreglando el techo y los planos ya estaba. No, después los pisos de madera! Eran unos pisos enormes, las habitaciones eran como estas grandes, viste. Hermosa la casa. Pisos de madera. Había que levantarlos, después.... entonces después me dijeron que si los plastificaba podían pasar. Pero parece que salió otra resolución claro, que se modificó, viste que son Decretos que modifican. La resolución es una ino es cierto mi amor? Pero por ahí puede ser un Decreto que modifique esa parte. ... Y hacía las cuentas, este eee después entré en conflicto con el

\footnotetext{
${ }^{120}$ Ibidem (pp. 158)
} 
dueño, porque claro para hacer el techo, viste mi amor el techo ese de telgopor. Fue mucho dinero! Me empecé a atrasar en el alquiler, pero no porque quería sino porque no había plata. Entonces agarra O..., y me llama por teléfono y me dice: mire Señora me enteré de los atrasos del alquiler(no se entiende) y si Doctor, yo nunca me atrasé pero el asunto del techo que usted me dijo. El un día me dijo que ....... (no se entiende) y que no lo molestara. iSi pero degenerados, le digo, por ustedes! Yo inconvenientes no tengo. Te digo que cuando me pongo mala, me pongo terrible (por teléfono nada más). Entonces me dice, bueno, hagamos una cosa, me entrega la casa. ciCómo?! .. iSabés la guita que había invertido y él que le entregara la casa y chau! $Y$ que me perdonaba ese mes y medio. ¿iCómo?! le digo. Y sí, dice .... le doy 24 horas de plazo ya que de lo contrario voy a accionar judicialmente. Pero cómo se atreve, escúcheme yo quiero hablar con usted doctor. Yo le voy a exponer todo lo que he invertido. (confuso)... se agarraba de ahí. Bué, mirá después no me acuerdo como siguió el caso es que me hizo juicio de desalojo y cobro de pesos. (Dionisio)

Se supone que al existir una única normativa las indicaciones que reciban deberían ser las mismas. La referencia a la presencia de madera en pisos no es azarosa, este ha sido uno de los puntos conflictivos en la aplicación de la normativa. Habitualmente los propietarios alquilan una casa antigua para la instalación de los hogares, estas presentan pisos de pinotea con una cámara de aire por debajo. No está permitido porque es considerado un factor de riesgo importante, pero al mismo tiempo no se ha construido un criterio unificado.

Para ir culminando presentaré una caracterización (tipo diagnóstica) de la situación de los dos Municipios que configuraron el escenario para el trabajo de campo. La municipalidad de Chascomús ha establecido como "problema social" la clandestinidad de los hogares, se ha preocupado por el tipo de servicio que reciben los personas mayores allí albergadas y ha generado varias estrategias tendientes a revertir la situación de clandestinidad. Entre ellas el trabajo conjunto con el Ministerio de Salud, la creación del Servicio de orientación prestacional, la creación del área de Tercera Edad. La ciudad de La Plata es la capital de la Provincia de Buenos Aires, cabecera de la Región Sanitaria XI. La Municipalidad no ha expresado preocupación por la existencia de geriátricos clandestinos, y no ha generado estrategias que busquen revertir esta situación.

\section{III - A MODO DE SÍNTESIS}

Para ir finalizando el capítulo daremos cuenta de los hallazgos alcanzados y construidos y presentaremos provisorias respuestas a los interrogantes que habíamos presentado en el desarrollo de la tesis.

En el desarrollo de la misma planteamos que los objetivos y desafíos de esta investigación tenían que ver con:

- dar cuenta de la trama de significados que se tejen en la prestación de Hogar Geriátrico en la actualidad,

- aportar a la desnaturalización de las tragedias cotidianas que acontecen en estas instituciones, 
- aportar a la instalación en la agenda pública del tema de la fiscalización de estas instituciones.

- responder a las preguntas vinculadas a las respuestas asilares que continúa dando la política pública frente a la vejez pobre y sobre la eficacia simbólica y corporal del mismo.

En el capítulo III presentamos los puntos significativos que aparecieron como marcadores de la prestación. Por un lado la Historia y Trayectoria Institucional o Mito de origen vinculado a fines altruistas y comerciales conjugados. Esta conjugación efectuada de forma singular de acuerdo a la trayectoria de vida del propietario. $Y$ el punto Caracterización de los propietarios junto al anterior nos ratifica que las diferencias prestacionales tienen que ver con las posiciones que toma quien dirige la institución frente a la persona mayor que alberga. Si sólo se la concibe cómo un cuerpo a conservar en pos de garantizar la rentabilidad las respuestas en la prestación van a ser de tipo asilar y si a la persona mayor se la concibe como un ciudadano, sujeto de derecho las respuestas van a estar signadas por el profesionalismo, con criterio sanitario.

Por otro lado apareció la centralidad de los residentes a la hora de dar cuenta de las dimensiones de la prestación. Por lo tanto las Personas Mayores se configuran en la Población objetivo de la prestación. También dimos cuenta de las Dimensiones alimentaria, atención sanitaria, admisión, autonomía e integración. Cómo común denominador de las dimensiones surgió que la persona mayor es situada en un espacio de objeto de cuidado / protección, desconociéndose las múltiples capacidades, deseos, derechos que poseen los mismos. En el punto admisión encontramos un correlato entre criterio de admisión y objetivo institucional. Si el objetivo que prima es maximizar ganancia el criterio de admisión está centrado en "ocupar la cama", por lo tanto no encontramos ni valoración geriátrica ni funcional, no opera el criterio sanitario como base fundante de la admisión. Encontramos los casos de las instituciones que trabajan para el INSSJyP en los que el criterio de admisión ocupa un lugar de externalidad ya que es la obra social la que define el criterio, podríamos inferir que el criterio de la institución Hogar Geriátrico es cumplir con lo que dice el Instituto. $Y$ por otra parte aparece la admisión que estipula el Estado. En uno de los Hogares Municipales, y que es representativo de la mayor parte de los geriátricos de gestión municipal de la provincia, el criterio es albergar al adulto mayor autoválido sin recursos. Pues entonces podríamos afirmar que los municipios responden frente a la vejez pobre con el encierro, escondiendo y desconociendo que en la mayor parte de los casos el problema a resolver es la vivienda. Cómo ya hemos trabajado hablar de familia es hablar de estructura y dinámica. En las estructuras familiares se ocupan posiciones de acuerdo a determinas reglas de juego, por lo que frente a la falta de vivienda lo que se resuelve es expulsar al más viejo y ocupar su casa, su cama, su habitación.

Asimismo surgió fuertemente la cuestión de la falta de capacitación y formación por parte del personal que trabaja cotidianamente con los mayores. Esto lo habíamos puesto en tensión en el capítulo I cuándo nos referimos a las exigencias que expone la Ley de Enfermería y la normativa específica para Hogares Geriátricos en la provincia. Cuándo analizamos el tópico atención sanitaria decíamos que la persona mayor era colocada en un lugar de "objeto de registro" con el agravante de que algunas veces la información recabada no se utilizaba o no se sabía utilizar. Y en el tópico autonomía decíamos que la persona mayor no ocupaba un lugar de autonomía, es decir ocupaba un lugar de 
heteronomía ${ }^{121}$. Presentamos la forma en que la persona mayor institucionalizada era "corrida" de las decisiones de ingreso a la institución y manejo de sus bienes, por lo que decíamos que se producía un proceso de infantilización que conceptualizábamos como propio del racismo.

Y en el punto Integración dimos cuenta de los lazos que se construyen en la dinámica institucional y nos animábamos a decir que se producen mecanismos de compensación. Hay una clara referencia a la estrechez que caracterizan a los vínculos que establecen los residentes entre sí y los residentes con el personal que lo asiste en el cotidiano. Esto posibilita transitar la vida en el hogar con mayor fortaleza y al mismo tiempo los expone con mayor vulnerabilidad a situaciones de violencia y maltrato. Con esto quiero decir que depender exclusivamente de un cuidador con el que se ha establecido un vínculo "amistoso" puede ser muy beneficioso. Pero si este cuidador deja de brindar el servicio adecuado y manipular las decisiones de la persona mayor puede convertirse en un riesgo. Recordemos que en las instituciones los mayores no ejercen autonomía.

En el tópico Familia de los residentes trabajamos una de las cuestiones que opera fuertemente en la realidad de los geriátricos. Por un lado porque advertimos que la familia de los residentes es quien se sitúa en el lugar de "cliente a satisfacer" dando lugar a la construcción de una omnipresencia institucional.

Y en el punto de Casos paradojales se ejemplificó a partir de la presentación de algunas situaciones las prácticas y significados que se construyen sobre las personas mayores institucionalizadas y al mismo tiempo algunas paradojas sobre las acciones del estado. Y allí presentamos los casos de Nelly, María Clara y una persona que padecía una cuadriplejía que fueron prototípicas.

En cuanto a la caracterización de los propietarios aparece por un lado la reflexión en torno a los propietarios de los hogares clandestinos y por otro una descripción de las características de los propietarios que configuraron la muestra trabajada. Ambas caracterizaciones nos permitieron afirmar que varios de los propietarios de los geriátricos presentan "fragilidad relacional" y el vínculo más fuerte que poseen es con el personal de la institución y con los residentes. Este vínculo no es horizontal sino que obviamente aparece una relación asimétrica que en algunas oportunidades opera y en otras se desdibuja. Estos agentes sociales presentan los rasgos típicos del desgaste del cuidador informal.

\section{IV - ALGUNAS PROPUESTAS DE INTERVENCION}

Del desarrollo de la investigación surge que la prestación brindada en los Hogares Geriátricos presenta dimensiones de análisis diversos. Por un lado, en tanto actividad regulada por el estado las acciones que el mismo genere en este sentido se inscriben en el desarrollo de políticas públicas. Al mismo tiempo se trata de una oferta prestacional del campo de la salud y de la gerontología por lo que operan los criterios científicos construidos en cuanto a las condiciones que justifican su oferta. Asimismo en la vida cotidiana se cristaliza, se hace presente la prestación en si misma y esto también se analizó.

\footnotetext{
121 De heterónomo. Heterónomo: Dicho de una persona que está sometida a un poder ajeno que le impide el libre desarrollo de su naturaleza. (Biblioteca de Consulta Microsoft $₫$ Encarta $₫$ 2005. (C)
} 
Tras este recorrido estamos en condiciones de afirmar que es necesaria la intervención del estado en el desarrollo de políticas que garanticen el cumplimiento de los derechos humanos y de las funciones esenciales de la salud pública. A continuación se desarrollan algunas ideas para compartir tendientes a generar propuestas de intervención del Estado, a saber:

- Creación de una Mesa Provincial sobre Política de Vejez de la Provincia de Buenos Aires integrada por todos las áreas provinciales vinculadas a la temática a fin de construir un diagnóstico de la situación en el distrito y líneas de trabajo en conjunto.

- Fortalecimiento de las capacidades técnicas del Estado Provincial generando espacios de formación académica de los agentes profesionales existentes y avanzar hacia la construcción de criterios sanitarios unificados.

- Incremento del recurso humano de la Dirección de Fiscalización Sanitaria. Se sugiere la contratación de Profesionales para el desarrollo de las actividades de fiscalización (Médicos, Arquitectos, Trabajadores Sociales, Ingenieros, Técnicos en Seguridad e Higiene, Lic. en Enfermería, Abogados).

- Continuar con las actividades de capacitación al recurso humano municipal (fortalecimiento de la experiencia iniciada en Marzo 2006), tendiente a la unificación de criterios.

- Recuperar los Criterios Unificados para la Regulación y Control de Residencias para Mayores y Centros de Día elaborados por la entonces Secretaria de Tercera Edad y Acción Social Nacional, a fin de evaluar su factibilidad en la realidad provincial.

- Fortalecer la implementación del Plan Nacional de Cuidadores Domiciliarios.

- Generar la Matriculación de los mismos en la Dirección de Fiscalización Sanitaria, previa evaluación de los alcances de su título.

- Posibilitar la formación de personal de enfermería en los distritos en los que actualmente no se cuenta con este recurso humano de salud. Esto en cumplimiento de la Función Esencial de Salud Pública "Desarrollo de recursos humanos y capacitación en salud pública"

- Implementar espacios de formación de los propietarios de los actuales establecimientos o fortalecer la experiencia del Curso de "Gestión de Instituciones Geriátricas" iniciado en el año 2005 por el Ministerio de Salud.

Creemos que estas propuestas posibilitarían la generación de políticas que resguarden la vida de las personas mayores que transitan los últimos años de su vida en estas instituciones. Es necesaria la presencia de un estado fuerte en cuanto a capacidad técnica y política, por lo que se requiere un esfuerzo de coordinación para la generación de consensos. También es fundamental que los profesionales se sitúen en una pretensión interdisciplinaria y por sobre todo estén comprometidos. En este sentido retomamos una cita de Marilda Iamamoto: "El rumbo ético - político requiere un profesional informado, culto, crítico y competente. Exige romper tanto con el teoricismo estéril como con el pragmatismo que deja prisionero al profesional en el hacer por hacer, pensando en metas e intereses inmediatos. Demanda competencia, pero no la competencia autorizada y permitida, la 
competencia de la organización que diluye el poder como si no fuera ejercido por nadie, como si derivara de las "normas" de la institución, de la burocracia. El requisito es otro, se trata de una competencia crítica capaz de descifrar la génesis de los procesos sociales, sus desigualdades y las estrategias de acción para enfrentarlas. Supone competencia teórica y fidelidad al movimiento de la realidad, competencia técnica y ético - política que subordine el cómo hacer y éste al "deber ser", sin perder de vista sus raíces en el proceso social". ${ }^{122}$

Llevar a cabo esta investigación exigió un gran esfuerzo analítico y de "extrañamiento" por lo que creímos necesario culminar la exposición con un esbozo de propuesta.

Al mismo tiempo advertimos una constante en las entrevistas efectuadas a las Trabajadores Sociales que ejercen su profesión en este campo. Todos plantearon la necesidad de formación específica. Los entrevistados pertenecían generacionalmente a momentos diferentes: formados en Institutos terciarios en los años 70, en la UBA en los 80 y en la U.N. de La Plata en los 90. El común denominador era la carencia de abordaje en la formación de grado del tema del envejecimiento. Por lo que pudimos indagar, las ofertas de formación en gerontología son todas de Posgrado y aranceladas. No existen ofertas de formación específica para Trabajadores Sociales en el campo gerontológico. Y las producciones que aborden la "especificidad" del Trabajo Social en este campo son escasas $^{123}$. Y aquí es necesario recuperar el aporte de Abraham Monk que ya en los años 70 nos planteaba que "la práctica del Trabajo Social con los viejos se diferencia de la práctica en otras áreas, ya que los trabajadores se confrontan con muchas situaciones y problemas que inevitablemente enfrentarán ellos también" ${ }^{124}$

Por lo expuesto es que creemos necesario el desarrollo de tres líneas de trabajo en este sentido:

- Incentivar la incorporación en la formación de grado del abordaje del tema envejecimiento y vejez.

- Propiciar la des - mercantilización de la oferta de formación en el pos grado.

- Posibilitar el financiamiento de las investigaciones llevadas a cabo por Trabajadores Sociales sobre los interrogantes que surgen del proceso de intervención.

Creemos que afianzar la formación en esta línea implica el desarrollo de competencias teóricas y metodológicas que se pondrán en juego a la hora del ejercicio profesional. Un profesional crítico tenderá a desnaturalizar la realidad, a interpelarla y a generar propuestas superadoras tendientes al resguardo de los derechos de los ciudadanos más allá de los años que porten.

\footnotetext{
${ }^{122}$ IAMAMOTTO, Marilda SERVICIO SOCIAL Y DIVISION DEL TRABAJO. Cortez Editora. Brasil, 1997. (pp. 100)

${ }^{123}$ En los últimos 10 años la editorial Espacio ha publicado 5 libros sobre el campo de la Gerontología y el Trabajo Social, dos de ellos son solo una presentación introductoria de los aportes de la Gerontología.

${ }^{124}$ MONK, Abraham "El trabajo Social con los viejos: Principios de práctica" - Años 70 (Sin más datos)
} 


\section{BIBLIOGRAFÍA CONSULTADA}

$\checkmark$ ACUÑA; Carlos y CHUDNOVSKY, Mariana "EL SISTEMA DE SALUD EN ARGENTINA" Documento 60 Marzo 2002 http://cdi.mecon.gov.ar/biblio/docelec/cedi/dt60.pdf

$<$ AGUIRRE, A. y GODOY, D. LAS OBRAS SOCIALES EN LA ARGENTINA. CTA Prov. Bs. As. 1999.

$<$ AGUIRRE, Patricia "10 años de convertibilidad en la seguridad alimentaria del área metropolitana bonaerense. Una visión desde la antropología alimentaria." En: Sabulsky (Comp) ENFOQUE INTEGRAL DEL DESARROLLO EN LA INFANCIA: EL FUTURO COMPROMETIDO. Fundación CLACYD, Córdoba, 2004.

$<$ AIZEN, Rosa (Comp.) TEMAS DE GERONTOLOGÍA SOCIAL. Editado por Direccion General de Tercera Edad. Bs. As. 2004.

\& ALONSO, Guillermo POLITICA Y SEGURIDAD SOCIAL EN LA ARGENTINA DE LOS 90. Editorial Miño y Davila (Serie Flacso). Madrid, 2000

$<$ aLVAREZ, María del Pilar "El concepto de Vejez". En: ENVEJECIMIENTO Y VEJEZ. NUEVOS APORTES. Editorial Atuel, Buenos Aires, 1998 (pp.16)

$<$ AMEGEIRAS, Aldo "El pensar popular: Entre la memoria popular y el imaginario colectivo en la cotidianeidad del ámbito barrial". En: FORNI, Floreal (comp.) DE LA EXCLUSIÓN A LA ORGANIZACIÓN. HACIA LA INTEGRACIÓN DE LOS POBRES EN LOS NUEVOS BARRIOS DEL CONURBANO BONAERENSE. Ediciones Ciccus. BS As

$<$ ANDRENACCI, LuCiano IMPARIS CIVITATIS. ELEMENTOS PARA UNA TEORÍA DE LA CIUDADANÍA DESDE UNA PERSPECTIVA HISTÓRICA. Bs. As. 2002 (Sin publicar)

\& ANDRENACCI, Luciano "Algunas reflexiones en torno a la cuestión social y a la asistencialización de la intervención social del estado en la Argentina contemporánea". En: ANDRENACCI (org.) CUESTION SOCIAL Y POLÍTICA SOCIAL EN EL GRAN BUENOS AIRES Ediciones AI Margen. Bs. As. 2002

$\&$ ARIAS, Ana TESIS DE MAESTRIA "La Centralidad de las Prácticas Asistenciales en Organizaciones Territoriales. Un Estudio de Caso en el Segundo Cordón del Conurbano" Maestría en Políticas Sociales. Facultad de Ciencias Sociales - UBA

$\checkmark$ ARIAS, Claudia Josefina RED DE APOYO SOCIAL Y BIENESTAR PSICOLÓGICO EN PERSONAS DE EDAD. Ediciones Suárez. Mar del Plata, 2004.

$\checkmark$ AUYERO, Javier LA POLÍTICA DE LOS POBRES. Editorial Manantial. Bs. As. 2001

$\&$ BARBERENA, Mariano ADULTOS MAYORES SIN COBERTURA PREVISIONAL EN ARGENTINA: DE LA NEGACIÓN DE SU VISIBILIDAD A LA POSIBILIDAD DE SU CONSTRUCCIÓN COMO PROBLEMA SOCIAL. UNA MIRADA DESDE EL TRABAJO SOCIAL. Tesis de Maestría en Servicio Social Pontificia Universidad Católica de San Pablo. Año 2001.

\& BARBEITO, Alberto y LO VUOLO Rubén LA MODERNIZACION EXCLUYENTE. Transformación económica y Estado de Bienestar en Argentina. Bs. As. 1992

$\checkmark$ BARTOLOMÉ, Miguel "En defensa de la etnografía".

\& BAZO, María Teresa "Institucionalización de personas ancianas: un reto sociológico" En: REVISTAS ESPAÑOLA DE INVESTIGACIONES SOCIOLÓGICAS. № 53, CIS (Centroi de Investigacionsines Sociológicas) Enero - Marzo 1991

$<$ BIOY CASARES, Adolfo. DIARIO DE LA GUERRA DEL CERDO. Editorial Altaya. Barcelona, 1999 (pp. 146/7)

$<$ BOIVIN, Mauricio, ROSATO, Ana ARRIBAS, Victoria "La observación participante". En CONSTRUCTORES DE OTREDAD. Una introducción a la Antropología Social y Cultural. Editorial Antrpofagia. Tercera Edición, segunda reimpresión. Bs. As. 2006

$<$ BOURDIEU , Pierre "Estructura, hábitus y practicas" En: EL SENTIDO PRÁCTICO, 1990

$<$ Bourdieu, Pierre "Algunas propiedades de los campos" En: SOCIOLOGÍA Y CULTURA. México, Grijalbo, 1990

$<$ CARBALLEDA, Alfredo "Del orden social a la nueva fragmentación de la sociedad". En: DEL DESORDEN DE LOS CUERPOS AL ORDEN DE LA SOCIEDAD. Editorial de la UNLP, La Plata, 2001

\& CASTEL, Robert "La inserción y los nuevos retos de las intervenciones sociales". En: MARGINACIÓN E INSERCION. LOS NUEVOS RETOS DE LAS POLITICAS SOCIALES. Editorial Endymion. Madrid 1.992

$\&$ CASTEL, Robert "Introducción". LA METAMORFOSIS DE LA CUESTIÓN SOCIAL.

\& CAZZANIGA, Susana "La formación de los Trabajadores Sociales en el actual contexto". En: Revista Escenarios $n$ o 8 Escuela Superior de Trabajo Social, 2004

$\&$ CIAPPA, Gustavo ALGUNAS APRECIACIONES SOBRE EL ENVEJECIMIENTO Y LAS POLÍTICAS PARA EL ADULTO MAYOR. Inédito, 2003

$<$ DANEL, Paula "Compartiendo algunos interrogantes y análisis efectuados sobre nuestra intervención" En: Golpe, I y Arias j (EDITORAS) CULTURA INSTITUCIONAL Y ESTRATEGIAS GERONTOLÓGICAS. Editorial Suárez, Mar del Plata, marzo 2005

$<$ DANEL; Paula Mara "Hacia la comprensión de la existencia de hogares geriátricos clandestinos" publicado el artículo en Revista Topia: www.topia.com.ar en el mes de Abril 2005 
\& DANEL; Paula Mara "Los viejos y el Trabajo Social". Publicado en formato digital : www.concienciasocial.unc.edu.ar

$\varangle$ DE ALVEAR, Carmen "Aspectos sociales y familiares de la dependencia. Los cuidadores. Aspectos intergeneracionales." En: http://www.ceoma.org/vicongreso/ponencias/Ponencia\%205.doc

4 DE LA CUESTA ARZAMENDI, José Luis (Ed.) EL MALTRATO DE PERSONAS MAYORES. Detección $Y$ Prevención desde un prisma criminológico interdisciplinar. Hurkoa Fundazioa. Instituto vasco de Criminología. 2006 (ISBN 84-611-0017-4)

4 DECRETO 3280/90 reglamentario de la Ley 7314/67. Boletín Oficial de la Prov Buenos Aires 20 de Septiembre de 1.990

4 DEFENSORÍA DEL PUEBLO DE LA CIUDAD DE BUENOS AIRES. "Papeles de Trabajo - Gerontovida 2004: IoS adultos mayores, sus derechos y un nuevo modelo prestacional sin excluídos". Bs As, Mayo 2005

\& DELEUZE, Giles "Las sociedades de control" En: Ferrer Christian (comp.) EL LENGUAJE LIBERTARIO. Buenos Aires, Altamira, 1999

\& DE LOS REYES, María Cristina "Institucionalización de ancianos y cuidadores familiares". En: Revista margen n 019 año 2000.

\& DURKHEIM, Emile "Las clasificaciones primitivas" En: CLASIFICACIONES PRIMITIVAS Y OTROS ENSAYOS DE ANTROPOLOGÍA POSITIVA. Madrid, Ariel, 1996

\& ECO, Umberto CÓMO SE HACE UNA TESIS. Técnicas y Procedimientos de investigación, estudio y escritura. Editorial Gedisa. Barcelona España.1995

\& EPELE, María "Violencias y traumas. Políticas del sufrimiento social entre usuarios de drogas". En: Cuadernos de Antropología Social No 14 - Facultad de Filosofía y Letras. Buenos Aires. 2001

\& EPELE; María "Lógica Causal y (auto) cuidado. Paradojas del Control Médico del VIH-SIDA". En: Revista del Centro de Ciencias Etnolinguisticas y Antropológico Sociales. Universidad Nacional de Rosario, 1997

\& ESQUIVEL, María Laura "La Salud" En: FUNDACION PAR. LA DISCAPACIDAD EN ARGENTINA. Un diagnóstico de situación y políticas públicas viqentes al 2005 . Fundación Par, Bs. As. 2005 (pp. 151)

4 FASSIO, Adriana "'La población de adultos mayores institucionalizada según datos censales". En: GOLPE, L y ARIAS, C (comp.) Cultura Institucional y Estrategias Gerontológicas. Primer Anuario del Simposium Argentino de Gerontología Institucional. Ediciones Suárez. Mar del Plata, 2005.

4 FISCELLA, Sergio "Conceptos ordenadores básicos. Marco teórico conceptual". En: ESTADO, CIUDADANÍA Y POLITICA SOCIAL. Espacio Editorial BS. As, 2005

\& FORNOS ESTEVE, Monserrat "La persona mayor en el modelo familiar" Clase dictada en el marco de Programa de Seminarios por Internet Clase no 5 http://psiconet.com/seminarios

$\&$ FOUCAULT Michel "Las redes del poder" En: Ferrer Christian (comp.) EL LENGUAJE LIBERTARIO. Buenos Aires, Altamira, 1999

\& FOUCAULT, Michel 1996 "La ética del cuidado de uno mismo como práctica de la libertad". En: ЦA HERMENEÚTICA DEL SUJETO. La Plata: Editorial Altamira. 1996

$\&$ FOUCAULT, Michel UN DIALOGO SOBRE EL PODER. Alianza Editorial, Madrid, 2000 (Séptima reimpresión)

\& FREYSSELINARD; Edgardo; ODDONE, María Julieta, PAOLA, Jorge y PASSADORE, Norma "Hogares de ancianos: una aproximación al estudio de sus características institucionales". En: INFORME SOBRE TERCERA EDAD EN LA ARGENTINA. Secretaria de Tercera Edad y acción Social, Bs. As. 2001 (pp. 393)

\& GARCÍA CANCLINI, Néstor "Ideología y Cultura" Conferencias de la Facultad de Filosofía y Letras de la Universidad de Buenos Aires, 1984

\& GASCÓN Silvia. Las Redes Sociales, nuevas formas de participación e inclusión de mayores.

$\varangle$ GASCON, Silvia y REDONDO, Nélida "Marco de referencia para la programación de servicios integrados de cuidados de larga duración para personas de edad frágiles y dependientes en Argentina, Chile y Uruguay". OPS Dosumento Preliminar Argentina, 2005

\& GATTINO, Silvia, AQUIN, Nora LAS FAMILIAS DE LA NUEVA POBREZA. Espacio Editorial, Bs. As. 1999

\& GIMENEZ, Gilberto "El Estado". En: PODER, ESTADO Y DISCURSO. UNAM, México, 1986

\& GOLBERT, Laura y LO VUOLO, Rubén "El sistema Previsional en Discusión". En: ISUANI - TENTI ESTADO DEMOCRÁTICO Y POLITICA SOCIAL. EDUDEBA, Bs As, 1989

\& GOLPE; Laura "Edaísmo y trayactoria vital: una encrucijada en la cultura". EN: GOLPE, BIDEGAIN y ARIAS (Comp.) EDAÍSMO Y APOYO SOCIAL. Editorial suárez , Mar del Plata, 2003.

\& GOLPE; Laura y ARIAS, Claudia (Editoras) SISTEMAS FORMALES E INFORMALES DE APOYO SOCIAL PARA ADULTOS MAYORES. Ediciones Suárez, Mar del Plata, 2006

\& GOOD, B 1994 "How Medicine Constructs its Objects". En: Medicine, Rationality and experience. An Anthropological Perspective. Cambridge University Press, 1994

$\&$ GRAGLIA, Emilio DISEÑO Y GESTION DE POLITICAS PUBLICAS. Hacia un modelo relacional. Editorial Universidad Católica. Córdoba, 2005

\& GUBER, Rosana 
\& HUENCHUAN NAVARRO, Sandra "Política de vejez en América latina: Una propuesta para su análisis" 2003 CELADE - CEPAL

\& HUENCHUAN NAVARRO, Sandra "Definición de la cuestión en las políticas de vejez:pobreza e integración" En: MARCO LEGAL Y DE POLÍTICAS A FAVOR DE LAS PERSONAS MAYORES EN AMERICA LATINA. CEPAL, Santiago de Chile, 2004. (pp. 34)

\& IACUB, Ricardo "De los mitos a los goces. El pluralismo sexual" En: ERÓTICA Y VEJEZ. Editorial Paidós. Bs. As. 2006

\& IAMAMOTTO, Marilda SERVICIO SOCIAL Y DIVISION DEL TRABAJO. Cortez Editora. Brasil. Julio 1997.

$\&$ I.N.S.S.J. y P. - Grillas de Evaluación y auditoría a Hogares geriátricos

$\varangle$ ISUANI. Ernesto Aldo "Regulación estatal y federalismo". En : I SAGI Primer simposium Argentino de Gerontología Institucional. Facultad de Psicología. UN Mar del Plata, 2004

$\varangle$ IZAGUIRRE, Inés (Comp) VIOLENCIA SOCIAL Y DERECHOS HUMANOS. EUDEBA, Bs as.

\& KNOPOFF; René y ODONNE; María Julieta (Comp) DIMENSIONES DE LA VEJEZ EN LA SOCIEDAD ARGENTINA. Centro Editor de América Latina. Buenos Aires, 1991.

\& LAFOREST, J "“Crisis de pertenencia". En: INTRODUCCIÓN A LA GERONTOLOGÍA. Editorial Herdes, España, 1991

\& LAURELL, Asa " La reforma del sector salud. Hacia la mercantilización de los servicios." En: LA REFORMA CONTRA LA SALUD Y LA SEGURIDAD SOCIAL. Fund. Friedrich Ebert, México. 1997

$\&$ LAURELL, Asa "El nuevo sistema de pensiones. De la solidaridad al contrato individual privado". En: LAURELL, Asa LA REFORMA CONTRA LA SALUD Y LA SEGURIDAD SOCIAL. Fund. Friedrich Ebert, México. 1997

\& Laurell A. C. "La salud-enfermedad como proceso social" En: Revista Latinoamericana de Salud. Nueva Imagen, 1982

\& LE BRETON, David "El envejecimiento intolerable: el cuerpo deshecho". En: $\underline{\text { ANTROPOLOGÍA DEL CUERPO }}$ Y MODERNIDAD. Ediciones Nueva Visión. Buenos Aires, 2002.

$\&$ LEY 12245 De Enfermería

4 LLOYD - SHERLOCK ANCIANIDAD Y POBREZA EN EL MUNDO EN DESARROLLO Editorial: Miño y Dávila Editores. Ciepp. Madrid. 1999 (2 edición)

\& LUDI, María del Carmen LLEGAR A VIEJO. Diagnóstico de situación de vejez en la Provincia de Entre Ríos. Publicación Secretaría de Extensión UNER - EDUNER. Paraná, 1997.

\& LUDI; María del Carmen ENVEJECER EN UN CONTEXTO DE (DES) PROTECCIÓN SOCIAL. Espacio Editorial. Buenos Aires, 2006

4 MARX, Karl EL CAPITAL. LIBRO PRIMERO. TOMO I VOLUMEN I. Editorial Siglo XXI. Buenos Aires. 2002

$\&$ MATUSEVICH, Daniel "Envejecimiento e Institucionalización geriátrica" En: FERRERO (Comp.) Envejecimiento y Vejez. Editorial Atuel, Bs. As. 1998.

\& MENENDEZ, Eduardo "Racismo, colonialismo y Violencia Científica" En: REVISTA TRANSFORMACIONES, Buenos Aires, Centro Editor de América Latina, 1973.(pp.1)

\& MENÉNDEZ Eduardo MORIR DE ALCOHOL. Saber y hegemonía médica. México, Alianza Editorial Mexicana, 1990

\& MONK, Abraham "El Trabajo Social con Viejos. Principios de práctica" (Sin más datos)

\& MUÑOZ, Fernando; LOPEZ - ACUÑA, Daneil; HALVERSON, Paula, GUERRA DE MACEDO, Carlyle; HANNA, Wade; LARRIEU, Mónica; UBILLA, Soledad y ZEBALLOS, José Luis "Funciones esenciales de la salud pública: un tema emergente en las reformas del sector de la salud". Revista Panamericana de salud Pública n a 8 , año 2000.

\& MUÑOZ PORRA, Fernando FORTALECIMIENTO DE LA PRÁCTICA DE LAS FUNCIONES ESENCIALES DE SALUD PÚBLICA. En: http://www.clad.org.ve/anales4/munozpor.html\#arriba

\& NAVARRO LEGISLACIÓN EXTRANJERA SOBRE CASAS DE REPOSO PARA EL ADULTO MAYOR. En: http://www.navarro.cl/defensa/casas\%20de\%20reposo/index.htm

\& NIEVAS, Fabián "Disciplina". En: EL CONTROL SOCIAL DE LOS CUERPOS. Editorial EUDEBA, Buernos Aires, abril 1999

\& OPS-OMS "La Salud Pública en las Américas, Nuevos Conceptos, Análisis del Desempeño y Bases para la Acción", Washington D.C.: OPS, 2002, Publicación Científica y Técnica No 589, Capítulos 3,4 y 6

$\&$ OSZLACK, Oscar LA FORMACION DEL ESTADO ARGENTINO: Editorial Belgrano. Bs. As. 1982

$\&$ PAOLA; Jorge HISTORIAS FUNDACIONALES DE LAS RESIDENCIAS PARA MAYORES DE LA ARGENTINA. RITUALES INSTITUCIONALES Y EXPERIENCIAS SIGNIFICATIVAS PARA EL CAMPO GERONTOLÓGICO. Actas del III Simposium Argentino de Gerontología Institucional CD- ROM n o de ISBN 987-544-199-6, Mar del Plata, 2005. 
\& PAOLA, Jorge "Aportes del Trabajo Social a la construcción del pensamiento gerontológico en nuestro medio". En: Dossier. Revista del Consejo Profesional de Graduados en Servicio Social o Trabajo Social. Bs. As, 2000

\& PAOLA, J; PENAS, L; FERNANDEZ; m; PEREZ, O.; MARTÏNEZ, L; DEMARCO; M "Los centros de día en el marco de la formulación de políticas sociales para la tercera edad". En: CONSTRUYENDO EL TRABAJO SOCIAL CON ADULTOS MAYORES. Editorial Espacio, Bs. As. 2003

4 PEREIRA, Potyara NECESIDADES HUMANAS. Cortez editora. San Pablo, 2002

4 PEREZ IRIGOYEN, Claudio "Política Pública y Salud" En: ISUANI, Ernesto y TENTI, Emilio (Comp) ESTADO DEMOCRÁTICO Y POLITICA SOCIAL. Editorial EUDEBA. Bs As, 1989

$\&$ PETRIZ; Graciela "Transformaciones psíquicas en el proceso de envejecimiento". En: www.edupsi.com

$\&$ PIQUERAS, Andrés INTRODUCCION A LA ANTROPOLOGIA PARA LA INTERVENCION SOCIAL. Editorial Tirant lo Blanch, Valencia, 2002

\& RODRIGUEZ RODRIGUEZ, Pilar (Coord) RESIDENCIAS PARA PERSONAS MAYORES. Manual de Orientación. Editorial Médica panamericana, Madrid, 2000

4 ROZAS PAGAZA, Margarita "Bienestar social en el contexto de la modernidad". En: UNA PERSPECTIVA TEÓRICA METODOLÓGICA DE LA INTERVENCION EN TRABAJO SOCIAL. Espacio Editorial. Buenos Aires. 1998

\& ROZAS PAGAZA, Margarita "Estado neoliberal, cuestión social e intervención profesional". En: LA INTERVENCION PROFESIONAL EN RELACION CON LA CUESTION SOCIAL. El caso del Trabajo Social. Espacio Editorial. Buenos Aires. 2001

4 RUBIO, María Isabel "Contexto Etnográfico y uso de las técnicas de investigación de Antropología Social". En: de la Cruz (Comp) INTRODUCCION A LA ANTROPOLOGÍA PARA LA INTERVENCIÓN SOCIAL. Editorial Tirant lo blanch, Valencia, 2002

4 RUIZ TORRES "Biología del Envejecimiento" En: MANUAL DE GERIATRÍA. España, 2000

\& SALVAREZZA. Leopoldo (comp.) LA VEJEZ: Una mirada gerontológica actual. Editorial PAIDÖS. Bs. As. 1998

4 SANCHEZ, Carmen Delia (Editora) LA MUJER DE EDAD MAYOR EN UNA SOCIEDAD FEMENIZADA. (EUNED) Editorial Universidad Estatal a Distancia. Costa Rica, 2002

$\&$ SANCHEZ SALGADO, Carmen Delia GERONTOLOGIA SOCIAL. Espacio Editorial. Bs. As. 2.000

\& SARMIENTO, Natalia y DANEL, Paula "La intervención del Trabajo Social en Instituciones de adultos mayores" - Ficha de cátedra Seminario de Grado Facultad de Trabajo Social Universidad Nacional de La Plata

$\&$ SECRETARIA DE TERCERA EDAD Y ACCIÓN SOCIAL INFORME SOBRE TERCERA EDAD EN LA ARGENTINA, AÑO 2000. Buenos Aires, 2001

\& SUAREZ, Francisco y GONZALEZ, Natalia "Cultura Institucional y Estrategias de Vida de los Adultos Mayores en la Argentina en la población inserta en residencias geriátricas" En: PRIMER ANUARIO DEL SIMPOSIUM ARGENTINO DE GERONTOLOGÍA INSTITUCIONAL. Ediciones Suárez. Mar del Plata, 2005

$\&$ TAMAGNO, Liliana LOS TOBAS EN LA CASA DEL HOMBRE BLANCO. Ediciones desde el margen. La Plata, 2001

\& TAUSSIG, M. "La reificación y la conciencia del paciente". En: UN GIGANTE EN CONVULSIONES: EL MUNDO HUMANO COMO SISTEMA NERVIOSO EN EMERGENCIA PERMANENTE. Editorial Gedisa. España. 1992

\& TENTI FANFANI, Emilio "Estrategias típicas de intervención". En: ESTADO Y PROBREZA: ESTRATEGIAS TIPICAS DE INTERVENCION/1. Centro Editor de América Latina. Bs As, 1989 (pp36)

$\varangle$ WACQUANT, Loïc "La nueva línea de color urbana: Estado del gueto en la Norteamérica pos - fordista". En: PARIAS URBANOS. Editorial Manantial, BS. As. 2001 